\title{
Fractures of the Zygomaticomaxillary Complex
}

\author{
Elavenil Panneerselvam, Poornima Ravi, and B. Sasikala
}

\subsection{Introduction}

The zygomaticomaxillary complex (ZMC) refers to the skeletal unit [1] formed by the zygomatic bone and maxilla (Fig. 56.1). These two bones are referred to as a complex, because of the structural and functional relationship between them; they articulate with each other over a wider area, and any traumatic impact on one bone generally influences the other. This duo complex also constitutes a major part of the orbit, spanning the infra-orbital rim, lateral wall, and floor. Hence the ZMC is also termed orbitozygomaticomaxillary complex [2]. Because of its multiple articulations, various names are commonly used to describe ZMC fractures such as "tripod, tetrapod, or pentapod" [3, 4] fractures.

Fractures of the ZMC commonly result in severe cosmetic and functional deficits because of the prominent anatomical position of the zygoma and its proximity to adjacent vital structures such as the globe. Precise reduction and fixation of these fractures is challenging due to their complex anatomic form, multiple articulations, and deformation in multiple planes. The scope of this chapter encompasses the biodynamics of ZMC fractures, clinical implications, and guidelines for successful management.

Disclosure: Authors have no financial conflicts to disclose.

Electronic Supplementary Material The online version of this chapter (https://doi.org/10.1007/978-981-15-1346-6_56) contains supplementary material, which is available to authorized users.

E. Panneerselvam $(\square)$

Department of Oral and Maxillofacial Surgery,

SRM Dental College, Ramapuram, Chennai, Tamil Nadu, India

Department of Orbit and Oculoplasty, Aravind Eye Hospital, Chennai, Tamil Nadu, India

P. Ravi · B. Sasikala

Department of Oral and Maxillofacial Surgery, SRM Dental

College, Ramapuram, Chennai, Tamil Nadu, India

\subsection{Surgical Anatomy}

The term zygoma denotes a "yoke or bar," in Greek. Quite aptly, the zygoma extends as a prominent, sturdy bar across the face, contributing to its transverse width and anteroposterior projection. The clinical significance of this bony complex is attributed to its role in defining facial esthetics and globe function.

\subsubsection{Articulations}

The zygoma articulates with four bones [5]; superiorly frontal, medially maxilla, laterally temporal bone, and posteriorly sphenoid, through five processes [4] (Fig. 56.1), namely, the zygomaticotemporal (ZT), zygomaticomaxillary (ZM), infra-orbital (IOR), fronto-zygomatic (FZ), and sphenozygomatic (SZ) or zygomaticosphenoid (ZS). These processes are clinically significant in establishing the three-dimensional structural integrity of the upper lateral face.

Fractures of the ZMC have been traditionally called the "tripod or trimalar fractures" because it involved separation at the three processes of the zygoma - the FZ, IOR, and the ZM processes (Fig. 56.2a). The terminology was later modified to "quadripod or quadramalar fracture" to include separation at the fourth point of articulation, the ZT process (Fig. 56.2b). However, the importance of SZ articulation along the lateral wall of the orbit has been recognized lately, and, hence, ZMC fracture is currently called a pentapod fracture (Fig. 56.2c), to emphasize the necessity of restoring the five articulations during fracture management.

\subsubsection{Relations}

- Zygoma and orbit: ZMC forms the lateral and inferior part of the orbit, protecting as well as supporting the globe and associated soft tissues. The Whitnall's tubercle present on the zygoma (inferior to the FZ suture) provides 
attachment to the suspensory ligament of Lockwood that maintains the horizontal axis of the globe [6] (Fig. 56.3a). A fracture line located above the Whitnall's tubercle leads to inferior displacement of zygoma as well as the lateral attachment of Lockwood ligament resulting in antimongoloid slant to the eye (Fig. 56.3b). Thus ZMC fractures greatly influence the structure and function of the orbit. Further, the contents of the orbit including the globe, extraocular muscles, and orbital fat are intimately

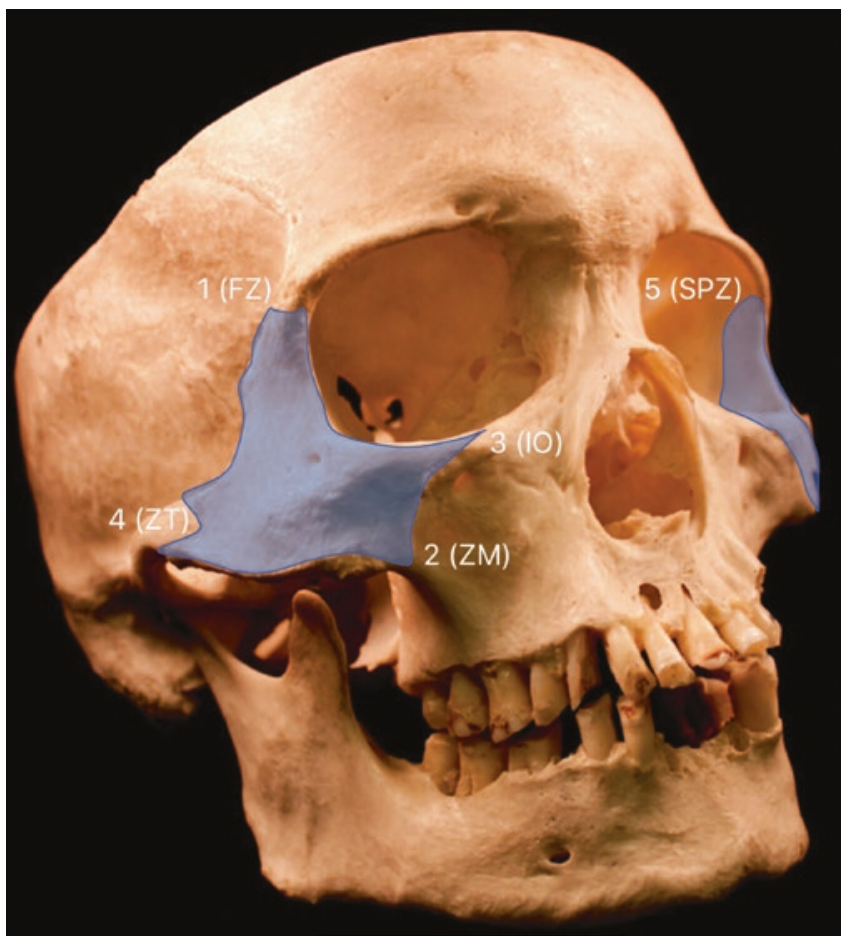

(CAssociation of Oral and Maxillofacial Surgeons of India

Fig. 56.1 ZMC skeletal unit. Articulations of zygoma with facial skeleton and articulating processes related to the zygoma and may be affected in fractures of the ZMC or its surgical manipulation.

- Zygoma and mandible: The zygoma and zygomatic arch are anatomically close to the coronoid process of the mandible. Therefore, a fractured zygoma or arch, when retro/medially positioned, may impede mandibular movements [7]. A displaced and untreated fracture of zygoma/ arch which is in close proximity to the coronoid process can result in extra-articular ankylosis [8].

- Zygoma and maxillary sinus: Fractures of the ZMC (except the isolated zygomatic arch fractures) involve the maxillary sinus and show features of hemosinus [4] or sinusitis [3].

\subsubsection{Muscle and Fascia Attachments}

The muscles attached to ZMC are the zygomaticus major, zygomaticus minor, orbicularis oculi, and masseter [9]. Masseter is attached to the zygomatic arch on the lateral and inferior aspect as well as the zygomatic tuberosity (Fig. 56.4a). The downward displacing forces of the masseter have been considered by many as the principal cause of post-reduction instability [10].

The temporal fascia attached to the arch superiorly plays a major role in resisting the downward displacement of fractured $\mathrm{ZMC}$ or arch due to the inferior pull of the masseter (Fig. 56.4b) [1].

\subsubsection{Zygomatic Arch}

The arch is the key parameter for re-establishing the sagittal projection as well as transverse width of the face [11]. An arch which is bent outward or inward gets shortened [4]. This leads to retrodisplacement of zygoma resulting in altered facial width (Fig. 56.5b). It is important to remember
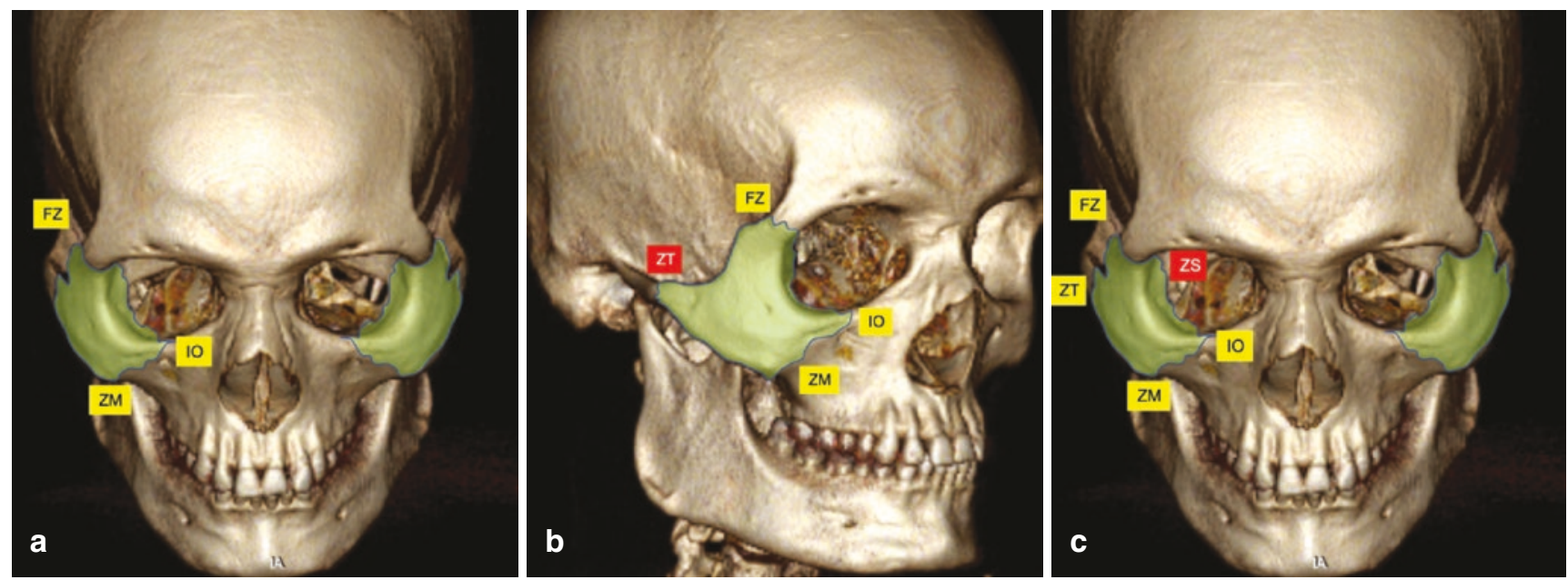

CAssociation of Oral and Maxillofacial Surgeons of India

Fig. 56.2 Types of ZMC fractures. (a) Tripod fracture. (b) Tetrapod fracture. (c) Pentapod fracture 

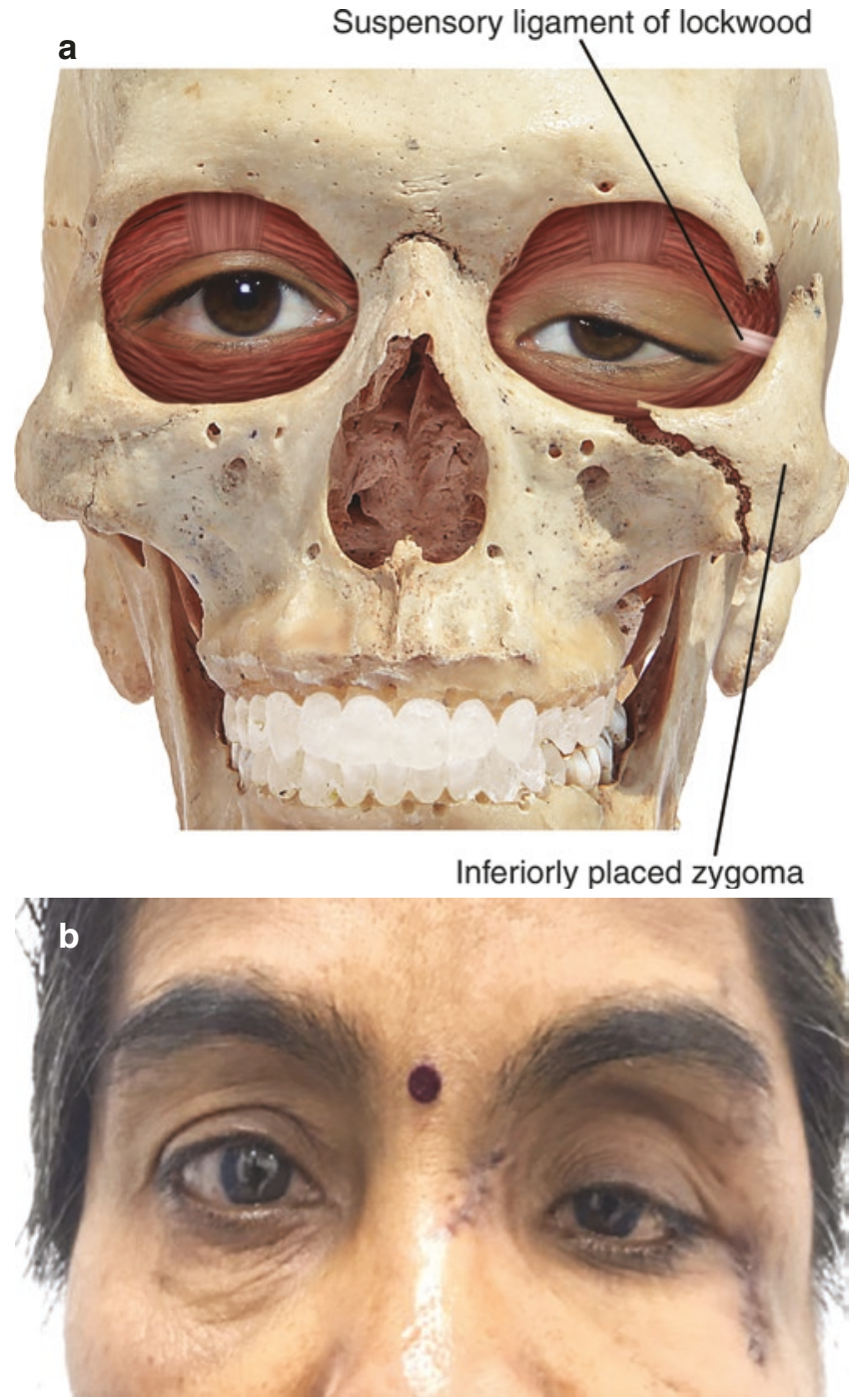

CAssociation of Oral and Maxillofacial Surgeons of India

Fig.56.3 Relation of suspensory ligament to zygoma. (a) Displacement of suspensory ligament of Lockwood leading to anti-mongoloid slant. (b) Clinical appearance of anti-mongoloid slant

that in spite of being referred to as an arch, it does not have an exaggerated curvature. Therefore, overzealous contouring during reduction of zygomatic arch fractures can result in compromised esthetics. The arch is encased by a thick periosteal and fascial envelope which counteracts the displacing forces of the masseter [1]. However, when the periosteal envelope is damaged due to high-velocity injuries, the fracture segments show more displacement.

\subsubsection{Nerves and Blood Vessels}

The nerves in close proximity to the ZMC are (1) infraorbital nerve and (2) zygomatic nerve [12] (Fig. 56.6a). The infra-orbital nerve runs along the ION groove and enters the

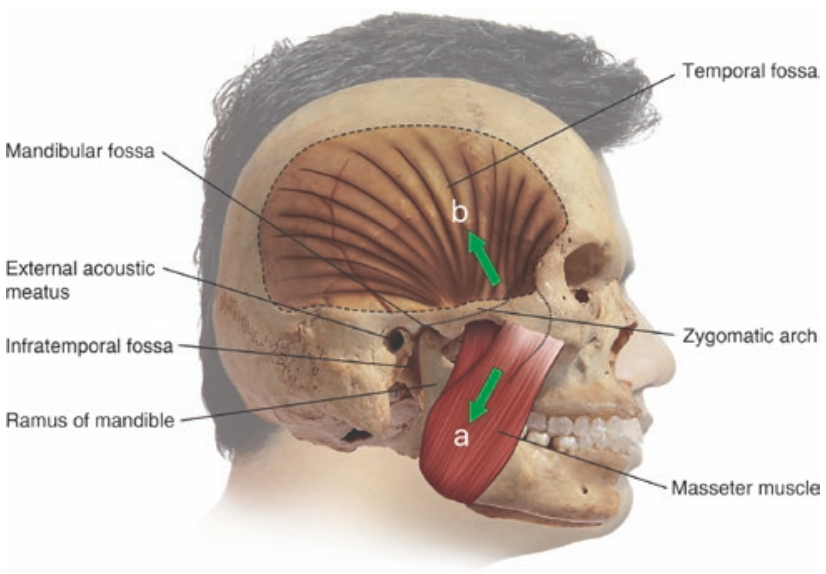

(C)Association of Oral and Maxillofacial Surgeons of India

Fig. 56.4 Displacing forces acting on the zygoma and arch. (a) Masseter exerting downward force. (b) Temporalis with a superior vector

ION canal giving off the superior dental plexus of nerves before exiting through the ION foramen onto the face. Here it innervates the lower eyelid, lateral aspect of the nose, and upper lip of the ipsilateral side. The zygomatic nerve which enters the orbit through the inferior orbital fissure divides into two branches, the zygomatico-facial and zygomaticotemporal which emerge onto the face through their respective foramina. The zygomaticofacial nerve innervates the skin over the malar area, while the zygomaticotemporal nerve supplies the skin over the anterior temporal region. These nerves may be injured due to trauma or during surgery. The severity of paresthesia which arises is generally proportional to the degree of displacement of a fractured zygoma [13]. The other nerves whose function may be affected in ZMC fractures are the optic nerve [14] and facial nerve [15]. Blood vessels of importance related to the ZMC are infraorbital artery and vein [16] (Fig. 56.6b) which accompany the infra-orbital nerve. Uncontrolled forces delivered during elevation of zygoma may injure these vessels resulting in severe intra-op bleeding.

\subsection{Classification}

\subsubsection{Classification of ZMC Fractures}

Numerous classifications have been proposed for ZMC fractures; this chapter would discuss the most practical ones which help in understanding the biodynamics of fracture as well as facilitate quick decision-making regarding the treatment.

- The classification proposed by Rowe and Williams [1] (Fig. 56.7) is based on the axis of rotation of ZMC and the 

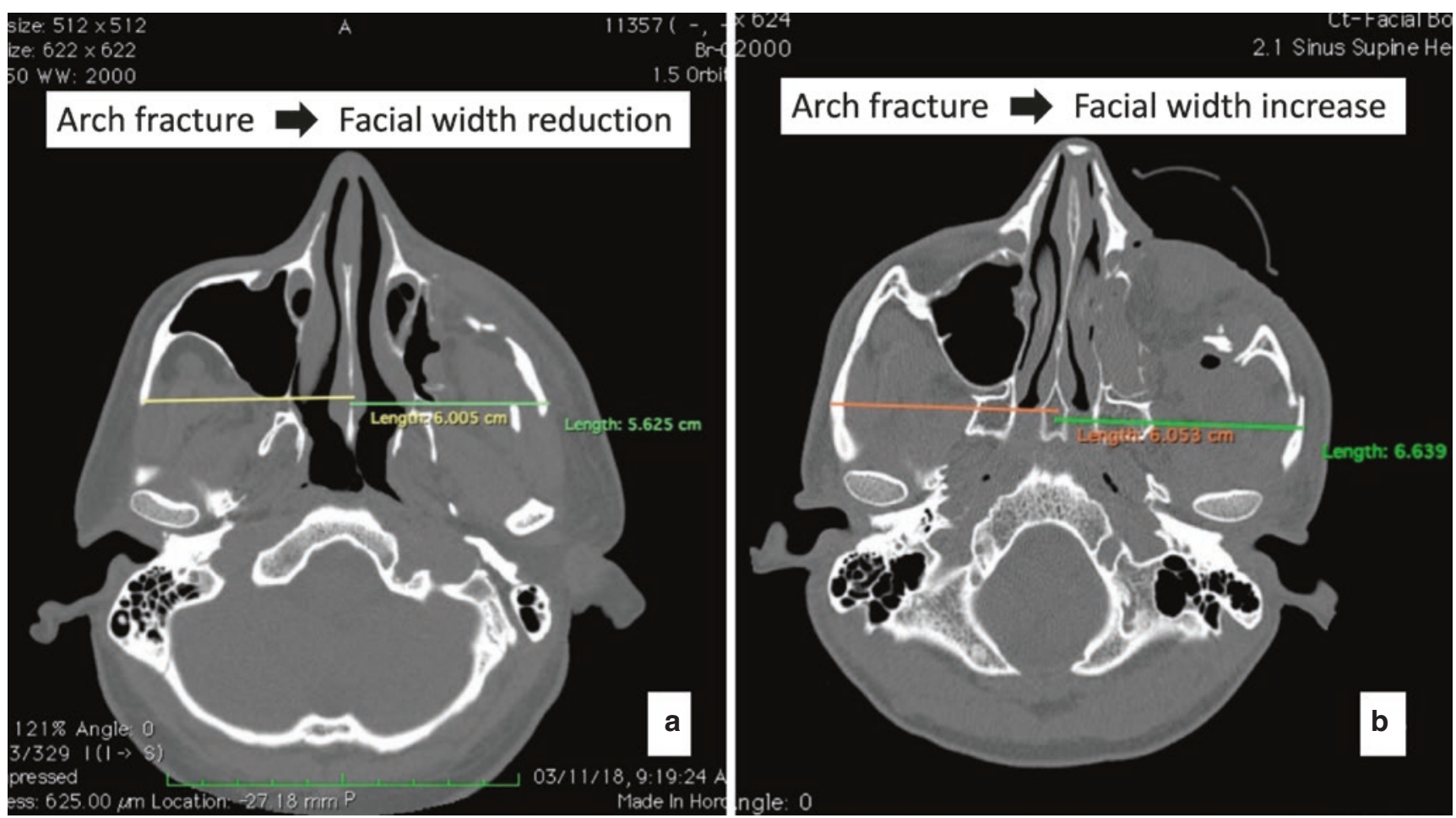

C)Association of Oral and Maxillofacial Surgeons of India

Fig. 56.5 Change in facial dimension in zygomatic arch fractures. (a) Inward bowing of arch. (b) Outward bowing of arch

stability after reduction. Following trauma, the zygoma may undergo rotation along two axes: vertical axis extending through the FZ suture and first molar and horizontal axis running across the infra-orbital foramen and zygomatic arch. According to this classification, fractures were considered as stable after elevation when they demonstrated (1) arch only fracture with medial displacement and (2) rotation around vertical axis (medially/laterally), while fractures were categorized as unstable after reduction when the following features were observed: (1) arch only fracture with inferior displacement (Fig. 56.8), (2) ZMC fracture rotated around horizontal axis (Fig. 56.7), (3) dislocated en bloc (inferiorly/laterally/medially) (Fig. 56.9a), and (4) comminuted (Fig. 56.9b).

This classification provides clinical guidance regarding the stability of fracture after reduction and the necessity for fixation.

- ZMC fractures have also been classified on the basis of "severity of traumatic impact" [4] into low-, medium-, and high-energy patterns, as demonstrated on CT; lowenergy type is associated with non-displaced/minimally displaced "en bloc" fractures, medium-energy type is displaced fractures with or without fragmentation, and highenergy type is associated with fractures with massive displacement, comminution, or fragmentation.

- Zing et al.'s [17] classification (Fig. 56.10a-e) is a simple but practically useful method based on the anatomic site involved; type A1 refers to isolated zygomatic arch frac- ture, and types A2 and A3 are separation at the FZ suture and IOR, respectively. Type B is a complete monofragment type with separation at all five sites of articulation and type $\mathrm{C}$ which is multifragmented.

A special and rare variant of zygoma injuries includes avulsion of zygoma [18] (Fig. 56.11). These injuries result from tangentially directed forces with high velocity or greater energy. The fractured zygomatic fragment characteristically becomes a non-vascularized-free graft whose management is complex.

\subsubsection{Classification of Arch Fractures}

The fractures involving the zygomatic arch constitute a separate entity.

The various patterns of zygomatic arch fractures have been described by Ozyazgan et al. [19] (Fig. 56.12) based on the number of fracture lines and displacement of fracture fragments:

- Type 1 constitutes the isolated zygomatic arch fractures which are subdivided into (1) dual fracture (type I A) and (2) more than two fractures (type I B). This is further classified into V-shaped (type I B-V) and displaced fracture (type I B-D).

- Combined zygomatic arch fractures are referred to as type II, which can present as two variants: single (type II A) 


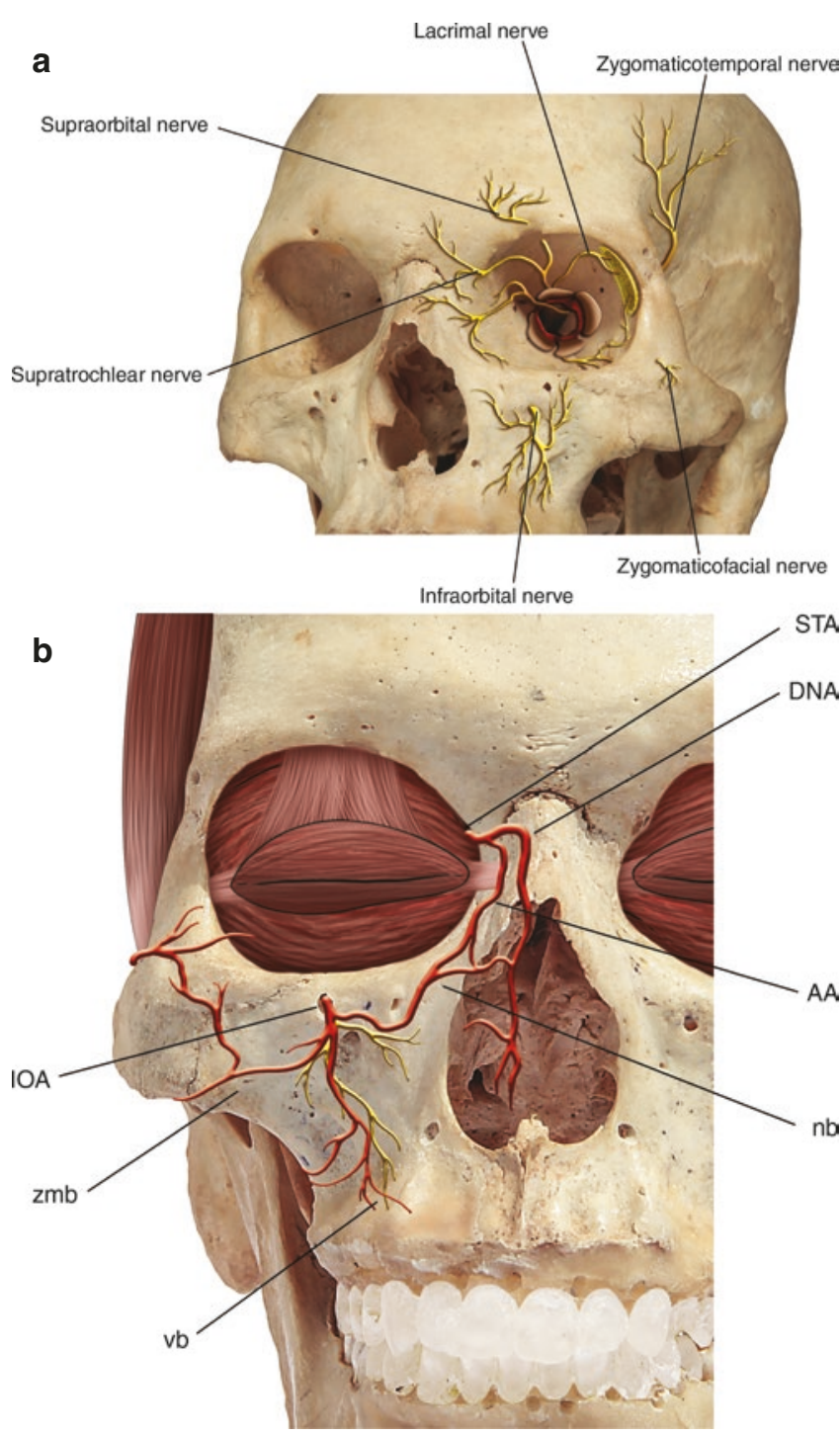

CAssociation of Oral and Maxillofacial Surgeons of India

Fig. 56.6 a, b Neurovascular structures related to ZMC fractures. OA, ophthalmic artery; nb, nasal branch; zmb, zygomatico-malar branch; $\mathrm{vb}$, vestibular branch

and plural fracture (type II B). Plural fractures are termed type II B-R when they are approximated or reduced and type II B-D, when displaced.

Yamamoto et al. classification [20] (Fig. 56.13) differentiates fractures based on displacement: type I, no displacement; type II, displacement with bone contact at all fracture lines; type III, displacement without bone contact at one fracture line; type IV, displacement without bone contact at two fracture lines; and type $\mathrm{V}$, comminution or displacement without bone contact at three or more fracture lines. Honig Merten et al. [21] (H-M classification) (Fig. 56.14) classified zygomatic arch fractures based on CT findings as class I which indicated isolated tripod fracture, class II as an isolated stick fracture of the arch, and class III a combined fracture of the malar bone and the zygomatic arch.

\subsection{Clinical Assessment}

The clinical assessment of ZMC fractures is performed by a thorough examination of the face and the eye. As the zygoma forms an integral part of the orbit (floor and lateral wall), any trauma to the ZMC may have profound impact on the integrity of the globe and vision $[2,22]$. This mandates a primary ophthalmic examination prior to facial examination.

\subsubsection{Examination of the Eye}

The globe is meticulously assessed for its form, position, and function. This is performed by a comprehensive examination protocol called "8-point eye exam" [23] provided by the American Academy of Ophthalmology (refer to Chap. 57).

\subsubsection{Examination of the Face}

The facial examination should focus on assessment of (1) facial symmetry and morphology and (2) functions such as mouth opening, vision, sensory perception, and occlusion.

The clinical characteristics of ZMC fractures $[1,4,5]$ may be divided based on their cosmetic and functional implications (Box 56.1) .

\section{Box 56.1: Clinical Features of ZMC Fractures}

\begin{tabular}{l|l}
\hline Cosmetic deficits & Functional deficits \\
\hline - Facial asymmetry due to & - Vision \\
- Periorbital edema & - Diplopia \\
- Hematoma & - Loss of vision (partial/ \\
- Emphysema & total) \\
- Facial asymmetry due to & - Restricted mouth opening \\
malpositioned zygoma & - Malocclusion \\
- Depression of malar & - Neurological deficit \\
prominence & - Paresthesia \\
- Transverse facial widening & (i) Infra-orbital nerve \\
- Changes in AP projection & (ii) Zygomaticofacial \\
- Orbital dystopia & nerve \\
- Discoloration & (iii) Zygomaticotemporal \\
- Subconjunctival & nerve \\
hemorrhage & - Paresis/palsy \\
- Periorbital ecchymosis & (i) Facial nerve \\
- Altered morphology/position & - Epistaxis/nasal congestion \\
of eye & - Compartment syndromes \\
- Anti-mongoloid slant & - SOF syndrome \\
- Increased scleral show & - Orbital apex syndrome \\
- Hypoglobus/hyperglobus & \\
\hline - Enophthalmos/ & \\
exophthalmos &
\end{tabular}




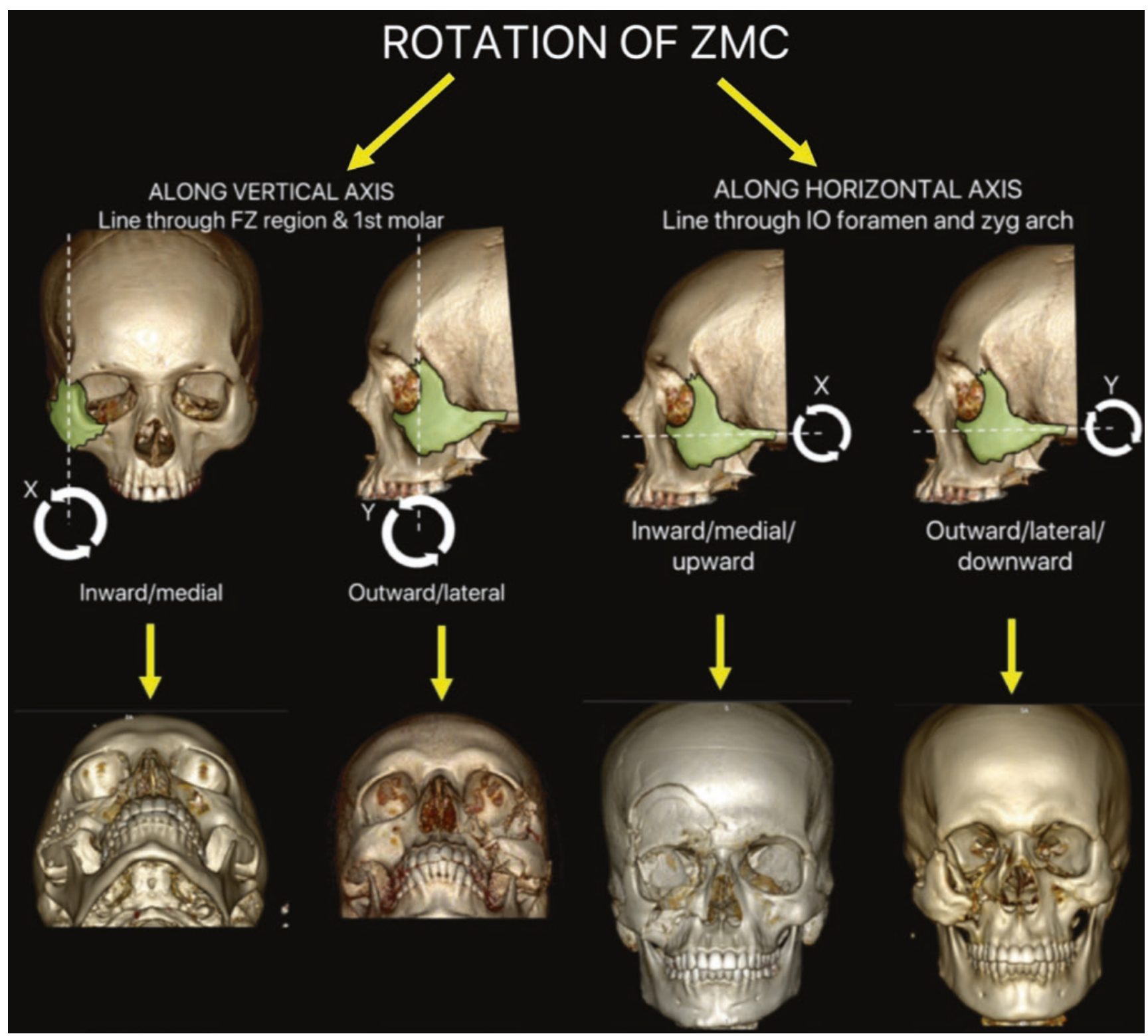

CAssociation of Oral and Maxillofacial Surgeons of India

Fig. 56.7 Axes of rotation of ZMC fractures

A description of clinical features with their associated pathophysiology is provided below.

- Periorbital edema and ecchymosis: The edema and ecchymosis in ZMC fractures are more dramatic due to the loose connective tissue in the periorbital region. Ecchymosis is commonly seen in the circumorbital region and maxillary buccal sulcus (Fig. 56.15).

- Subconjunctival hemorrhage (SCH): Subconjunctival hemorrhage or hyposphagma (Fig. 56.15) often occurs in ZMC fractures due to collection of the blood into the subconjunctival space, secondary to hemorrhage from the surrounding periosteum. Characteristically, $\mathrm{SCH}$ in $\mathrm{ZMC}$ fractures does not have a posterior limit in contrast to $\mathrm{SCH}$ due to globe injuries [24]. It is important to note that $\mathrm{SCH}$ without a posterior limit is also seen in skull base fractures [25].Chemosis and hyphema are also seen in some cases.

- Epistaxis: Occasional epistaxis may be observed due to escape of pooled blood from the maxillary sinus following ZMC fracture. This is typically ipsilateral. Resultant nasal congestion is a common clinical finding.

- Loss of facial prominence: Displacement of zygoma due to trauma leads to the characteristic flattening of malar prominence (Fig. 56.16). This is well observed in bird's eye and worm's view. Examination by palpation is done 
from behind the patient to detect malar depression. However, the flattening cannot be appreciated in the presence of moderate or severe edema.

- Eye signs: The eye signs are a very striking feature of zygomatic injury especially when rotated and inferiorly displaced. Inferior displacement of zygoma results in hypoglobus and an anti-mongoloid slant to the eye (Fig. 56.3b). Inferior or posterior displacement of the infra-orbital rim also causes lowering of the lower eyelid leading to increased scleral show (Fig. 56.17).

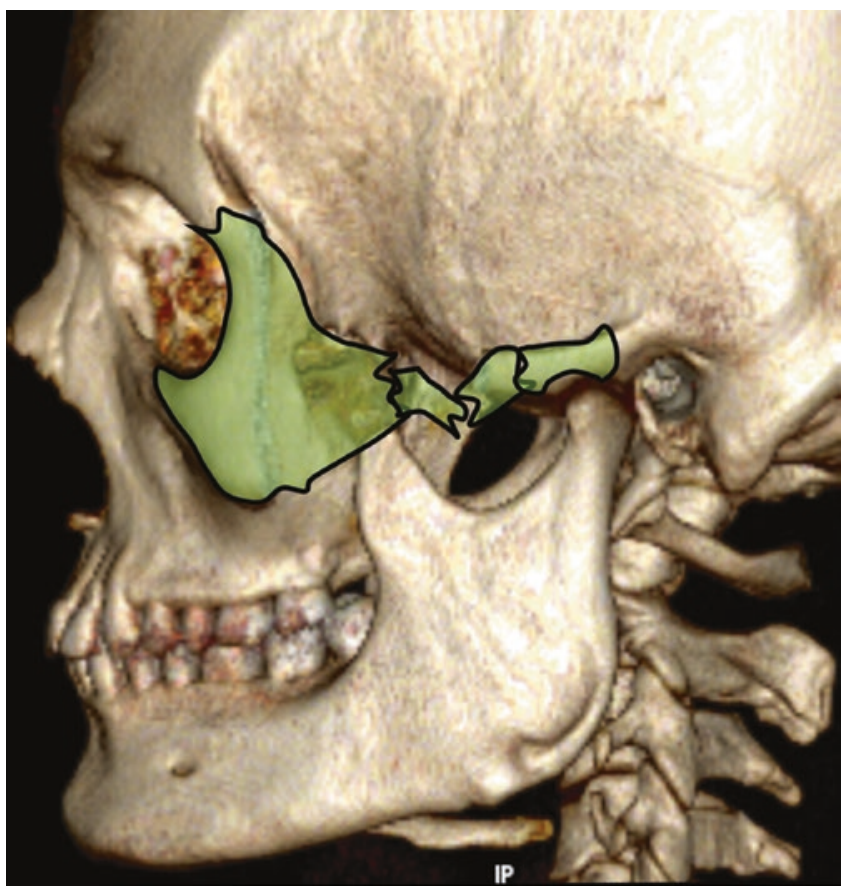

CAssociation of Oral and Maxillofacial Surgeons of India

Fig. 56.8 Inferior displacement of zygomatic arch
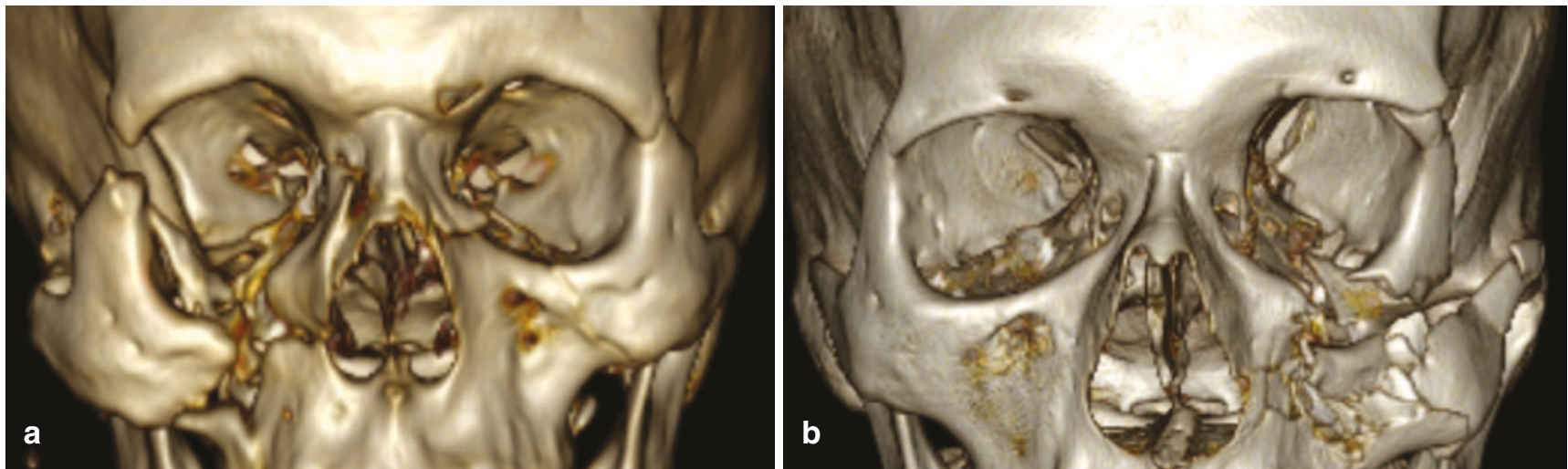

CAssociation of Oral and Maxillofacial Surgeons of India
The commonly observed variations in globe position are exophthalmos in posteriorly/medially displaced zygoma (Fig. 56.18a-c) and enophthalmos in laterally and inferiorly displaced zygoma (Fig. 56.19). En/exophthalmos resulting from ZMC fractures must be differentiated from enophthalmos arising from blow-out fractures involving the orbital floor. The clinical implications of the above are explained under "preoperative planning." Also, it is important to remember that the traditional assessment of en/exophthalmos by Hertel's exophthalmometer does not reflect the true position of the globe in displaced ZMC fractures because it uses the orbital rim as a point of reference. Naugle's which utilizes supraorbital rim as a reference is ideal in such cases [26]. However CT evaluation is the most preferred modality [27] (refer Chap. 57 on orbital fractures).

- Tenderness and step deformity: When edema is severe and inspectory findings are not conclusive, palpation gives more details. Tenderness on digital palpation, step deformity at the fronto-zygomatic, zygomatic buttress, and IOR are good indicators of fracture.

- Air emphysema: Palpation also helps to elicit air emphysema in the form of subcutaneous crackling. This occurs when there is a fracture through a sinus wall which allows air escape into the facial soft tissues. It usually disappears spontaneously, in 2-4 days [28]. However, this can be a potential cause of infection [29].

- Reduced mouth opening: Restriction in mouth opening can arise because of two reasons [30]: (1) mechanical obstruction to movement of the mandible by a retrodisplaced zygoma or a fractured zygomatic arch (Fig. 56.20a, b) and (2) a fractured arch impinging on the temporalis muscle causing reflex spasm/trismus. Likewise, injury to the masseter also can lead to trismus.

Fig. 56.9 En bloc and comminuted ZMC fractures. (a) En bloc displacement of the right ZMC. (b) Comminuted ZMC of left side 

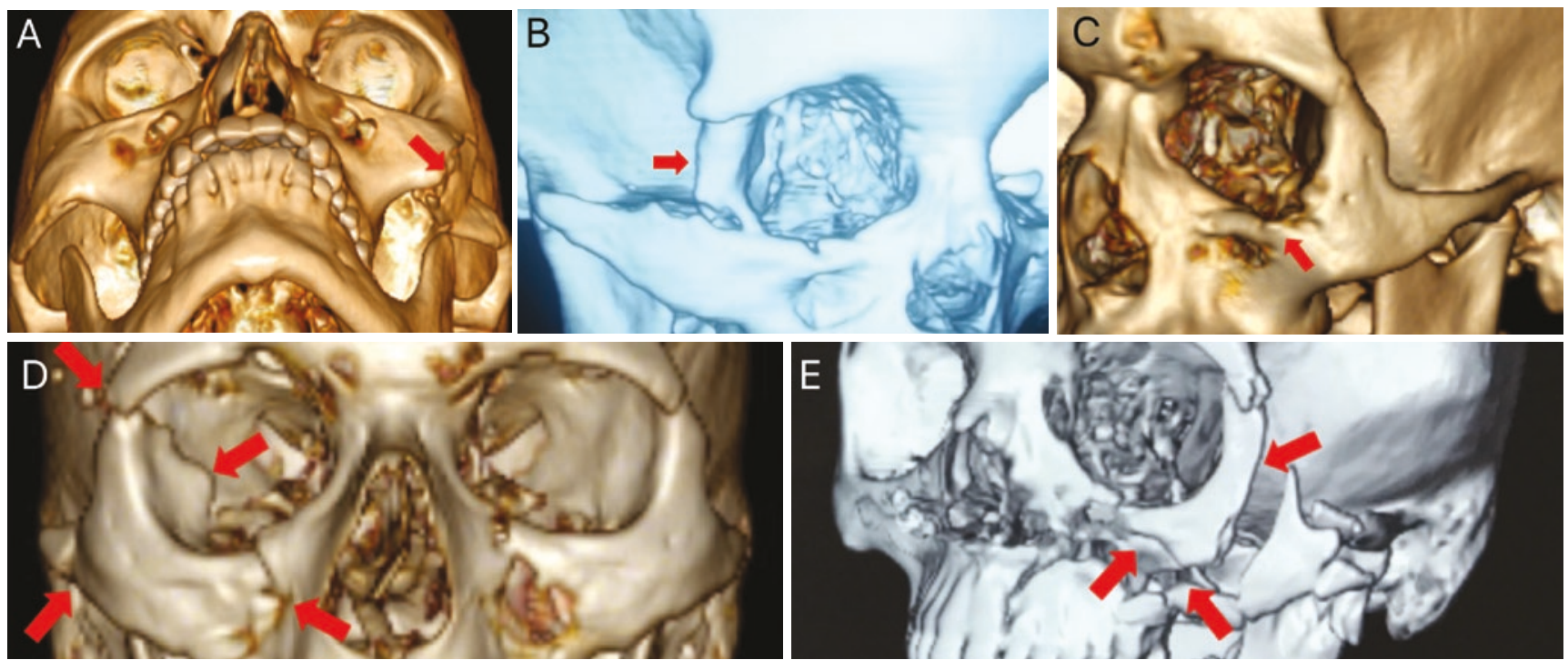

CAssociation of Oral and Maxillofacial Surgeons of India

Fig. 56.10 Zing's classification of ZMC fractures. (a) arch only (Type A1), (b) separation at fronto-zygomatic suture (Type A2), (c) separation at infra-orbital rim (Type A3), (d) complete mono-fragment (Type B) and (e) multi-fragment (Type C)

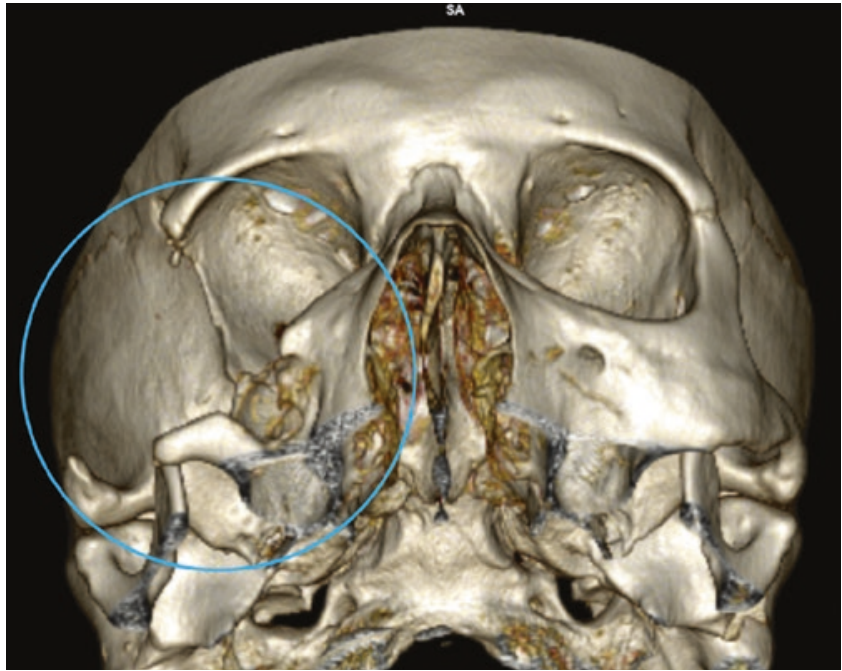

CAssociation of Oral and Maxillofacial Surgeons of India

Fig. 56.11 Avulsion of zygoma

- Paresthesia: Infra-orbital nerve being closely related to the zygoma gets compressed or pulled in displaced or comminuted ZMC fractures leading to paresthesia along the lower eyelid, upper lip, and lateral aspect of the nose. Occasionally, a patient may also have altered sensation involving the maxillary teeth leading to a perception of altered dental occlusion [5]. The other theory put forward for altered occlusion is the flexing of the ipsilateral maxillary alveolus leading to premature molar contact [31]. Paresthesia involving the zygomaticofacial and zygomaticotemporal nerves may be present. In rare occurrences, injury to the facial nerve leading to paresis has been observed in severely displaced or high-velocity injuries of the zygoma [15].

- Altered/loss of vision: Binocular diplopia is a common finding. The diplopia that develops following trauma can be the result of soft tissue (muscle or periorbital) entrapment, neuromuscular injury, intra-orbital or intramuscular hematoma/edema, or a change in orbital shape, with displacement of the globe [32]. A forced duction test (FDT) (Fig. 56.21) would confirm any physical impediment to ocular motility [4]. Diplopia due to edema/hematoma resolves in a few days, while that due to muscle entrapment does not, necessitating surgical correction.

Another rare but serious sequel to $\mathrm{ZMC}$ fractures is traumatic optic neuropathy which may present as total or partial loss of vision [33].

\subsection{Imaging for ZMC Fractures}

Radiological assessment is essential for accurate diagnosis and assessment of severity of the fracture. 


\section{I - Isolated arch}

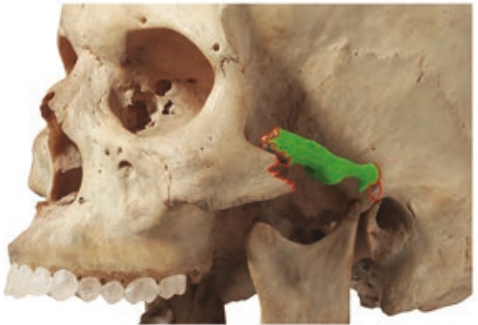

I-A

2 Fractures

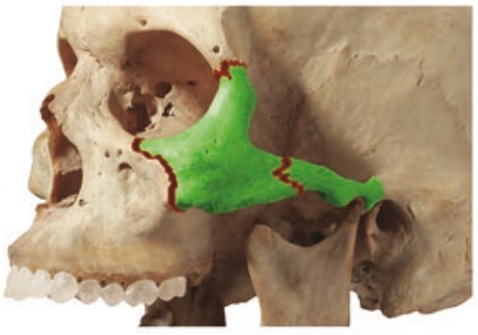

II-A

Single fracture

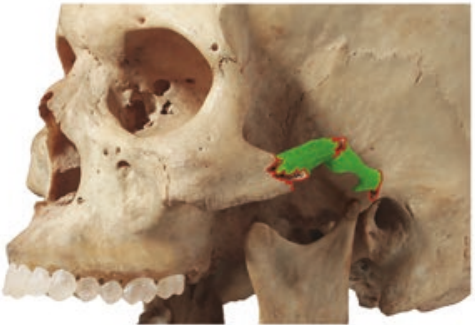

I-B-V

$>2$ Fractures

II - Combined arch

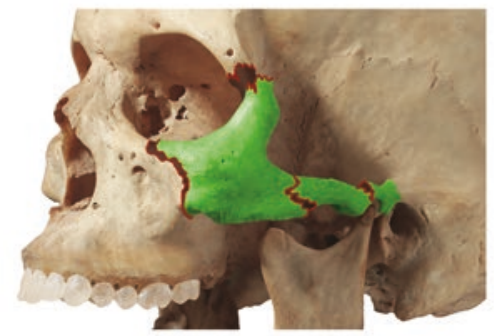

II-B

Plural fracture

II-B-R: Reduced

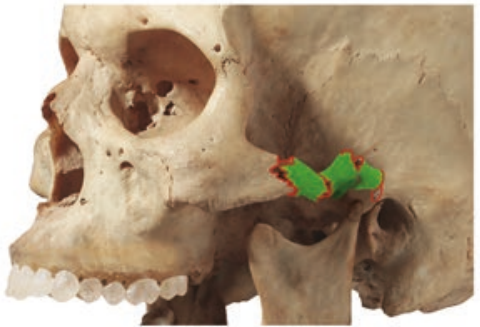

I-A-D

$>2$ Fractures

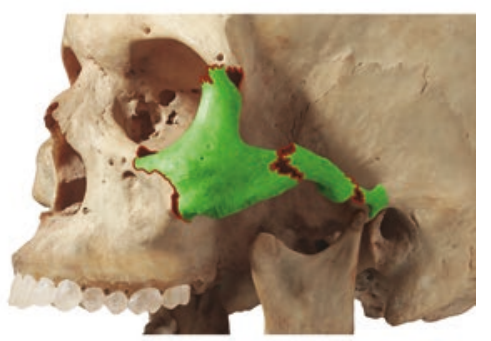

II-B

Plural fracture

II-B-D: Displaced

CAssociation of Oral and Maxillofacial Surgeons of India

Fig. 56.12 Ozyazgan et al. classification of zygomatic arch fractures

- Plain radiographs [31]: Conventional radiographs continue to remain the mainstay of imaging at some centers. Conventional radiographs may also be useful in the postoperative phase, to assess fracture reduction. However conventional radiographs are limited by superimposition of structures.

The commonly used views include the waters view $\left(37^{\circ}\right.$ occipitomental) (Fig. 56.22) which provides good visualization of the fractured zygoma and helps in comparing with the contralateral side. Tracing the McGrigorCampbell lines [34] (refer Chap. 55) or the Dolan's lines
[35] are useful in identification of fractures on the Water's view (Box 56.2).

Box 56.2 (Fig. 56.22): Radiographic Appearance in ZMC Fracture

- Disruption of the Dolan's lines Orbital line Zygomatic line Maxillary line

- Loss of elephant trunk appearance 


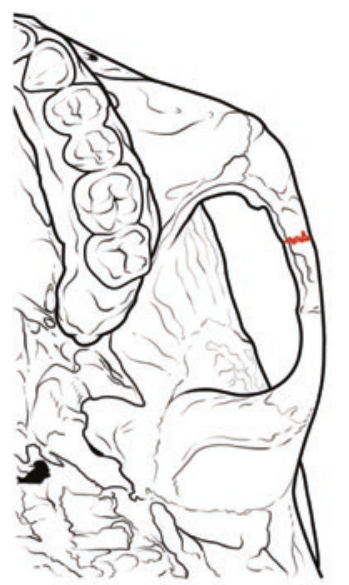

Type I

No Displacement
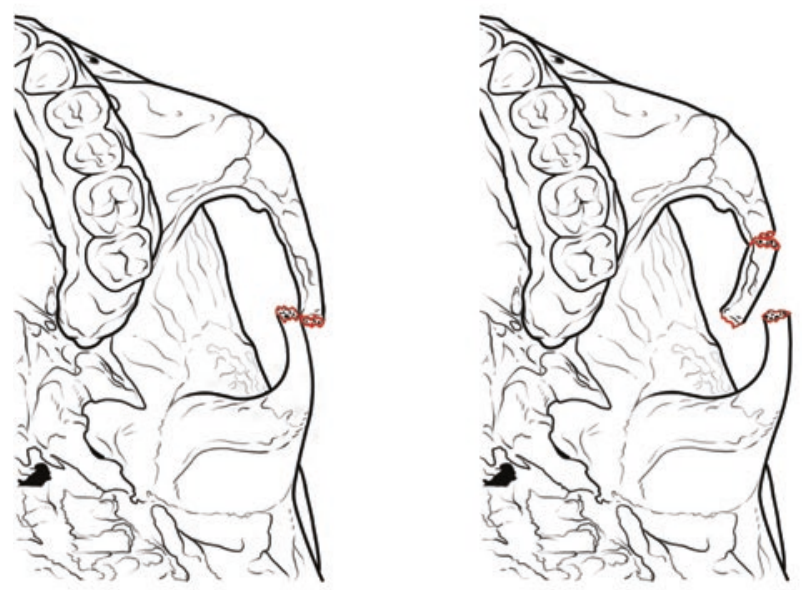

Type III

Displacement without bone contact at 1 \# line

CAssociation of Oral and Maxillofacial Surgeons of India

Fig. 56.13 Yamamoto et al. classification of zygomatic arch fractures
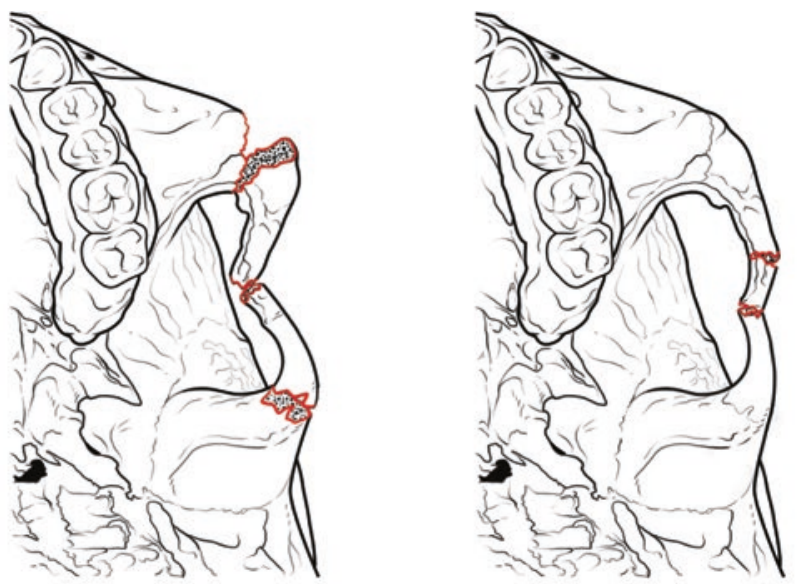

Type II

Displacement with bone contact at all \# lines

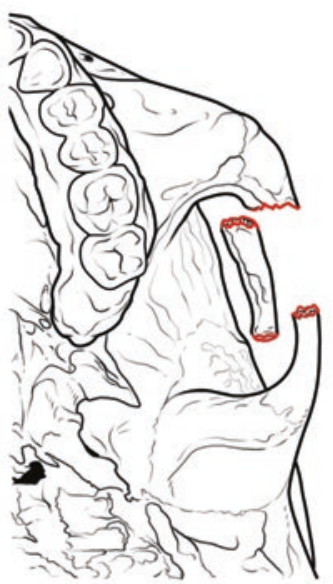

Type IV

Displacement without bone contact at 2 \# lines

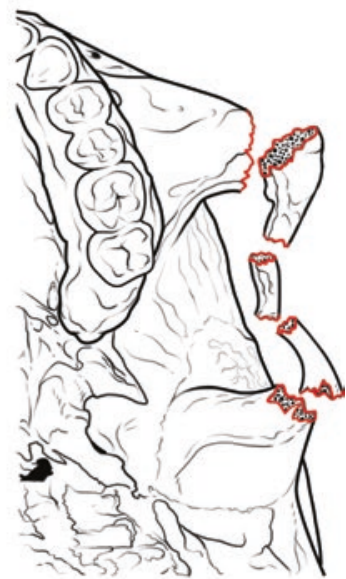

Type V

Comminution or displacement without bone contact at 3 or more \# lines 

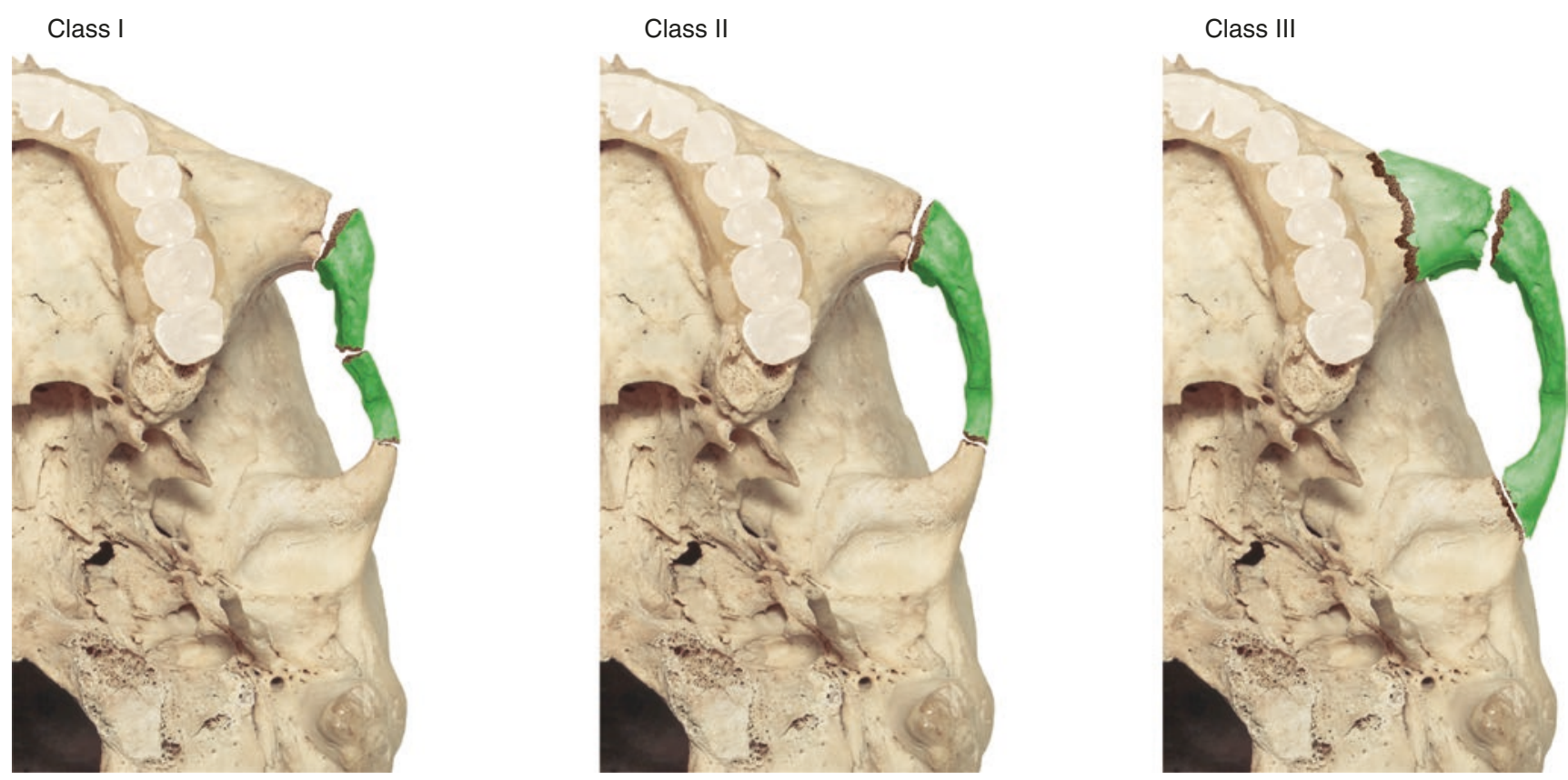

CAssociation of Oral and Maxillofacial Surgeons of India

Fig. 56.14 Hönig Merten (HM) et al. classification of zygomatic arch fractures

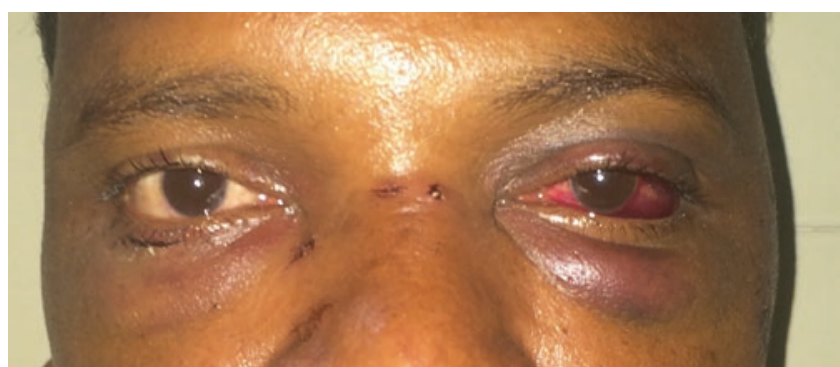

CAssociation of Oral and Maxillofacial Surgeons of India

Fig. 56.15 Periorbital edema, ecchymosis, and subconjunctival hemorrhage

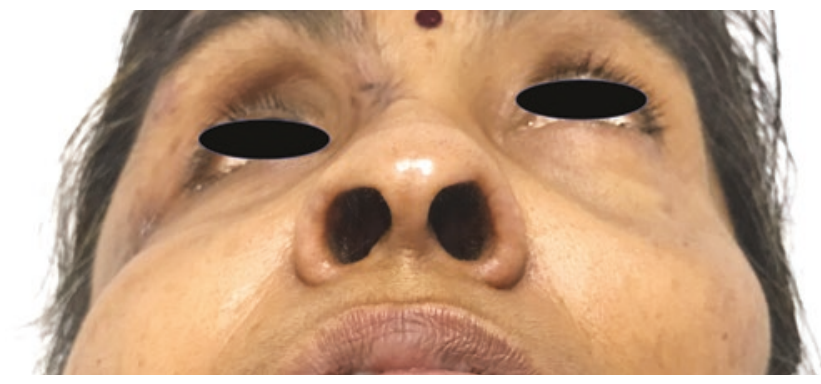

CAssociation of Oral and Maxillofacial Surgeons of India

Fig. 56.16 Loss of facial prominence in right malar region 


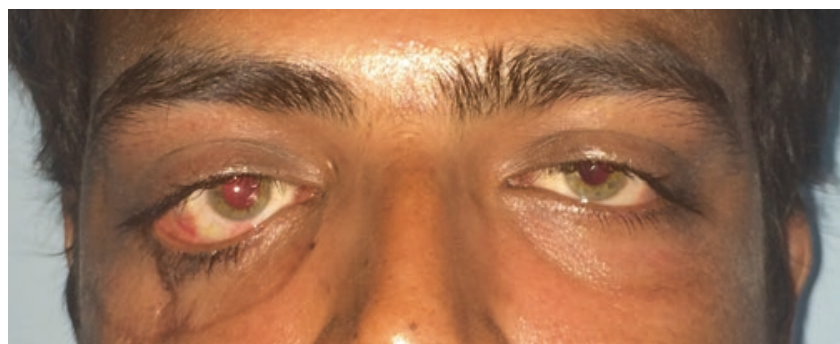

CAssociation of Oral and Maxillofacial Surgeons of India

Fig. 56.17 Increased scleral show on right side
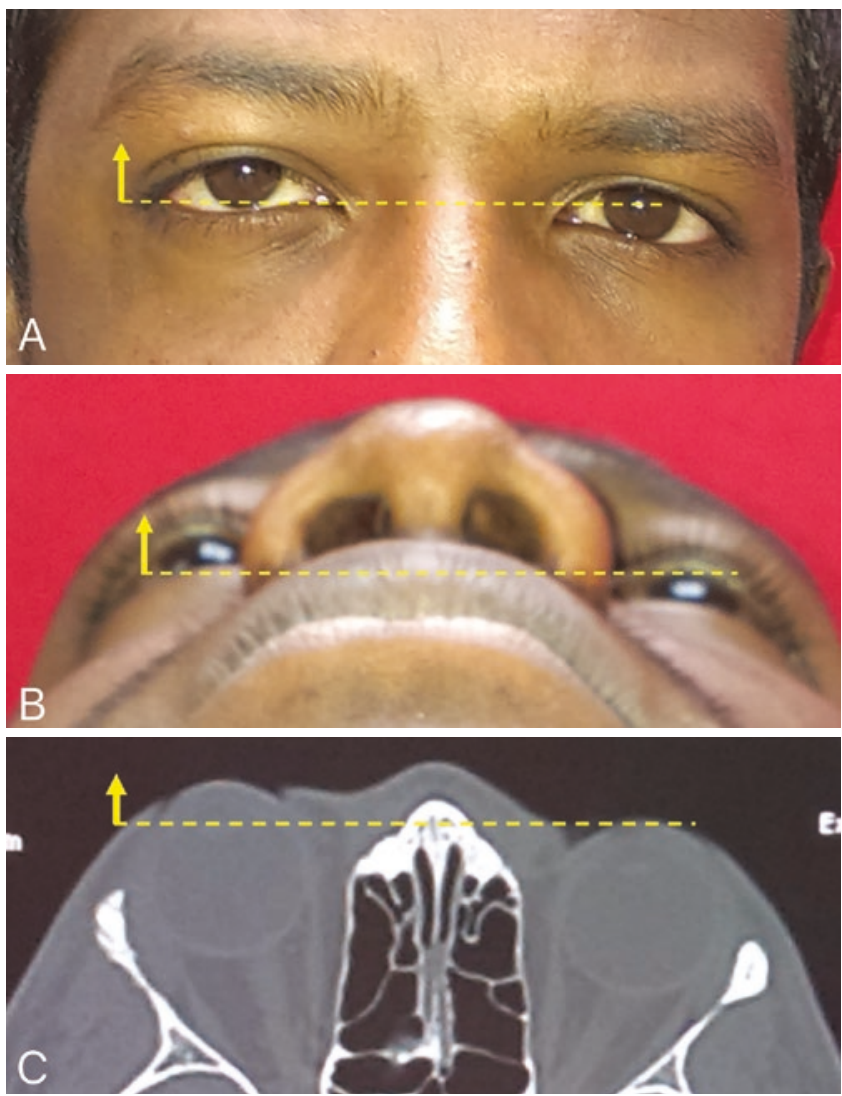

CAssociation of Oral and Maxillofacial Surgeons of India

Fig. 56.18 Exophthalmos. (a) Frontal view demonstrating exophthalmos and hyperglobus on right side. (b) Basal view of the same patient showing exophthalmos on right side. (c) Axial CT section demonstrating exophthalmos of the right eye

- The submentovertex/jug handle view [31] (Fig. 56.23) offers the best representation of fractures of the arch. Loss of elephant trunk appearance which is indicative of arch fracture is well appreciated in this view.
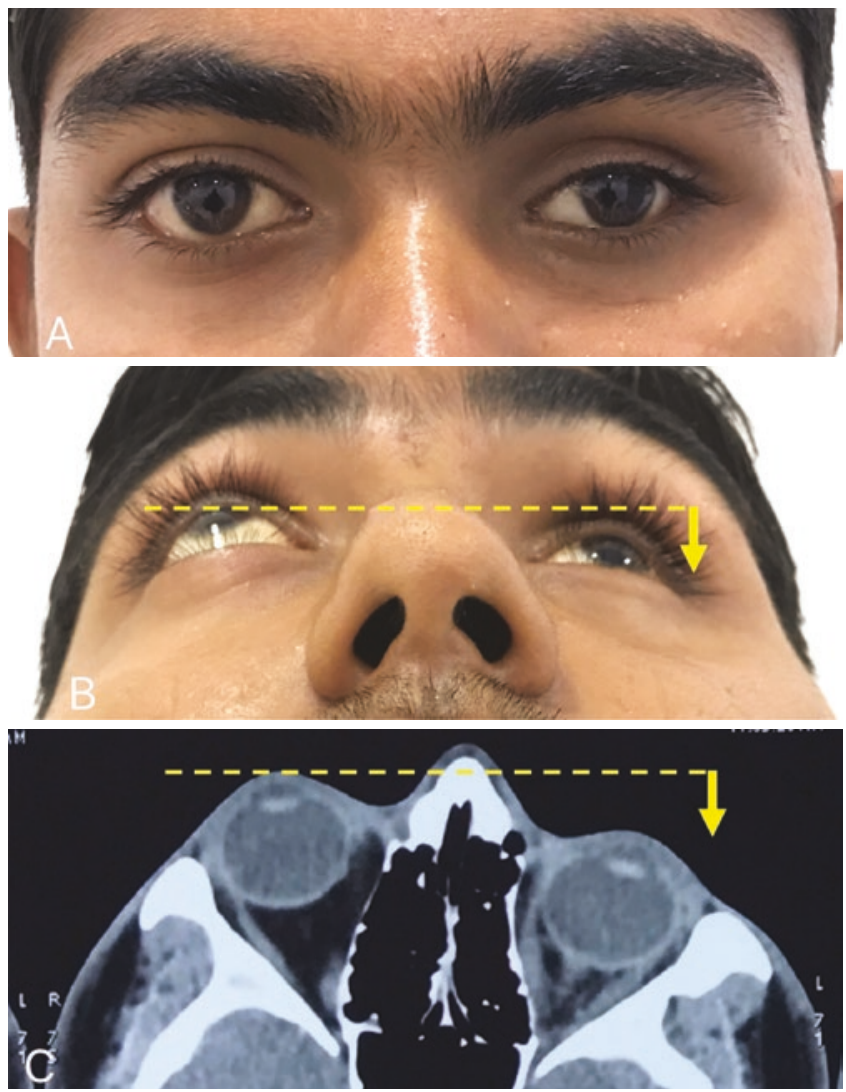

CAssociation of Oral and Maxillofacial Surgeons of India

Fig. 56.19 Enophthalmos. (a) Frontal view showing enophthalmos on left side. (b) Basal view of the same patient showing enophthalmos on left side. (c) Axial CT section demonstrating enophthalmos of the left eye

- Computed tomograms: CT remains the gold standard [31]. It enables a three-dimensional assessment of the fracture along with demonstration of soft tissue entrapment between the fracture fragments. Identification of sphenozygomatic diastasis is best appreciated on CT scans. They also aid in volumetric analysis of the orbital cavity and deficits of the orbital floor. The features demonstrated in different $\mathrm{CT}$ sections are highlighted (Fig. 56.24a-d). Figure 56.25 demonstrates CT scan image with volume rendering, which is useful in assessing the spatial orientation of fractured ZMC.

- $U S G$ is a useful tool for diagnosis of ZMC fractures with high degree of sensitivity for fractures of the arch and infra-orbital rim with the significant advantage of "zero" radiation exposure [36].

The role of intra-operative imaging is discussed in the later segments of the chapter. 

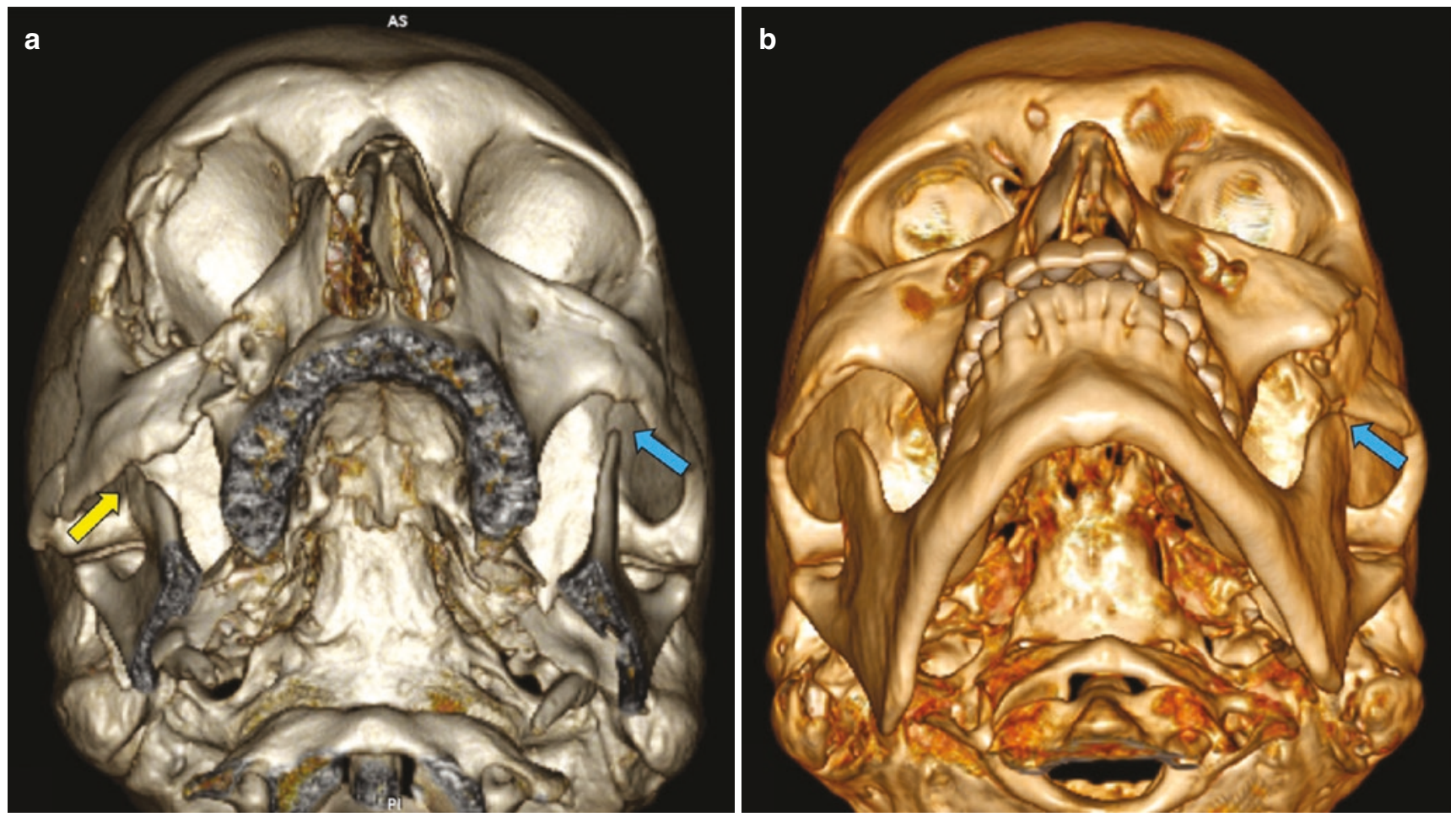

CAssociation of Oral and Maxillofacial Surgeons of India

Fig. 56.20 Restricted mouth opening in ZMC fractures. (a) Retrodisplaced zygoma impinging on the coronoid. Yellow arrow demonstrating restriction of space between the body of zygoma and coro- noid. Process, blue arrow demonstrating normal space. (b) Fractured arch impinging on the coronoid (Here, blue arrow demonstrates reduced space)

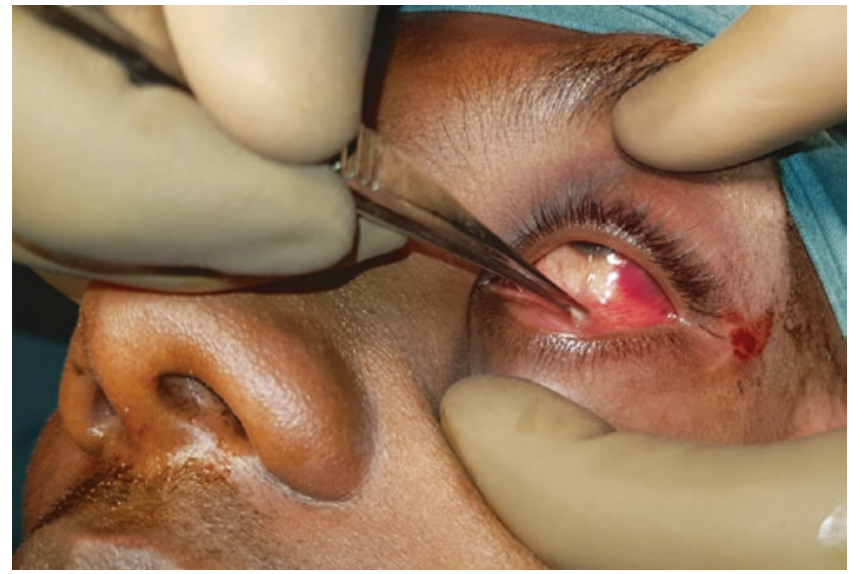

CAssociation of Oral and Maxillofacial Surgeons of India

Fig. 56.21 Forced duction test

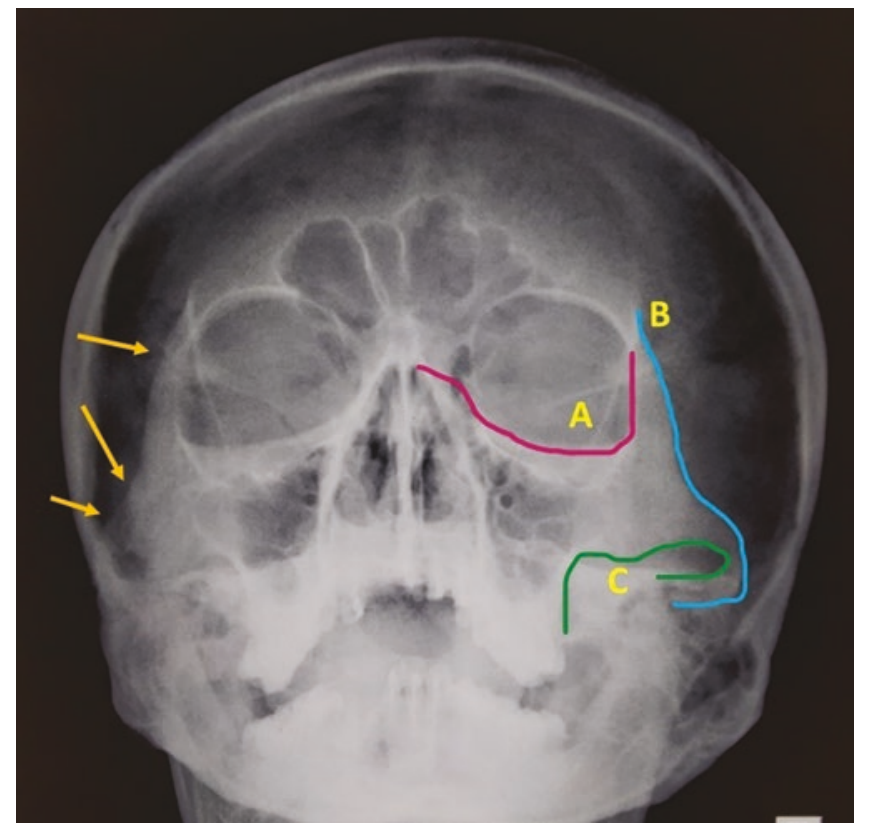

CAssociation of Oral and Maxillofacial Surgeons of India

Fig. 56.22 Waters view with Dolan's lines. (A) Orbital line, (B) Zygomatic line and (C) Maxillary line. The yellow arrows indicate fracture separations noted on the right ZMC 


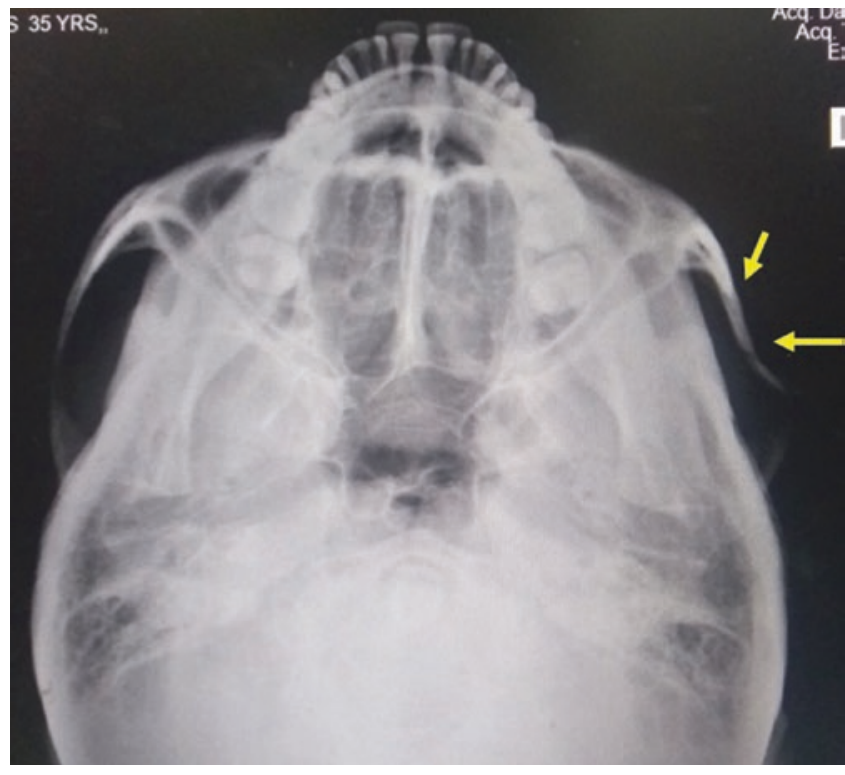

CAssociation of Oral and Maxillofacial Surgeons of India

Fig. 56.23 Submentovertex view demonstrating fractured arch on left side

\subsection{Principles of Management}

\subsubsection{Indications and Contraindications for Intervention [5, 37]}

Surgical outcome of ZMC fractures is greatly influenced by two important factors: (1) choosing the right indications for intervention and (2) ideal time for surgery. Not all fractures of the ZMC require surgical intervention. The decision to intervene should be based on signs and symptoms and presence of functional impairment (Fig. 56.26).

1. It is not necessary to intervene surgically if the fracture is incomplete, undisplaced, or minimally displaced with no compromise in esthetics or function. But such patients must be advised to follow soft, non-chewy diet for 2-6 weeks and monitored to identify displacement [38].

2. Indications for surgery include (1) presence of cosmetic defects in the form of facial deformity, loss of lower eyelid support, or ocular dystopia; (2) functional deficits such as limitation of mouth opening, sensory nerve deficit, and impaired ocular movements; and (3) ZMC fracture associated with OCR reflex in children (please refer to Chap. 57).

3. Postponement of surgical intervention is considered when the general neurologic status of the patient is questionable.

4. Surgical intervention is relatively contraindicated when the involved side has the only seeing eye. In a patient willing for surgery, "potential loss of vision" has to be included in the informed consent.

\subsubsection{Timing of Intervention [39]}

ZMC fractures are not emergencies, and treatment can be delayed, if necessary.

- When the decision is "no immediate intervention," surgery may be postponed for up to 2 weeks, following which a reassessment may be made.

- When the indications are questionable, for example, presence of severe edema or fractures with minimal displacement, it is advisable to wait for the edema to subside so that the deformity may be assessed better.

- When the indications are definite, immediate intervention provides better outcomes due to minimal soft tissue scarring and easier reduction of fractures.

\subsubsection{Surgical Objectives}

Management of ZMC fractures is aimed at achieving the surgical objectives highlighted in Box 56.3 [37].

Box 56.3: Surgical Objectives in ZMC Fracture

- Restoration of facial esthetics

- Restoration of premorbid ocular function

- Correction or prevention of enophthalmos/ exophthalmos

- Restoration of premorbid antral function

- Restoration of mandibular range of motion Mouth opening of $40 \mathrm{~mm}$, excursion - 4-6 mm

\subsubsection{Need for Prophylactic Antibiotics}

ZMC fractures may be categorized into three classes based on their propensity to develop postsurgical infection: clean fractures (isolated arch fractures), clean-contaminated (ZMC fractures compound into the antrum), and dirty (fracture which is open to exterior). While type three fractures require regular antibiotic prophylaxis, types 1 and 2 show minimal rates of infection and may either need "no" antibiotic prophylaxis [40] or a modified single-day postsurgical regimen [41].

\subsection{Preoperative Planning [42]}

ZMC fractures show high propensity for over or under reductions due to lack of objective intra-operative measures to assess reduction. This may be overcome with accurate pre- 

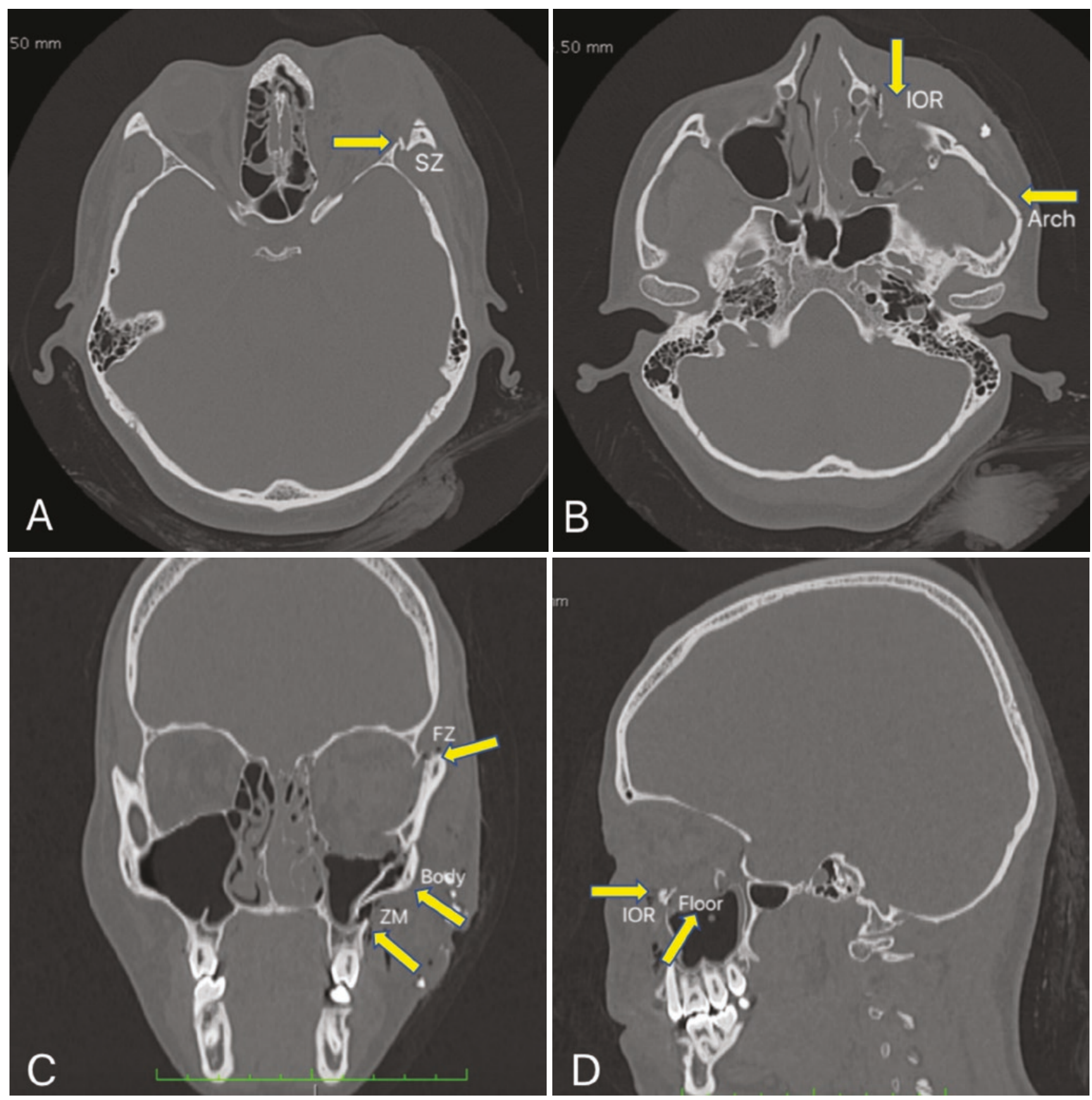

CAssociation of Oral and Maxillofacial Surgeons of India

Fig. 56.24 CT scan of patient with left ZMC fracture. (a) Axial view demonstrating overriding of fracture fragments at SZ suture. (b) Axial section demonstrating fracture at the IOR and buckling of arch. (c) Coronal section showing separation at the FZ and ZM sutures with medial displacement of the body of zygoma. (d) Sagittal section demonstrating posterior displacement of IOR and large blow-out fracture of orbital floor operative planning which helps in realizing surgical objectives in a predictable manner.

Preoperative planning includes three vital steps:

(i) $\mathrm{CT}$ evaluation

(ii) Model surgery

(iii) Soft tissue analysis

\subsubsection{CT Evaluation}

Proper CT evaluation is absolutely essential for choosing the ideal treatment; CT plays a very important role in differentiating en/exophthalmos due to ZMC fractures from those due to orbital fractures. This helps in arriving at a decision regarding internal orbit reconstruction (Box 56.4). 

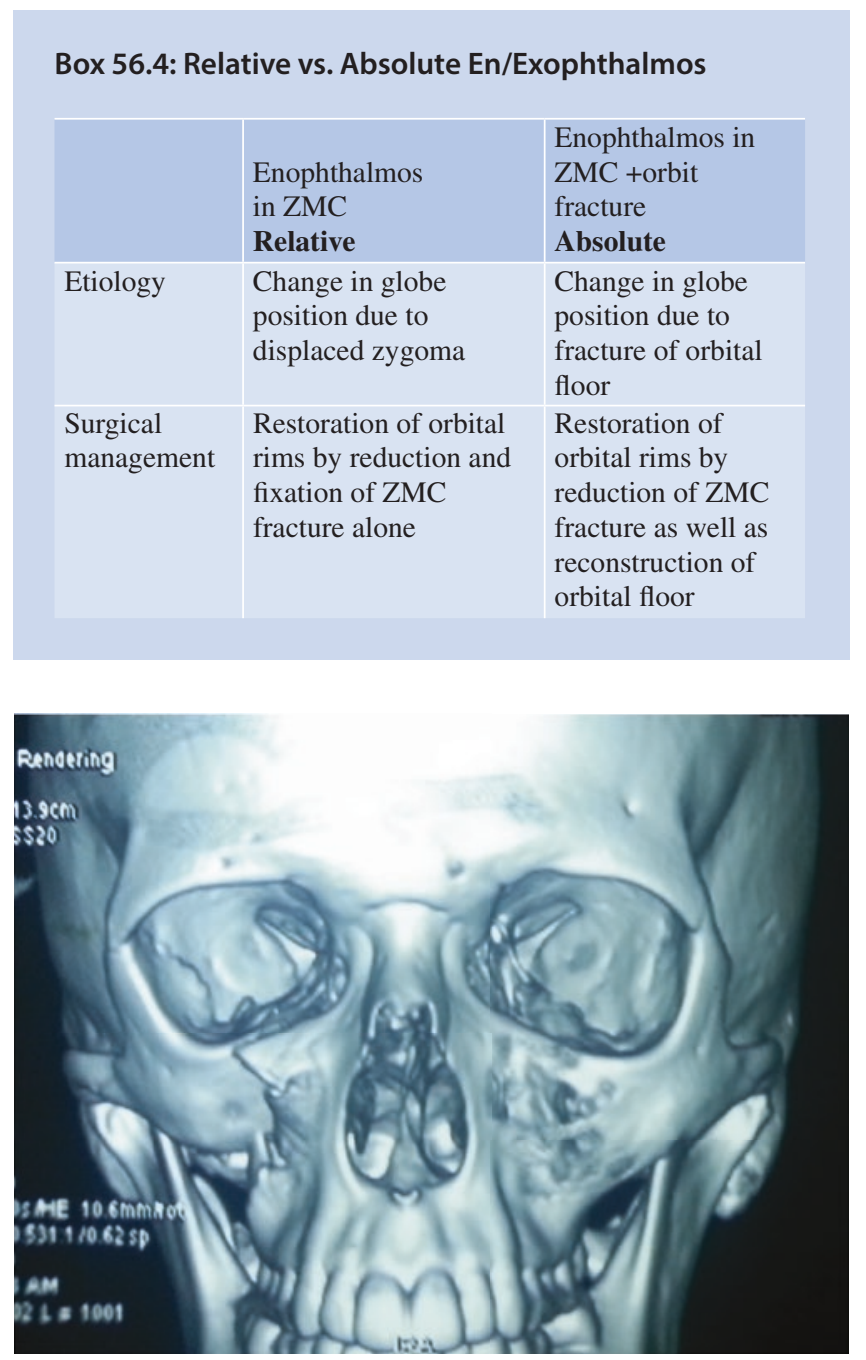

CAssociation of Oral and Maxillofacial Surgeons of India

Fig. 56.25 $\mathrm{CT}$ with $3 \mathrm{D}$ volume rendering demonstrating medially rotated right $\mathrm{ZMC}$ fracture

\subsubsection{Model Surgery}

The process begins with obtaining CT scans of the patient with minimum slice thickness of $0.6 \mathrm{~mm}$. This is followed by two different sequences of workflow (Fig. 56.27) which are described below.

\section{(A) Planning Using Physical Models}

The first step involves generation of a physical stereolithographic model (STL) from the CT scan of the patient. There are two methods by which this can be done.

1. STL model with the actual deformity: This model presents the post-traumatic deformity, as observed clinically. A routine model surgery is then performed, by which the displaced fragments are cut and repositioned to obtain optimal anatomical form.

\section{CLINICAL DECISION MAKING}

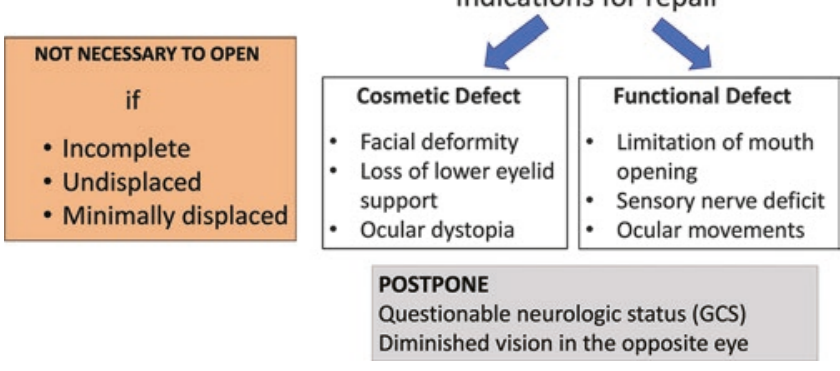

CAssociation of Oral and Maxillofacial Surgeons of India

Fig. 56.26 Indications and contraindications for intervention

The repositioned fragments are stabilized temporarily with wax. The fixation devices (miniplates) are then pre-contoured over the model. Such precontoured implants are used to guide intra-operative fracture reduction as well as fixation. Figure $56.28 \mathrm{a}-\mathrm{d}$ demonstrates the sequence described.

2. STL model after mirroring: CT scan is used to generate a virtual model wherein the normal side is mirrored onto the fractured side. The virtual model is used to print a physical model which demonstrates the skull which is bilaterally symmetrical, mimicking ideal reduction status. Similar to the earlier method, implants for fixation are pre-contoured over this model to help achieve optimal results intra-operatively. Figure 56.29a-d demonstrates a similar clinical scenario.

(B) Planning Using Virtual Models

This method utilizes the complete spectrum of computerassisted surgical planning. A CT scan is obtained to create a virtual model on which the entire surgical sequence of reduction is performed and on which the stents for intraoperative guidance are designed. Intra-operative stents are printed from these virtual designs. There is no physical "handheld" model here (Refer Chap. 41).

- In the case of a unilateral ZMC fracture, the normal side is mirrored to the fractured side to obtain bilateral symmetry. CAS technology is then utilized to design "guidance stents" on the mirrored side. These stents can be utilized intra-operatively to (1) verify ideal reduction position in primary trauma or (2) design the osteotomy and repositioning, in secondary corrections. Another important advancement in recent years is the design and printing of "patient-specific implants" (PSI) using virtual planning. These customized fixation devices double up as guidance stents also (Refer Fig. 57.54).

- In bilateral ZMC fractures [43], mirroring is not an option, and the ideal sequencing for such cases is discussed in Sect. 56.14, of this chapter. 
Fig. 56.27 Flow chart for preoperative planning in $\mathrm{ZMC}$ fractures

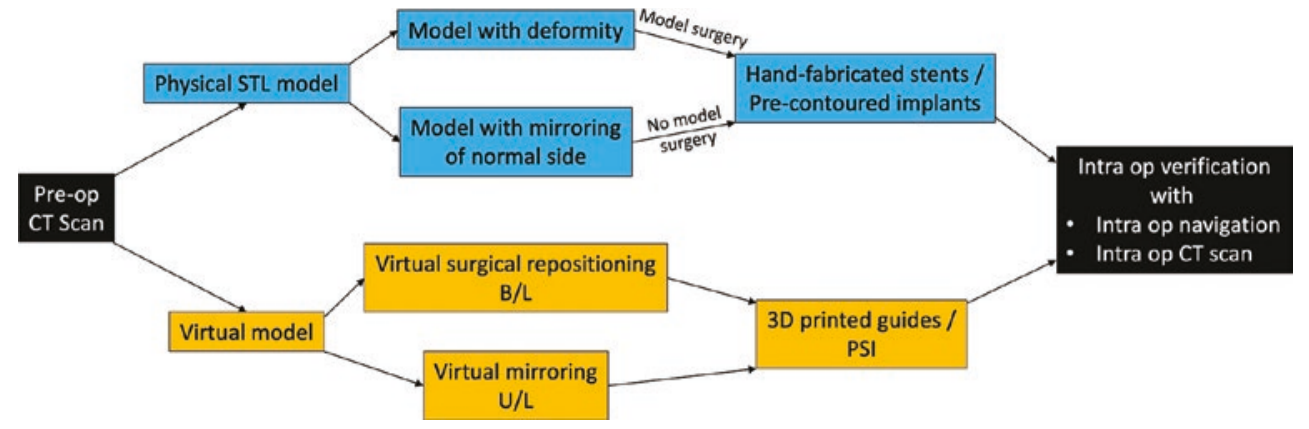

CAssociation of Oral and Maxillofacial Surgeons of India
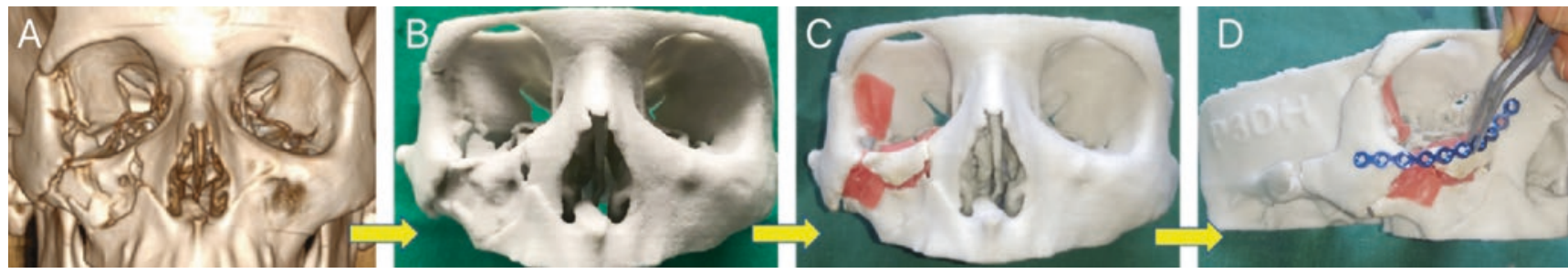

CAssociation of Oral and Maxillofacial Surgeons of India

Fig. 56.28 Model surgery for pre-contouring of implants. (a) CT image demonstrating fractured ZMC of right side. (b) STL model demonstrating deformity. (c) Repositioning of fracture fragments to anatomical position. (d) Pre-contouring of implants

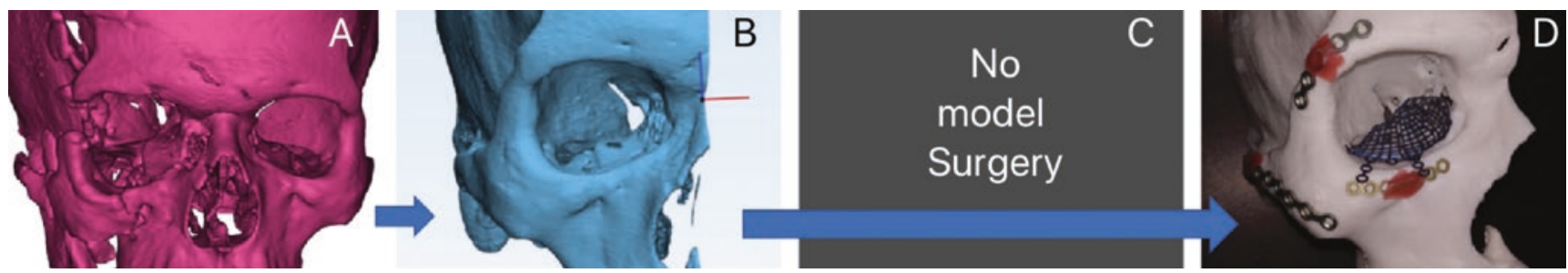

CAssociation of Oral and Maxillofacial Surgeons of India

Fig. 56.29 Use of mirrored models for pre-contouring of implants. (a) 3D CT image of fracture. (b) Mirroring of zygoma of normal side to fractured side. (d) Generation of mirrored STL model and pre-contouring of implants

\subsubsection{Soft Tissue Analysis}

Li et al. [44] have described a technique for 3D simulation and prediction of soft tissue-outcome analysis in ZMC fractures. This process enables prediction of postoperative soft tissue changes in patients with ZMC fractures who are indicated for primary/secondary surgical interventions. The planning involves utilization of CT data and 3D stereophotography for the analysis. The technique may also be utilized for evaluation of postsurgical results.

\subsection{Reduction of ZMC Fractures}

Reduction of zygoma is unique in two aspects:

1. Unlike the other facial bones, "reduction alone" may be the sole treatment in many cases of ZMC fractures.

2. The surgical approach for reduction may be different from that for fixation.
Fracture reduction may be done either by direct or indirect method, and the approaches may be extraoral or intraoral [1].

\subsubsection{Direct vs. Indirect Method}

The indirect method is a blind technique where fracture is reduced without exposure of the fracture site (e.g., Gillies reduction), while direct method involves reduction of the fracture under direct visualization (e.g., coronal approach to reduce arch fracture). The differences between the two methods are shown in Fig. 56.30. However, indirect method is more commonly practiced. Open method is resorted to when the ZMC fracture is (1) severely displaced, (2) complex or comminuted, (3) when stable reduction is doubtful, and (4) there is a need for internal orbit reconstruction. However, no "single technique" is superior, and sometimes, a combination of techniques is more effective. 


\subsubsection{Extraoral Techniques}

The extraoral reduction techniques may be either percutaneous, temporal, or endoscopic $[1,45]$.

- Temporal approach [46], commonly called the Gillie's (Figs. 56.31a-f and 56.32a), is the most popular method of ZMC reduction. This approach is favored because the incision is placed within the hairline which does not leave a visible scar. It also offers a very predictable force during reduction and may be used for reduction of both the arch as well as the zygoma. The technique is based on the anatomical basis that the plane between the temporalis fascia and the temporalis muscle offers direct access to the zygomatic arch and zygoma. The only contraindication to this approach is the presence of concomitant temporal bone fracture. The incision is placed at a level $2 \mathrm{~cm}$ above the helix of the ear, paralleling the anterior branch of the superficial temporal artery, well within the hairline (Fig. 56.33). Dissection is carried down through the skin, subcutaneous tissue, and galea aponeurotica (temporoparietal fascia-TPF) to reach the temporalis fascia.

\section{INDIRECT / CLOSED}

\section{\# site is not visualized}

Incision \& Instrumentation

away from \# site

\section{Difficult to assess reduction}

\section{Precise fixation is not possible}

\section{Surgical outcome- not predictable}

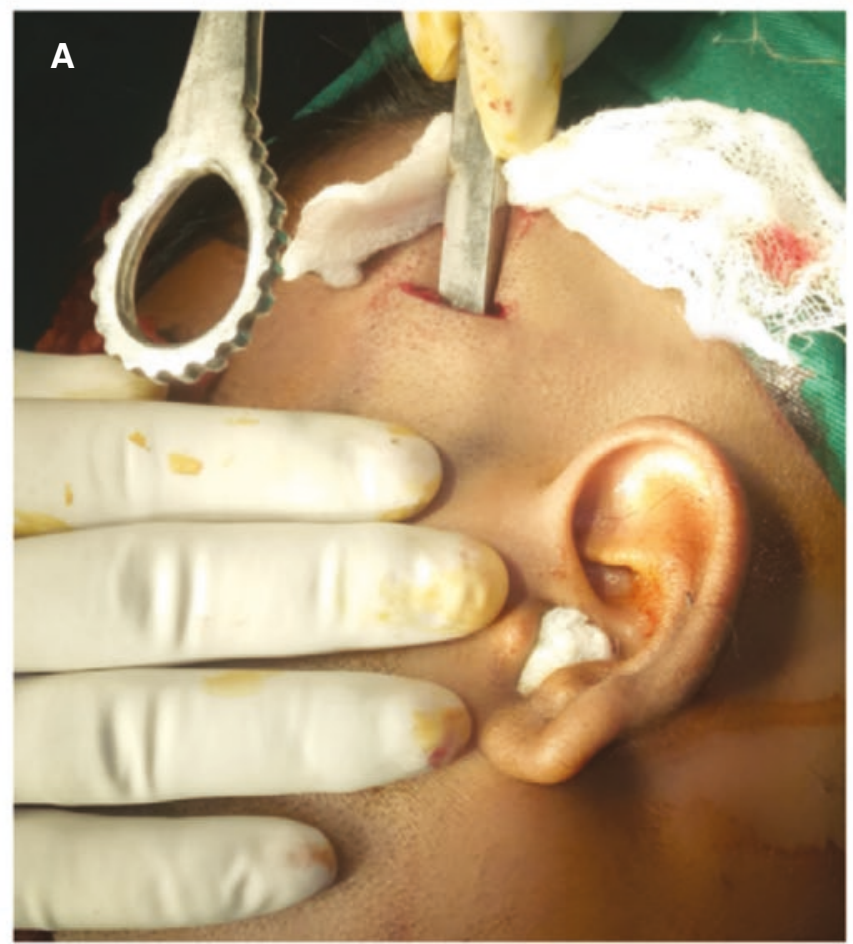

CAssociation of Oral and Maxillofacial Surgeons of India

\section{DIRECT / OPEN}

\section{\# site is visualized}

Instrumentation at \# site

\section{Can assess reduction}

\section{Precise fixation is possible}

\section{Predictable results}

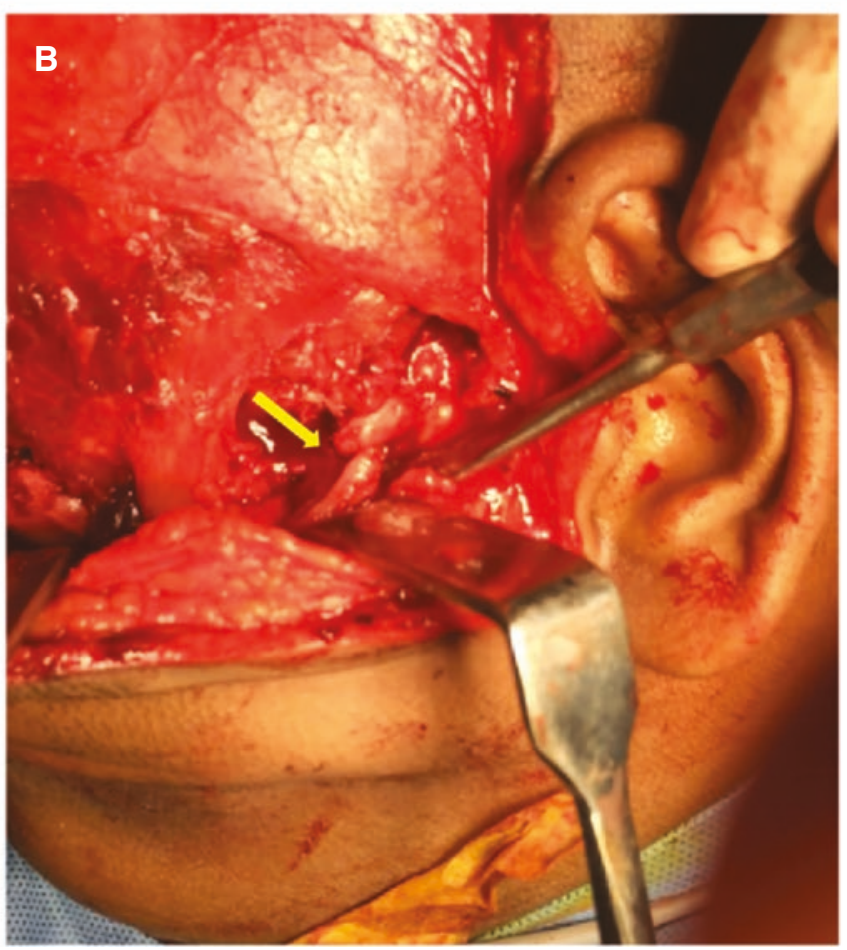

Fig. 56.30 (A) Indirect vs (B) direct reduction 

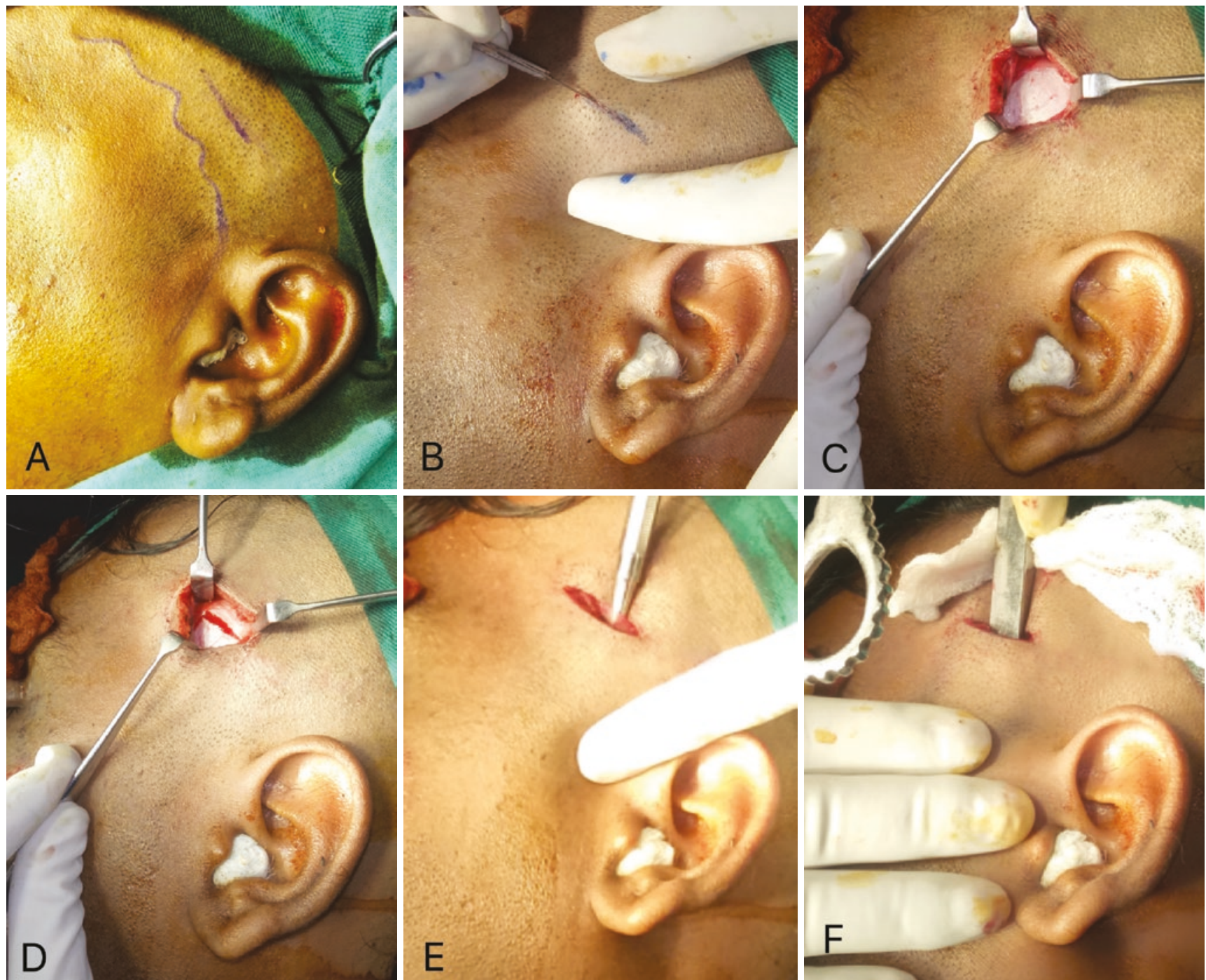

CAssociation of Oral and Maxillofacial Surgeons of India

Fig. 56.31 Gillies temporal approach. (a) Marking of incision parallel to frontal branch of superficial temporal artery. (b) Placement of incision. (c) Exposure of deep temporal fascia. (d) Incision through deep

An incision is made through the temporalis fascia to reveal the underlying temporalis muscle. A Howarth's elevator is inserted between the temporalis fascia and the muscle, to create a plane for the zygomatic elevator. Two types of zygomatic elevators, namely, the Bristow's and Rowe's (Fig. 56.34a), are commonly used; the Bristow' s has a single flat and elongated working tip attached to a handle and is used like a spatula for elevation, while the Rowe's elevator has an additional arm attached to the working tip which serves two purposes: (1) to provide the necessary countertraction during elevation so that it relieves the fulcrum off the temporal bone and (2) to evaluate the approximate depth of insertion of the working tip when inserted into the tissue. The zygomatic elevator is positioned in the plane created, directed inferiorly to reach the deeper surface of the zygoma and carefully elevated, while an ironing motion is used to smoothen the temporal fascia exposing temporalis muscle. (e) Developing plane of elevation with periosteal elevator. (f) Placement of Rowe's zygomatic elevator for elevation

collapsed arch form. Care is taken not to lever the elevator against the skull (Video 56.1).

\section{Clinical Tip}

1. It is good practice to keep a roll of gauze under the zygomatic elevator to prevent injury to the temporal bone.

2. Instead of extensive shaving of the temporal hair for a Gille's approach, a small patch $(1 \mathrm{~cm}$ by $3 \mathrm{~cm})$ of shaving/close trimming of hair can be done for better cosmesis.

- Percutaneous methods make use of a minimal facial skin incision, usually right over the zygoma or the lateral brow (Dingman's method) through which instruments may be inserted to manipulate and elevate the displaced zygoma. 

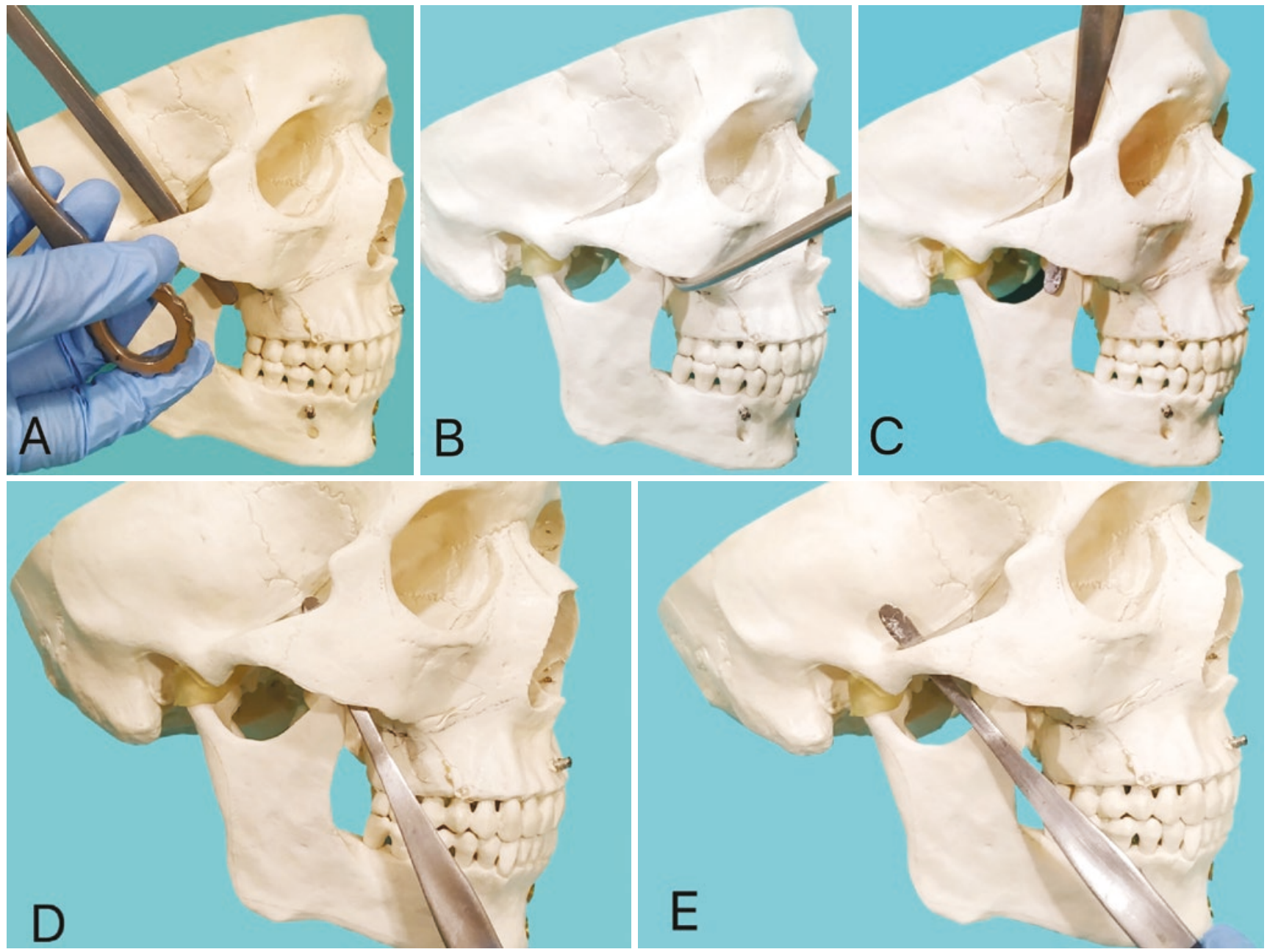

CAssociation of Oral and Maxillofacial Surgeons of India

Fig. 56.32 Different approaches for reduction of fractured ZMC. (a) Gillie's. (b) Poswillo. (c) Dingman. (d) Balasubramaniam. (e) Quinn

- Poswillo's approach. This involves a stab incision made at the point of intersection of two imaginary lines-a horizontal from the base of the nose and a vertical from lateral canthus (Fig. 56.35a, b). The incision is oriented along the skin crease, just enough for a Poswillo hook [47] to be engaged underneath the body of the zygoma (Fig. 56.32b and Fig. 56.34b). And the impacted zygoma is pulled upward or outward. Skin incision is closed with a single suture. Reduction through a zygoma approach may also be performed by using a Carroll-Girard screw [48]/universal bone reduction screw (Fig. 56.34c).

- Dingman's lateral brow approach [49] (1964) (Fig. 56.32c)

This technique is performed through a standard lateral brow approach where the fracture is visualized by a direct approach to the bone after incising through the skin, subcutaneous tissue, and periosteum. An elevator is then passed laterally and posterior to the orbital rim into the temporal fossa. The temporal aponeurosis (attachment of the deep temporal fascia to the lateral orbital rim) is incised, and the elevator is passed beneath it to lift the arch or the body of the zygoma in an upward, forward, and outward fashion. The original description by Dingman utilized trans-osseous wiring for stabilization of the front-zygomatic suture. However current methods incorporate the use of miniplate osteosynthesis through this approach.

\subsubsection{Intraoral Techniques}

The greatest advantage of intraoral techniques is "no skin incision." Commonly followed methods are:

- Balasubramaniam's/Keen's approach (upper buccal sulcus approach) [50] (Fig. 56.32d)

This approach uses a vestibular incision behind the zygomatic buttress. A Howarth's periosteal elevator is inserted in a supraperiosteal plane to engage the infratemporal surface of the zygoma. Reduction is achieved with an upward, forward, and outwardly directed force. When greater force is needed to elevate as in impacted zygomas 


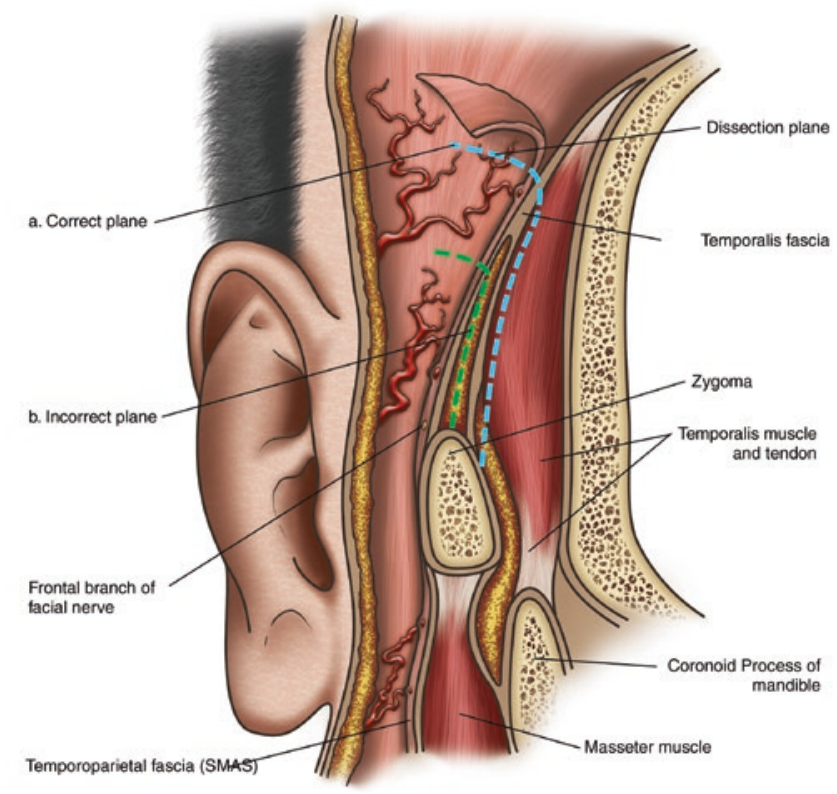

CAssociation of Oral and Maxillofacial Surgeons of India

Fig. 56.33 Gillie's correct plane for elevation. It is important to understand that the deep temporal fascia divides into two, to enclose the zygomatic arch and the fat above, approximately $2 \mathrm{~cm}$ above the arch. An incision placed too low may mislead the young surgeon into the fat plane (b, lateral to the arch) rather than the subfascial plane (a, medial to the arch) (Also refer Fig. 85.1a)

or delayed presentation, a Bristow's/Rowe's zygomatic elevator (Fig. 56.36) or the arm of an upper anterior forceps may be used. The technique offers more mechanical advantage than the extraoral method; less force is needed to elevate, because the force is directed entirely at the center of the zygomatic body, which is considered more effective.

- Quinn's procedure (lateral coronoid approach) [51] (Fig. 56.32e) employs an incision over the anterior border of the ramus. An elevator is inserted in a supraperiosteal plane, lateral to the coronoid process and paralleling the temporalis tendon to reach the medial surface of the zygomatic arch. Elevation of the arch may be done in an ironing fashion.

Both the abovementioned intraoral techniques are supraperiosteal methods.

\subsubsection{Reduction of Zygomatic Arch}

Elevation of the depressed arch is usually performed in an indirect manner, using the Gillie's technique. However numerous techniques have been advocated in literature. These include the "roller-coaster" lateral brow technique [52] and methods using percutaneous towel clip [53], traction suture [54], Foley's catheter [55], K wire [56], and Dingman elevator [57] to restitute the arch anatomy.
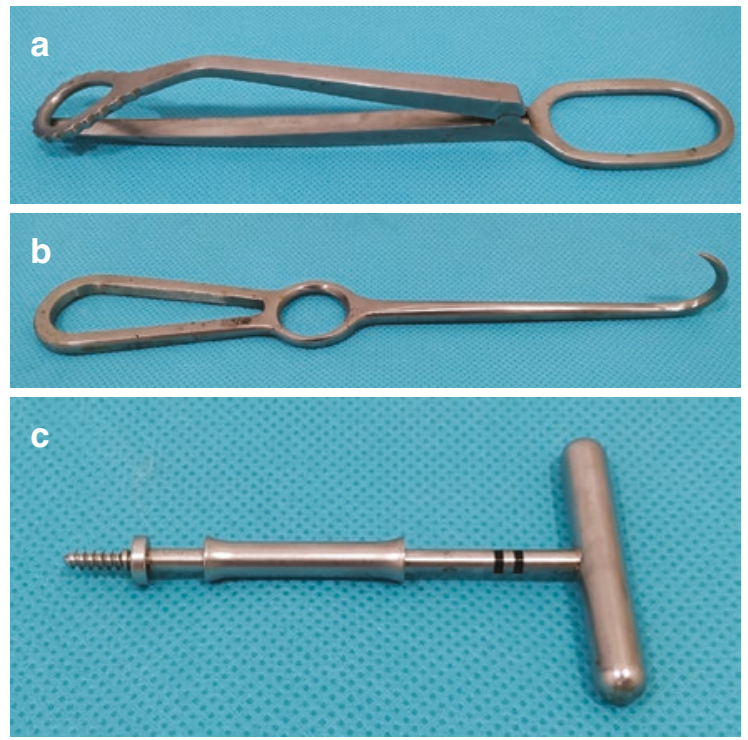

CAssociation of Oral and Maxillofacial Surgeons of India

Fig. 56.34 Instruments for reduction. (a) Rowe's . (b) Poswillo hook. (c) Universal bone reduction screw

\subsubsection{Intra-operative Assessment of Reduction}

The intra-operative assessment of reduction is a critical step in zygoma management, especially in closed reduction. The methods commonly used are (1) clinical assessment, (2) imaging, and (3) use of prefabricated guides/stents.

1. Clinical assessment is usually done by eyeballing, comparing with the normal side or palpation of the rims for steps. However, the adequacy of reduction may be difficult to assess intra-operatively because of edema as well as patient position. Audible click during manipulation is also indicative of reduction [58]. Surgical exposure of multiple suture sites is the other method to confirm reduction [59] but is less favored because of surgical morbidity. However, exposure at all sites of articulation is not required; two sites are considered perfect indicators of accurate reduction [5] (Box 56.5).

2. Intra-operative imaging [58] such as C-arm [60] (Fig. 56.37a, b), CT [59], O arm [61], or endoscopes [45] are valuable guides in confirming reduction of $\mathrm{ZMC}$ fractures. However, use of intra-op imaging other than endoscopes mandates use of lead aprons by operating room personnel to prevent radiation exposure.

3. Prefabricated guides/ stents [62] are valid tools which ensure accuracy of reduction, intra-operatively.

Box 56.5: Indicators of Accurate Reduction of ZMC \#

Reduction along the vertical axis-SZ suture Reduction along the horizontal axis-ZM suture 

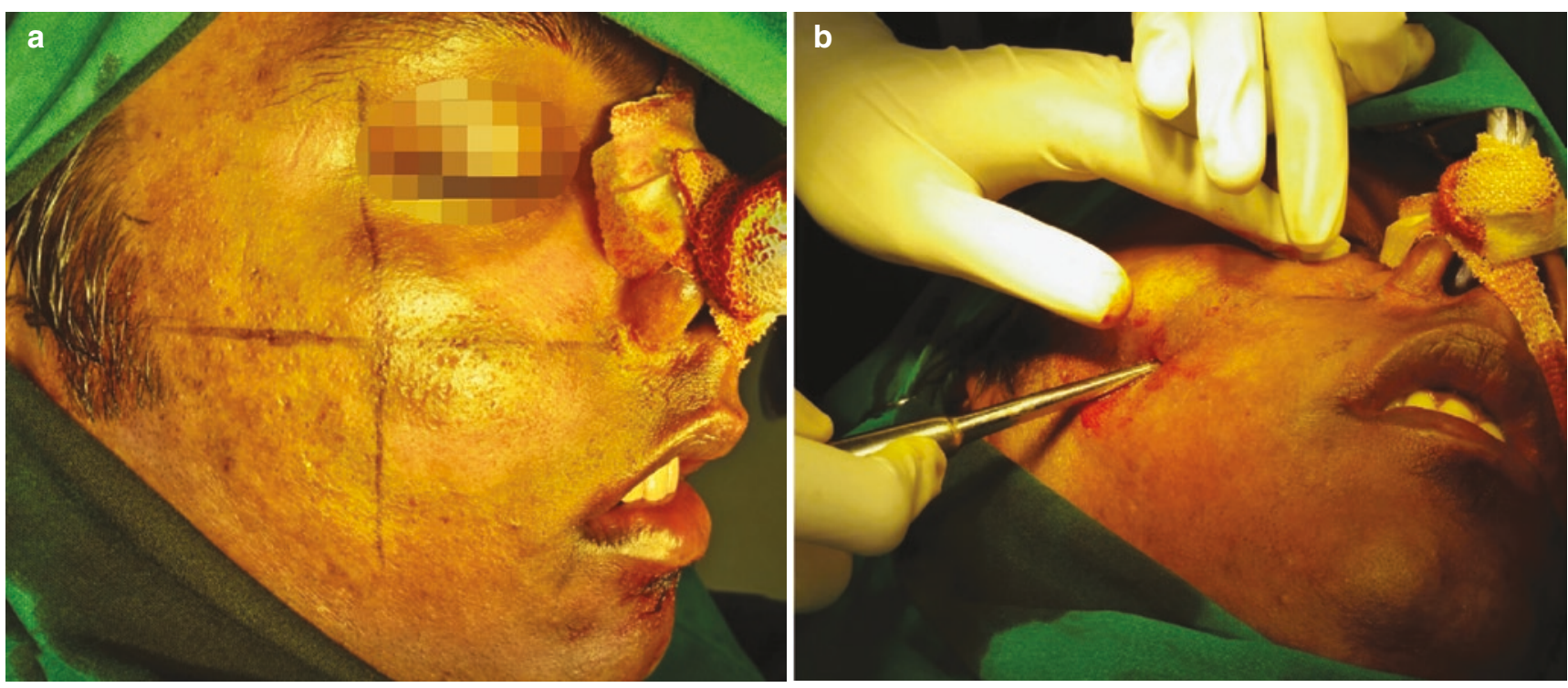

CAssociation of Oral and Maxillofacial Surgeons of India

Fig. 56.35 Percutaneous reduction with Poswillo's technique. (a) Marking on skin. (b) Percutaneous insertion of bone hook

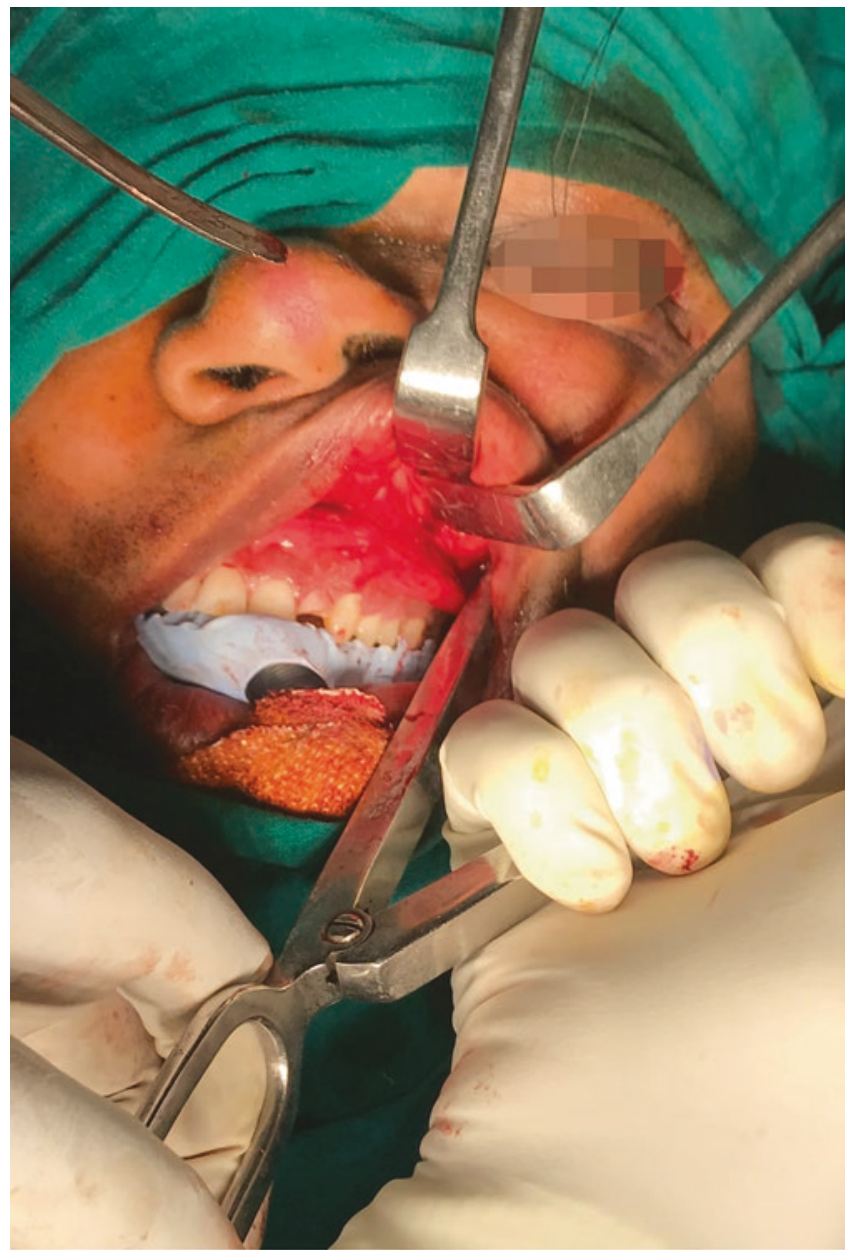

(CAssociation of Oral and Maxillofacial Surgeons of India

\subsubsection{Precautions During and After Reduction}

Manipulation of zygoma during reduction has been known to cause certain complications such as bleeding from infra-orbital vessels [16]. Use of controlled force during indirect reduction greatly reduces such complications. It is prudent to watch out for stimulation of Oculocardiac reflex (OCR) [63] as described later in the text. OCR may also be prevented by administering regional blocks before elevation [64].

Once the reduction is completed and found satisfactory, the fracture fragments need to be maintained in the reduced state. A Zimmer splint [65] (preformed aluminum splint with foam on the undersurface) may be adapted to the reduced arch and secured with sutures. It is maintained in situ for 2-3 weeks.

Finally, it is mandatory to do a force duction test (FDT) after elevation of zygoma [5] (Box 56.6).

\section{Box 56.6: FDT Is Mandatory After Reduction of ZMC}

Fractures (Fig. 56.21)

During reduction of ZMC fractures, as the fractured bones get realigned to normal anatomical position, entrapment of surrounding soft tissue or muscles may occur between the fragments

This may lead to port-surgical diplopia, necessitating a surgical revisit.

Fig. 56.36 Balasubramaniam's technique 

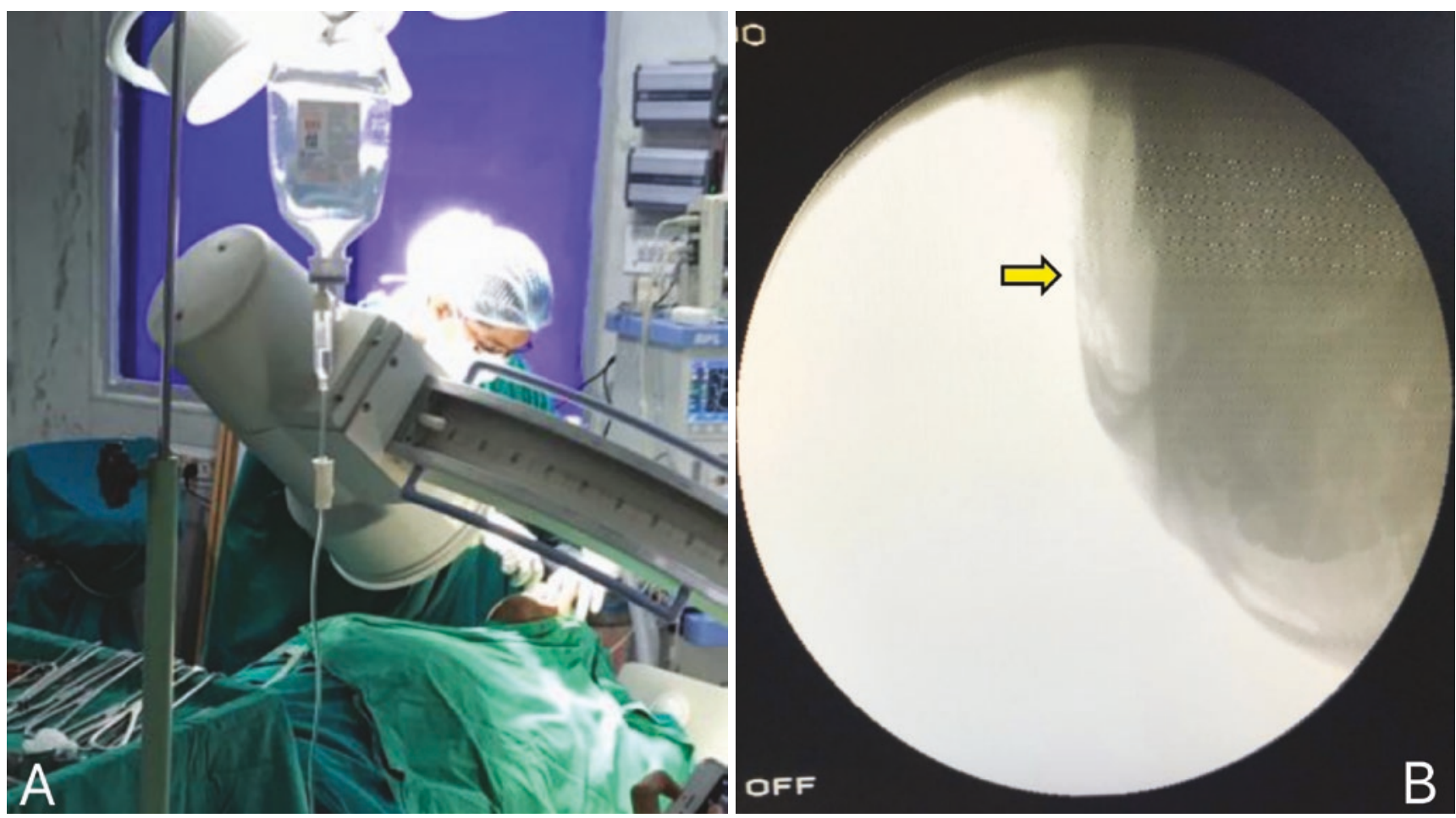

C)Association of Oral and Maxillofacial Surgeons of India

Fig. 56.37 Intra-operative assessment of reduction using C-arm. (a) Intra-operative positioning of C-arm. (b) Image demonstrating zygomatic arch after reduction

\subsection{Fixation and Stabilization of ZMC Fractures}

\subsubsection{Need for Fixation}

Fixation needs of ZMC fractures depend on the postreduction stability. Classification of fracture patterns by Rowe and Williams [1] provides guidance on assessment of fracture stability after reduction. Any fracture classified as stable after reduction does not require fixation, while those considered unstable, mandate fixation. However, a practical method would be to apply moderate digital pressure on the malar eminence after reduction. Displacement secondary to this maneuver, requires fixation [59]. The algorithm proposed by Rodrigo and Belini et al. is also a practical guide to manage $\mathrm{ZMC}$ fractures which are not associated with orbital component [3]. For ZMC fractures with orbital involvement, Ellis and Perez advocate guidelines for orbital reconstruction based on CT evaluation. Most of the studies indicate increase of fixation points from 1 to 2, 3, and 4 points based on the status of intraoperative stability after reduction. Involvement of orbit leading to changes in intra-orbital volume requires orbital reconstruction [59].

\section{Box 56.7: Ideal Sequence of Fixation}

1. Vertical buttress - to restore facial height

2. Zygomatic arch-to restore anteroposterior projection

\subsubsection{Fixation Principles}

The current dictum is "any zygoma which when fractured and displaced must be fixed" [37]. The objectives are to achieve a 3D reconstruction (transverse width, vertical height, and anteroposterior projection) and establish the buttresses. Attention needs to be given to the order of restoration $[66,67]$. The results of various biomechanical experiments indicate that the vertical buttress needs to be fixed first, to restore the facial height. Then, the anteroposterior projection may be achieved by restoring the arch (Box 56.7).

\subsubsection{Surgical Access to Fixation}

Surgical approaches for ZMC fixation are chosen based on the fracture pattern and fixation needs. A single or multiple 
incision may be used for the surgical exposure of ZMC fractures [30, 68, 69].

The incisions may be broadly classified as:

- Cutaneous (upper eyelid, lateral brow, subciliary, subtarsal, infra-orbital, preauricular, and coronal incisions)

- Conjunctival (transconjunctival with canthotomy/ transcaruncular)

- Mucosal (intraoral vestibular)

The list of incisions and the exposure achieved (green shaded areas on Fig. 56.38) by each are highlighted in Box 56.8 (Fig. 56.38)

The following is a description of the various incisions used to access the fixation points in ZMC fractures. It is important to take adequate measures for globe protection while placing any periorbital incisions [70]. The commonly followed methods include either a temporary tarsorrhaphy (Fig. 56.39) or a corneal shield (Fig. 56.40). The tarsorrhaphy also offers the additional advantage of being used as a retraction suture during surgery.

\begin{tabular}{|c|c|}
\hline Intraoral vestibular incision & $\mathrm{ZM}, \mathrm{IOR}$ \\
\hline $\begin{array}{l}\text { Lower eyelid cutaneous incisions } \\
\text { (Subtarsal, subciliary, infraorbital) }\end{array}$ & IOR, orbital floor \\
\hline Transconjunctival & SZ, FZ, IOR, floor \\
\hline Lateral brow & $\mathrm{FZ}, \mathrm{SZ}$ \\
\hline Upper eyelid & SZ, FZ \\
\hline Coronal & SZ, FZ, arch \\
\hline Preauricular & Arch \\
\hline
\end{tabular}

\subsubsection{Supraorbital/Lateral Brow Incision}

(Fig. 56.38)

The lateral brow incision is otherwise called as "in the brow" incision and offers a fast and direct access to the frontozygomatic suture and lateral part of the supraorbital rim. The extensions for the incision must be well within the eyebrow which provides an ideal camouflage (Fig. 56.41a). However, this incision may not be ideal in people who are cosmetically inclined to maintain a higher eyebrow. Absence of any important neurovascular structures in this area makes this incision easy to perform, even by beginners.

After infiltration of LA solution containing vasoconstrictor, a $2 \mathrm{~cm}$ long incision is placed along the curve of the
Fig. 56.38 Incisions to access ZMC fractures

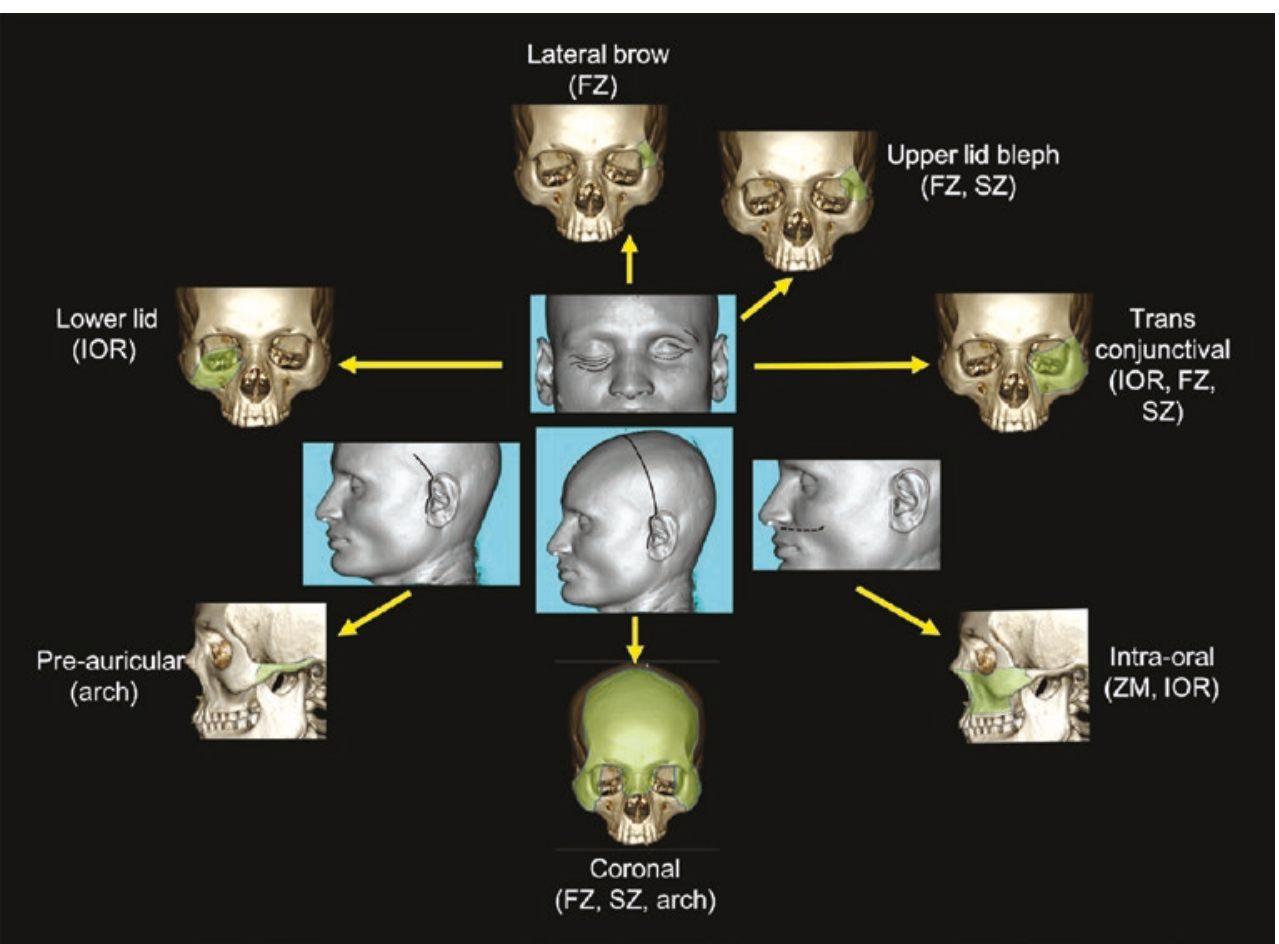

CAssociation of Oral and Maxillofacial Surgeons of India 


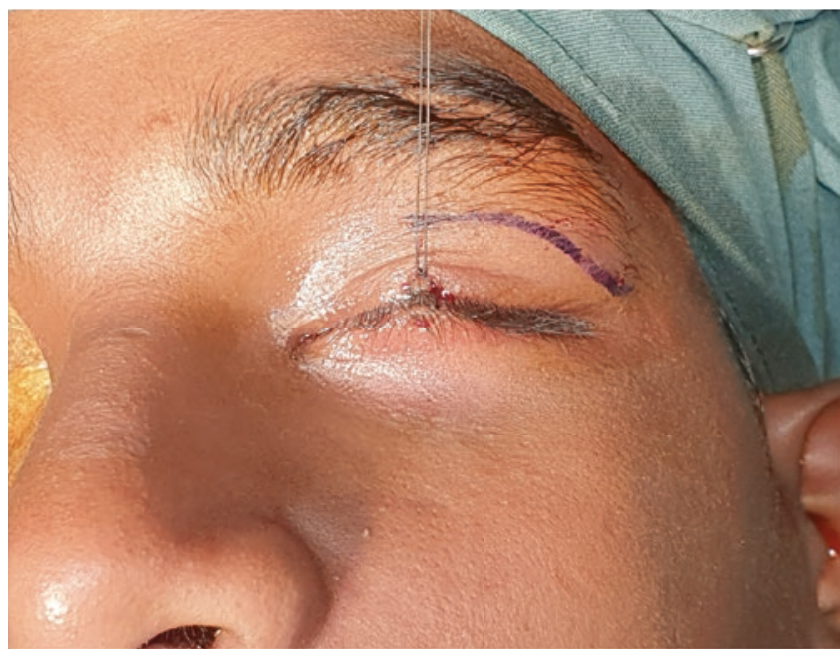

CAssociation of Oral and Maxillofacial Surgeons of India

Fig. 56.39 Tarsorrhaphy

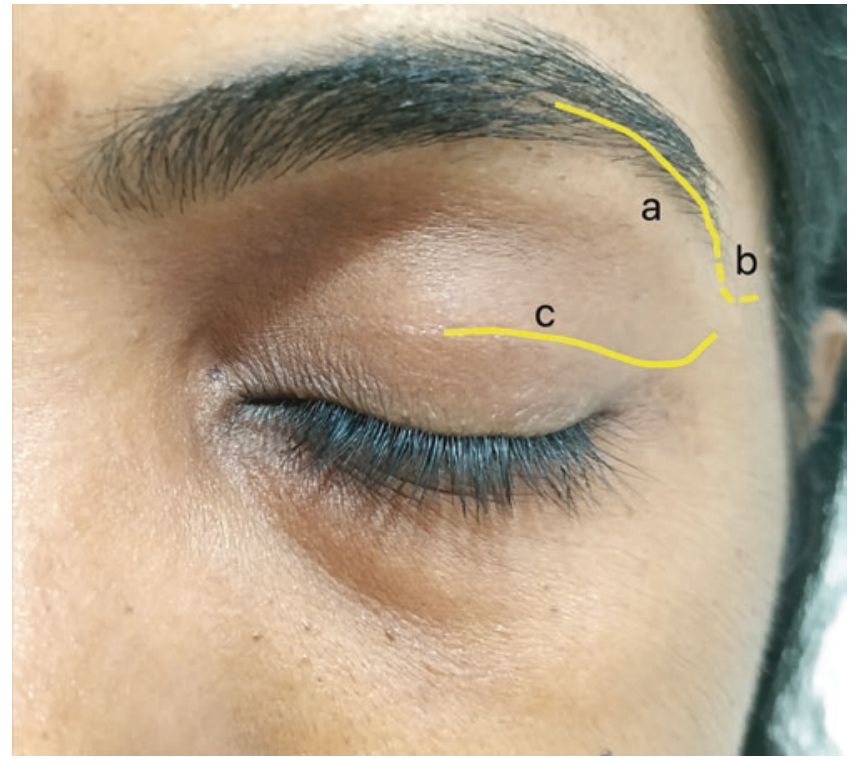

CAssociation of Oral and Maxillofacial Surgeons of India

Fig. 56.41 Periorbital incisions for FZ suture. (a) Lateral brow incision. (b) Lateral brow extension (shown in dotted lines). (c) Upper lid blepharoplasty

superolateral part of the orbital rim. Care is taken to incline the blade parallel to the hair so that the shafts are not transected. Failure to do so may cause linear alopecia along the incision line, which may be unaesthetic. Incision is carried through the skin, subcutaneous tissue, and the orbicularis oculi muscle. The flap is undermined in the supraperiosteal plane to permit ease of retraction. A periosteal incision is then placed above the fronto-zygomatic suture for reduction and fixation (Fig. 56.42a, b).

When additional exposure is needed on the medial aspect, the incision is extended up to the supraorbital nerve. For additional inferior extension, a gradual $90^{\circ}$ turn into the

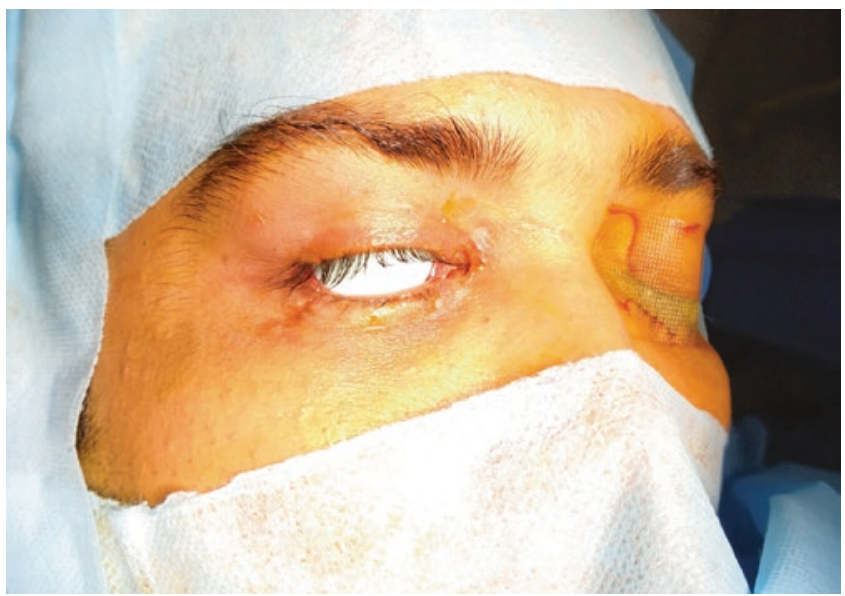

CAssociation of Oral and Maxillofacial Surgeons of India

Fig. 56.40 Corneal shield

crow's feet wrinkle which is restricted to the skin only, is utilized to provide a much wider access [70] (Fig. 56.41b). This extension must remain $6 \mathrm{~mm}$ superior to the lateral canthus. Inferior limit of the incision along the lateral orbital rim should not cross the RSTL (resting skin tension lines) to avoid unaesthetic scars.

Closure is performed in layers with approximation of the periosteum and subcutaneous tissues (Video 56.2).

\subsubsection{Upper Eyelid Blepharoplasty Incision} (Fig. 56.38)

The upper lid blepharoplasty incision is otherwise called as the supratarsal fold or upper eyelid crease incision. It offers the most esthetically favorable approach to the frontozygomatic suture region. The incision is made along the eyelid crease, $10 \mathrm{~mm}$ above the free margin of the eyelid (Fig. 56.41c). As the incision extends laterally, it should be at least $6 \mathrm{~mm}$ above the lateral canthus. When eyelid anatomy is distorted with edema or hematoma, the contralateral lid crease measurements are used to mark the incision.

The incision is placed through the skin and muscle and is raised as a skin-muscle flap for good viability of the overlying skin. The plane of dissection is below the orbicularis oculi in a superior and lateral fashion to reach the periosteum (Fig. 56.43a, b). The periosteum is sharply incised to expose the bone underneath. Further dissection along the bony margins is strictly subperiosteal; any violation of the periosteum may cause herniation of the lacrimal gland which is present in the superolateral concavity of the orbit. Closure of the incision is done in layers, starting with periosteum, followed by the orbicularis oculi, and the skin.

An important advantage of the upper lid blepharoplasty incision is the extensive access it offers to the entire superolateral aspect of the orbit. It also permits good visualization and access to the spheno-zygomatic suture which is the most important indicator of reduction of ZMC fractures. 

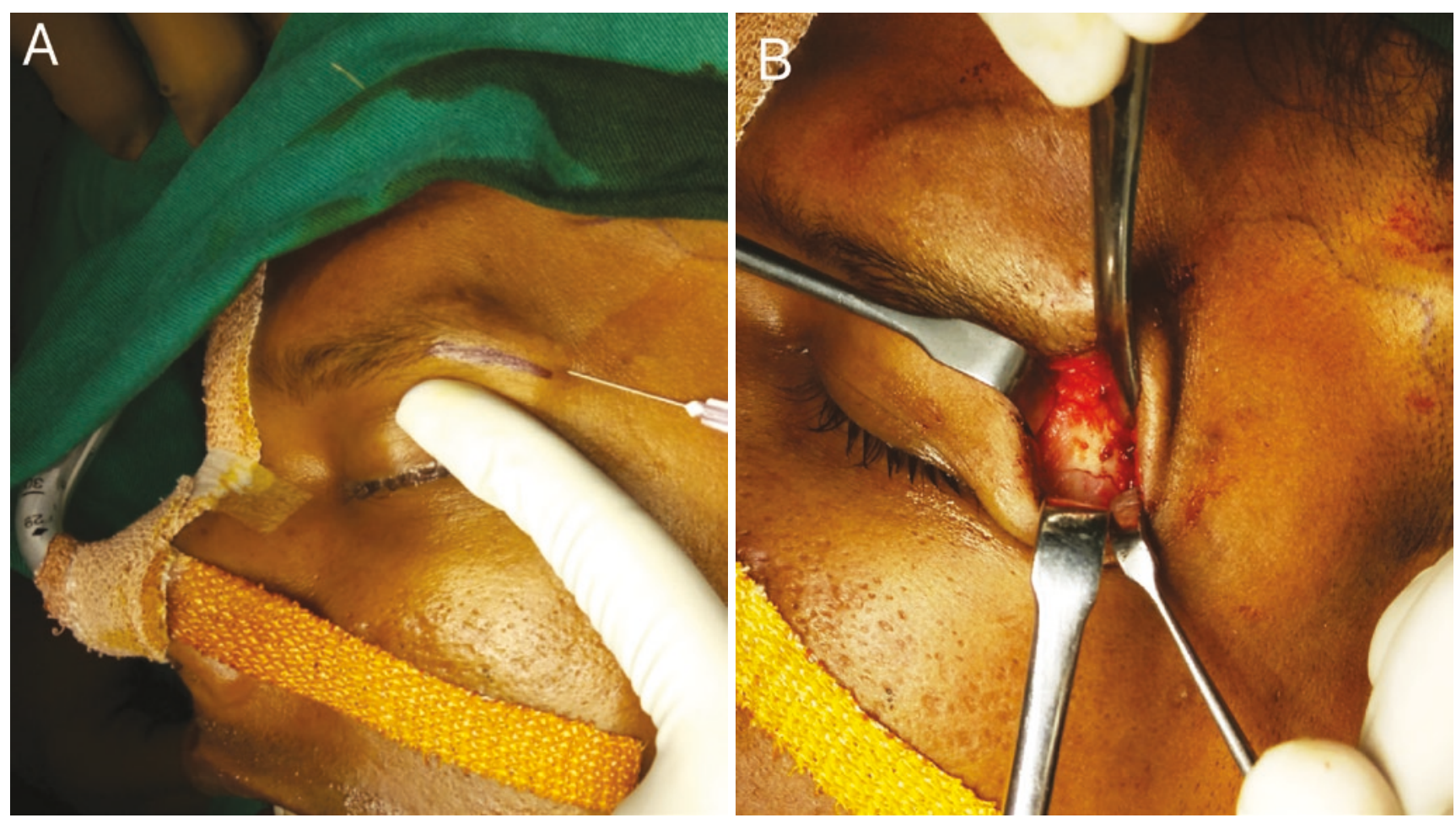

CAssociation of Oral and Maxillofacial Surgeons of India

Fig. 56.42 Lateral brow incision-intra-operative. (a) Marking. (b) Exposure
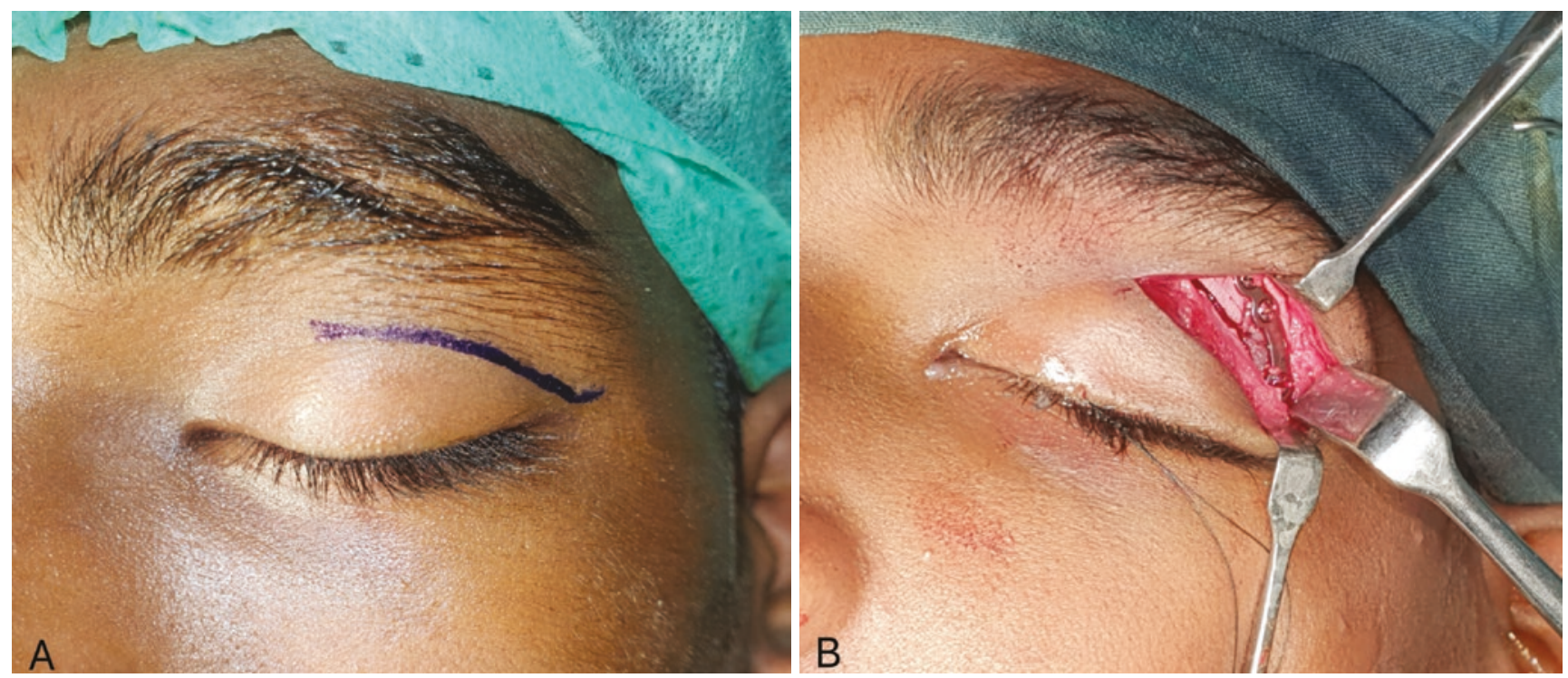

CAssociation of Oral and Maxillofacial Surgeons of India

Fig. 56.43 Upper lid blepharoplasty intra-operative. (a) Marking. (b) Exposure demonstrating ORIF 
56.9.3.3 Subciliary Incision [71, 72] (Figs. 56.38, 56.44a and 56.45a, b)

The subciliary incision is a commonly used transcutaneous approach which offers good exposure of the infra-orbital rim along with the entire orbital floor. This may be a very useful approach in the management of ZMC fractures which involve the orbital floor also.

The skin incision is placed along the entire length of the lower eyelid, $2 \mathrm{~mm}$ below the level of the eye lashes to conceal the future scar.

The incision must not be extended more than $2 \mathrm{~cm}$ lateral to the lateral canthal ligament. This prevents any inadvertent damage to the temporal branch of the facial nerve which is present about $3 \mathrm{~cm}$ lateral to the lateral canthal ligament.

Once the skin is incised, the dissection may proceed in three different ways [30, 70] (Fig. 56.45b) (Box 56.9):

(i) "Skin-alone" flap technique where the plane of dissection is along the subcutaneous plane between the skin of

Box 56.9: Comparison of Variants of Subciliary Incisions

\begin{tabular}{|c|c|c|c|}
\hline & Skin flap & $\begin{array}{l}\text { Skin- } \\
\text { muscle } \\
\text { flap }\end{array}$ & $\begin{array}{l}\text { Stepped } \\
\text { skin-muscle flap }\end{array}$ \\
\hline Skin incision & $\begin{array}{l}2 \mathrm{~mm} \text { below } \\
\text { the cilia }\end{array}$ & $\begin{array}{l}2 \mathrm{~mm} \\
\text { below the } \\
\text { cilia }\end{array}$ & $\begin{array}{l}2 \mathrm{~mm} \text { below the } \\
\text { cilia }\end{array}$ \\
\hline $\begin{array}{l}\text { Muscle } \\
\text { incision }\end{array}$ & $\begin{array}{l}\text { Just below } \\
\text { the infra- } \\
\text { orbital rim }\end{array}$ & $\begin{array}{l}\text { Same level } \\
\text { as skin } \\
\text { incision }\end{array}$ & $\begin{array}{l}2-3 \mathrm{~mm} \text { below } \\
\text { the skin incision }\end{array}$ \\
\hline $\begin{array}{l}\text { Periosteum } \\
\text { incision }\end{array}$ & $\begin{array}{l}\text { Just below } \\
\text { the infra- } \\
\text { orbital rim }\end{array}$ & $\begin{array}{l}\text { Just below } \\
\text { the } \\
\text { infra- } \\
\text { orbital rim }\end{array}$ & $\begin{array}{l}\text { Just below the } \\
\text { infra-orbital rim }\end{array}$ \\
\hline $\begin{array}{l}\text { Plane of } \\
\text { dissection }\end{array}$ & $\begin{array}{l}\text { Between skin } \\
\text { and } \\
\text { orbicularis } \\
\text { muscle }\end{array}$ & $\begin{array}{l}\text { Between } \\
\text { orbicularis } \\
\text { muscle } \\
\text { and } \\
\text { septum }\end{array}$ & $\begin{array}{l}\text { - Stepped } \\
\text { - Between skin } \\
\text { and orbicularis } \\
\text { muscle in } \\
\text { pre-tarsal } \\
\text { region } \\
\text { - Between } \\
\text { orbicularis } \\
\text { muscle and } \\
\text { septum- } \\
\text { inferior to the } \\
\text { tarsal region }\end{array}$ \\
\hline $\begin{array}{l}\text { Preservation } \\
\text { of pre- tarsal } \\
\text { fibers of } \\
\text { orbicularis } \\
\text { oculi }\end{array}$ & Preserved & Incised & Preserved \\
\hline Complications & $\begin{array}{l}\text { Skin } \\
\text { buttonholing, } \\
\text { discoloration }\end{array}$ & $\begin{array}{l}\text { Septal } \\
\text { perforation } \\
\text { Ectropion } \\
\text { Lid } \\
\text { shortening } \\
\text { Scleral } \\
\text { show }\end{array}$ & $\begin{array}{l}\text { Lesser incidence } \\
\text { of complications }\end{array}$ \\
\hline
\end{tabular}

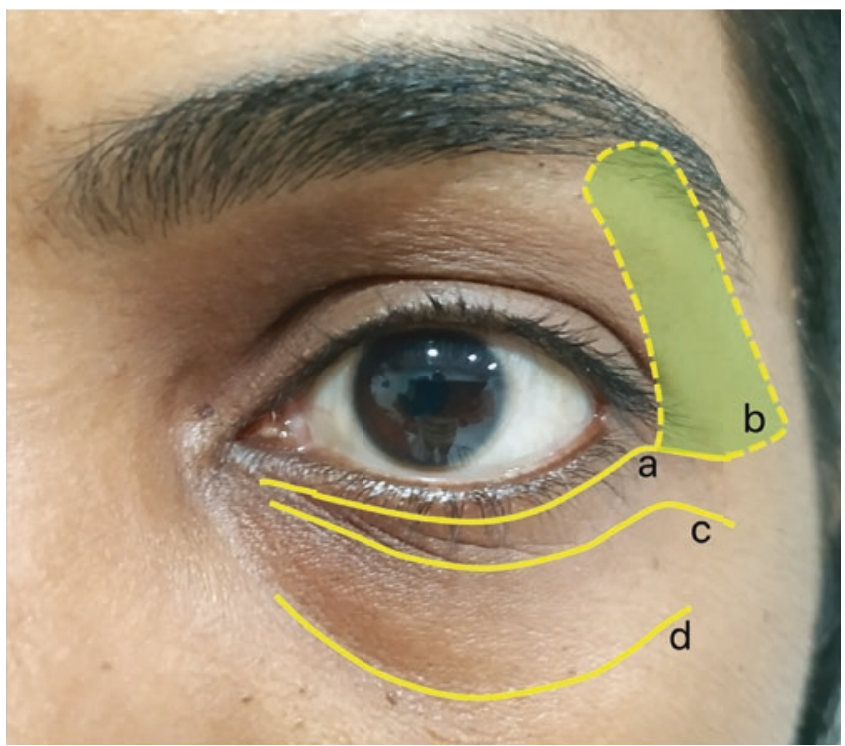

CAssociation of Oral and Maxillofacial Surgeons of India

Fig. 56.44 Lower eyelid incisions. (a) Subciliary. (b) Extended subciliary showing area of exposure shaded. (c) Subtarsal incision. (d) Infra orbital

the eyelid and the orbicularis oculi. On reaching the facial surface of the infra-orbital rim, the orbicularis muscle along with the periosteum is incised to reach the rim. The periosteal incision is generally placed at least 3-4 $\mathrm{mm}$ below the level of the infra-orbital rim (Fig. 56.45a and 56.45b1).

(ii) "Skin-muscle" technique: the incision is carried down from the skin into the pre-tarsal fibers of the orbicularis oculi, and the flap is dissected along the plane deep to the muscle but superficial to the tarsal plate. The dissection is then carried out superficial to the orbital septum till the rim is reached. Exposure of the rim is performed after sharp dissection of the periosteum just below the level of the rim (Fig. 56.45b2).

(iii) "Step" approach is performed in two different levels and is considered the best approach as it prevents most of the complications which are associated with the two former approaches. The incision is first placed through the skin, and the plane of dissection is carried in the subcutaneous plane, maintaining the pre-tarsal fibers of the orbicularis oculi. As the lower end of the tarsal plate is reached, the orbicularis oculi muscle is divided, and the plane is changed to include the muscle along with the skin as a "skin-muscle" flap (Fig. 56.45b3).

The development of a skin-alone flap at the marginal level and a "skin-muscle" flap at the subtarsal level creates a step in the plane of dissection. The dissection then proceeds caudally toward the infra-orbital rim in a submuscular plane superficial to the orbital septum. On reaching the rim, the periosteum is incised sharply about 3-4 $\mathrm{mm}$ below the level of the rim on the facial aspect. 


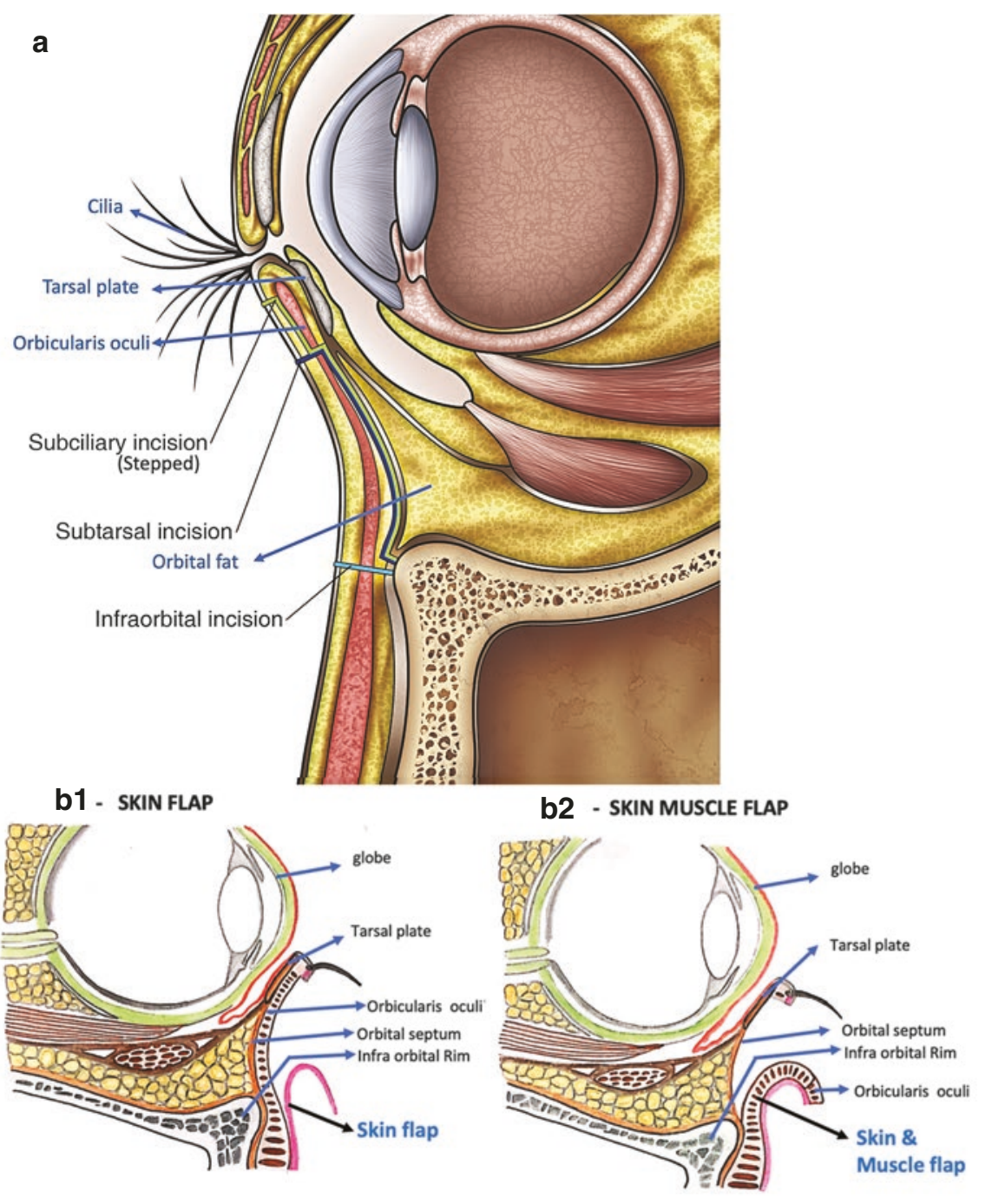

b3 - STEPPED TECHNIQUE

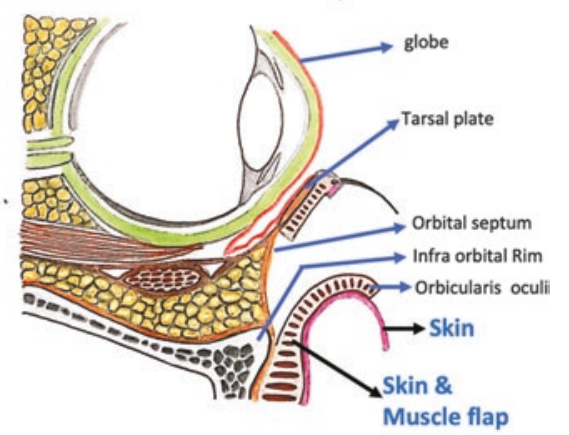

(C)Association of Oral and Maxillofacial Surgeons of India

Fig. 56.45 Lower eyelid incisions—-sagittal view. (a) Subciliary, sub tarsal and infra-orbital (b) Variants of sub-ciliary incision

The incision of the periosteum at this level not only helps preserve the attachment of the orbital septum along the rim margin but also lies above the level of the infra-orbital foramen which is seen about 7-8 mm below the level of the rim. Dissection of the periosteum can be performed along the entire length of the infra-orbital rim, anterior maxilla, and the zygoma to provide excellent exposure.

Advantages of the stepped approach include (1) minimal chances of buttonholing or darkening of the skin due to vascular compromise (2) lesser incidence of ectropion and entropion (3) reduced scarring at the eyelid margins due to preservation of the pre-tarsal orbicularis oculi fibers.

The differences between the three variants of subciliary incision are highlighted in Box 56.9 (Figs. 56.45b).

\subsubsection{Extended Lateral Exposure with the Subciliary Approach Fig. 56.46 [70]}

After placing a standard subciliary incision, supraperiosteal dissection is performed along the lateral orbital rim in the cephalic direction till the FZ suture or a few millimeters beyond (Figs. 56.44b and 56.46). This releases the skin flap and makes it amenable to easy retraction to reach the FZ region. The periosteum is then divided in the center of the lateral orbital rim along its length. In most cases the lateral canthal ligament may be stripped in a subperiosteal fashion to facilitate comfortable access to the FZ suture. This approach may be used to avoid an additional incision for exposure of the FZ suture.

\subsubsection{Subtarsal Approach [73] (Figs. 56.38,} 56.44c and 56.47)

Subtarsal or mid-lid incision was also described by Converse. The incision is marked 5-7 mm below the inferior lid margin corresponding to the lower border of the tarsal plate, along 


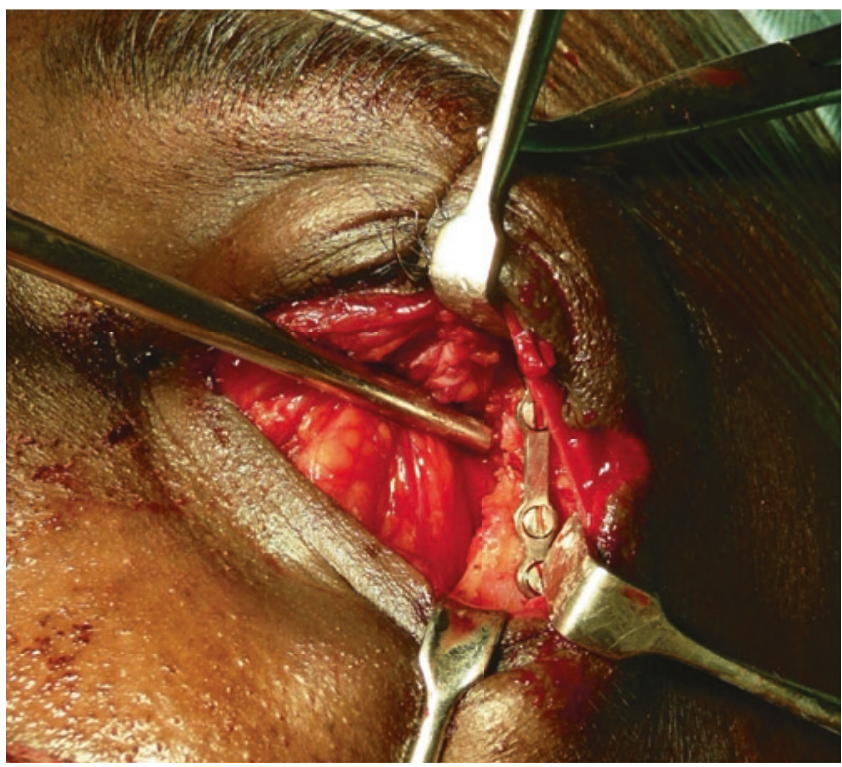

CAssociation of Oral and Maxillofacial Surgeons of India

Fig. $\mathbf{5 6 . 4 6}$ Subciliary with lateral extension demonstrating exposure of the FZ suture after ORIF

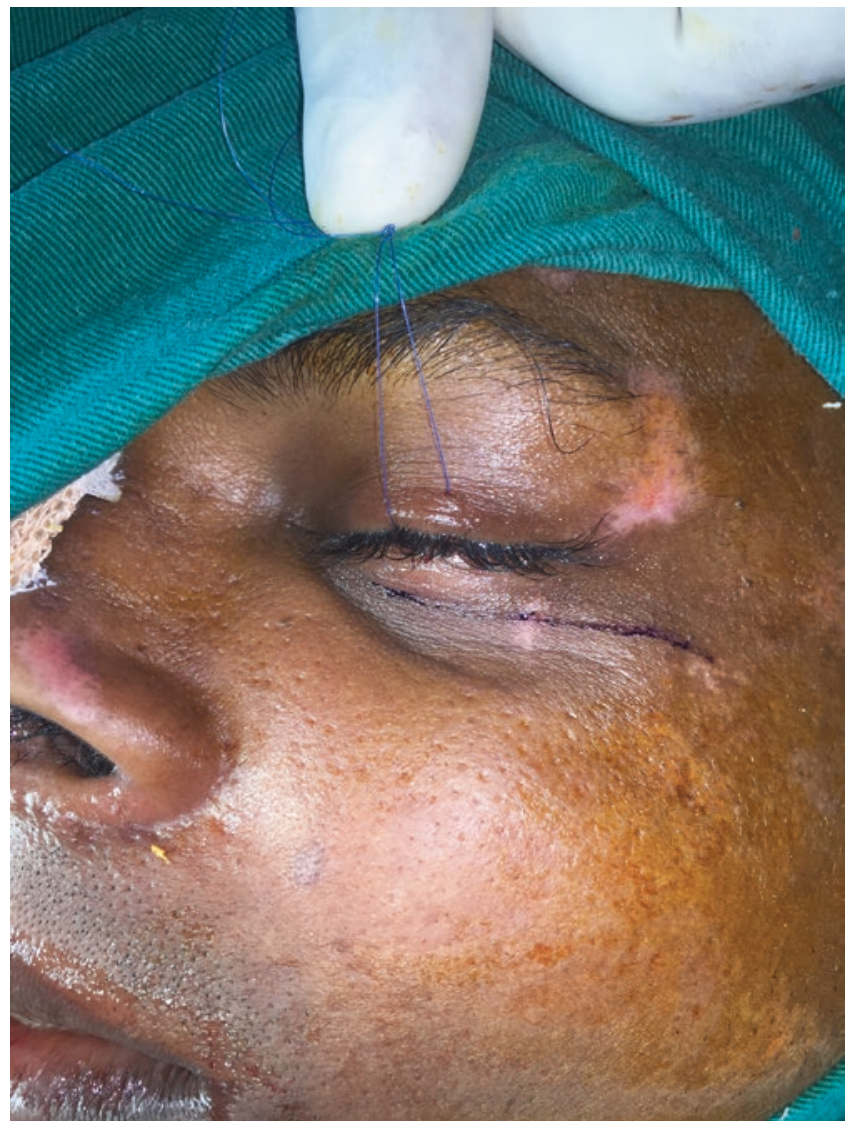

CAssociation of Oral and Maxillofacial Surgeons of India

Fig. 56.47 Subtarsal marking intra-operative the subtarsal crease (Fig. 56.47). The lateral extension of the incision may be extended up to $2 \mathrm{~cm}$ beyond the lateral canthal ligament similar to the subciliary incision, along one of the resting skin tension lines. The incision is made through the skin and subcutaneous tissue. The pre-septal fibers of the orbicularis oculi are also divided at the same level, and the plane of dissection is maintained superficial to the orbital septum. The dissection is carried out caudally to reach the infraorbital rim, and the periosteum is divided below the level of the rim on the anterior surface of the maxilla and zygoma.

The subtarsal approach is favored more than the subciliary [73] due to its easier technique and lesser incidence of complications (Box 56.10).

\begin{tabular}{|c|c|c|}
\hline \multicolumn{3}{|c|}{ Box 56.10: Subtarsal vs. Subciliary Incision } \\
\hline & Subtarsal & Subciliary \\
\hline Ease of technique & Easy & $\begin{array}{l}\text { Technically demanding } \\
\text { due to } \\
\text { - Stepped dissection and } \\
\text { closure } \\
\text { - Interference of lashes in } \\
\text { the surgical field }\end{array}$ \\
\hline $\begin{array}{l}\text { Time taken for the } \\
\text { approach }\end{array}$ & Quick & $\begin{array}{l}\text { Takes almost twice the } \\
\text { amount of time }\end{array}$ \\
\hline $\begin{array}{l}\text { Incidence of scleral } \\
\text { show or ectropion }\end{array}$ & $2.7-7.7 \%$ & $17-42 \%$ \\
\hline Cutaneous scar & $\begin{array}{l}\text { More } \\
\text { visible }\end{array}$ & Less visible \\
\hline
\end{tabular}

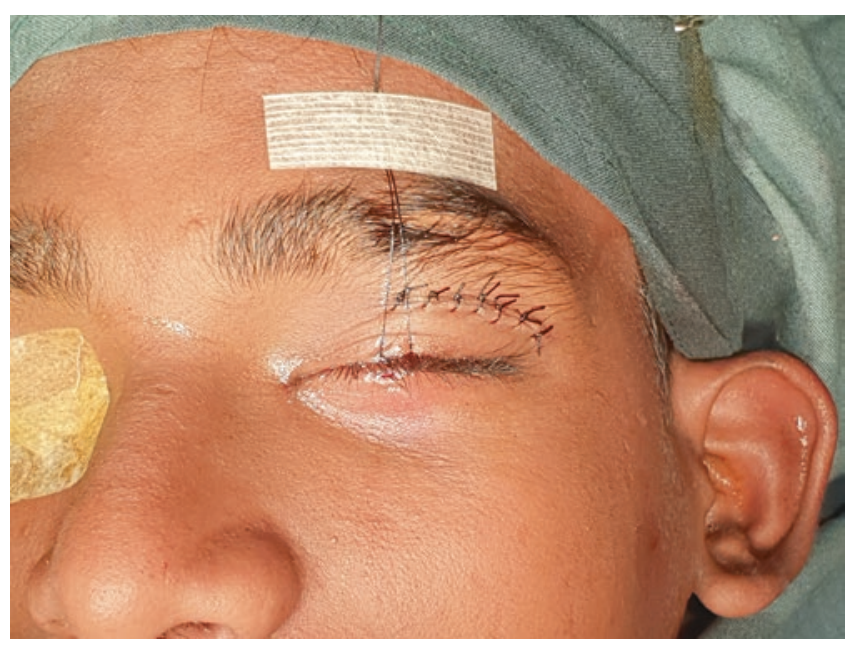

CAssociation of Oral and Maxillofacial Surgeons of India

Fig. 56.48 Figure demonstrates use of frost suture for ZMC fracture approached by transconjunctival and upper lid blepharoplasty incision. Technique for frost suture. A 4-0/5-0 nonabsorbable suture on a 3/8th circle needle is passed to engage the inferior tarsal plate, at the middle of the lower eyelid margin. The suture is taken either through the gray line or through the pre-tarsal skin to include the skin, orbicularis, and the tarsus. Appropriate tension is applied in superior direction by the anchoring the suture ends, to the supraorbital skin, $5 \mathrm{~mm}$ above the eyebrow using adhesive tapes 
An important consideration following lower eyelid approaches is the application of the "frost suture" [74] (temporary lower eyelid suspension suture) (Fig. 56.48), to prevent postoperative ectropion. Frost suture also permits visualization of the globe in the postoperative phase, when required (Refer Fig 11.13).

Nevertheless, lower rim incisions are often associated with postoperative ectropion and scleral show. While scleral show/lid traction refers to abnormal exposure of sclera (1 mm or more) with contact between bulbar conjunctiva and the lid, ectropion refers to eyelid eversion with no contact between bulbar conjunctiva and lid [75]. Ectropion requires correction for cosmetic reasons as well as functional problems arising from keratinization of exposed conjunctiva. Treatment varies from conservative modalities to surgical procedures [76, 77] (Box 56.11).

\section{Box 56.11: Measures to Correct Ectropion and Scleral Show}

- Conservative measures Corneal protection measures; artificial tears, ointment, temporary tarsorrhaphy

- Surgical procedures Release of cicatrization, sutures, skin/mucosal grafts, cartilage grafts, rotation flaps

\subsubsection{Infra-orbital Incision (Figs. 56.38 and $56.44 d$ )}

This is performed as an incision which simultaneously divides the skin, orbicularis muscle, and periosteum, along infra-orbital rim. Though the infra-orbital incision offers the

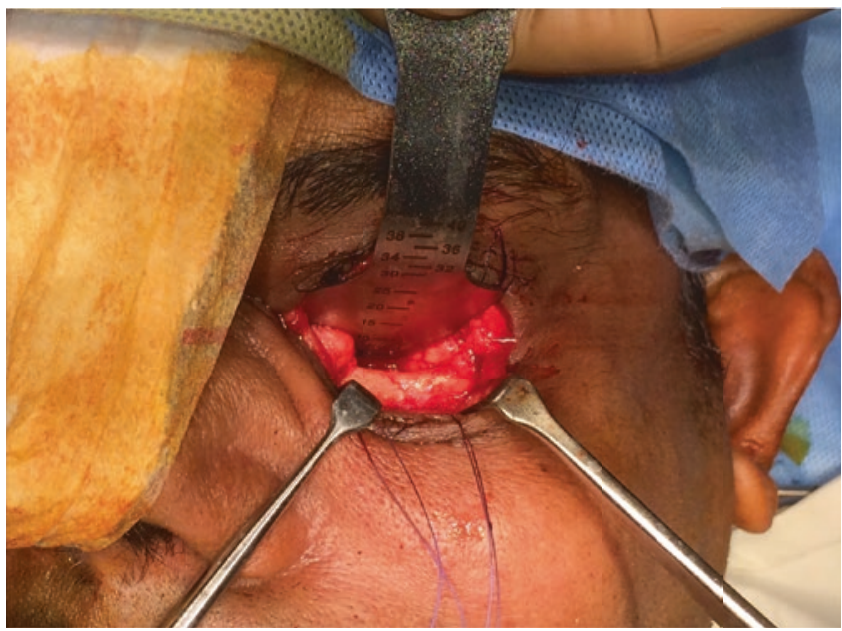

CAssociation of Oral and Maxillofacial Surgeons of India

Fig. 56.49 Transconjunctival intra-operative most direct approach to the infra-orbital rim and orbital floor, it is seldom preferred in contemporary surgery due to the unsightly postoperative scar and prolonged edema of the lower lid region due to disruption of lymphatic drainage.

\subsubsection{Transconjunctival Incision $[78,79]$}

(Figs. 56.38 and 56.49)

Transconjunctival incision has gained popularity because it completely negates the unesthetic scarring associated with skin incisions. This incision offers good access to the infraorbital rim and SZ regions with either a pre-septal or retroseptal approach. Refer to the Chap. 57 for a detailed description of the approach. The modified transconjunctival incision with a cutaneous $\mathrm{Y}$ extension when combined with lateral canthotomy offers excellent exposure to the IOR, SZ, as well as the FZ region [80-82]. The complications of transconjunctival incisions include entropion [82], in-curling of lashes (trichiasis) [83], or growth of the eyelashes in two layers (distichiasis) [84]. Malposed lateral canthus has also been observed following improper repositioning of the lateral canthus after canthotomy [82].

\subsubsection{Vestibular [85] Incision (Figs. 56.50 and 55.16)}

The vestibular incision is the most frequently used approach to access the ZM buttress. The popularity is due to its application for reduction of $\mathrm{ZMC}$ fracture as well as fixation at the ZM buttress. Refer to the Chap. 55 for description of the technique. The author of this chapter (EP) uses the vestibular approach to also fix the zygomatic arch fractures which override at the zygomaticotemporal suture, with transbuccal instrumentation (transoral arch fixation technique) (Refer to recent trends section 56.16).

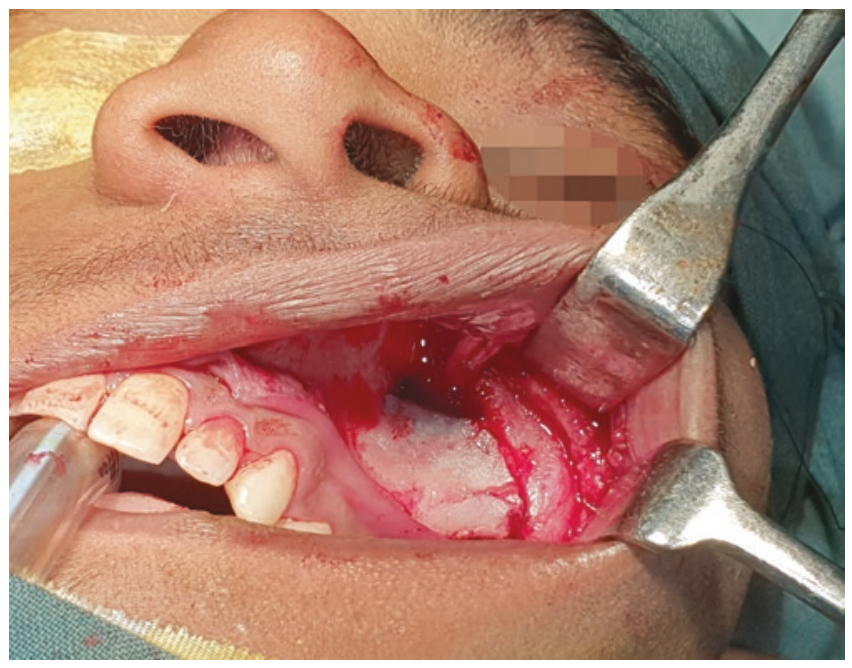

CAssociation of Oral and Maxillofacial Surgeons of India

Fig. 56.50 Vestibular incision demonstrating fracture at ZM buttress 
56.9.3.9 Preauricular [86] (Figs. 56.38, 56.51, 53.17a, b and 65.6) (Refer Video on pre auricular approach in Chap. 53)

Preauricular incision is useful for open reduction and fixation of arch fractures. After the routine skin incision, adopting the deep subfascial approach provides better protection to the facial nerve as compared to the other commonly used approaches, namely, the subfascial and suprafascial procedures [87]. Figure 56.51 demonstrates the use of preauricular incision with deep subfascial dissection to expose a malunited zygomatic arch fracture.

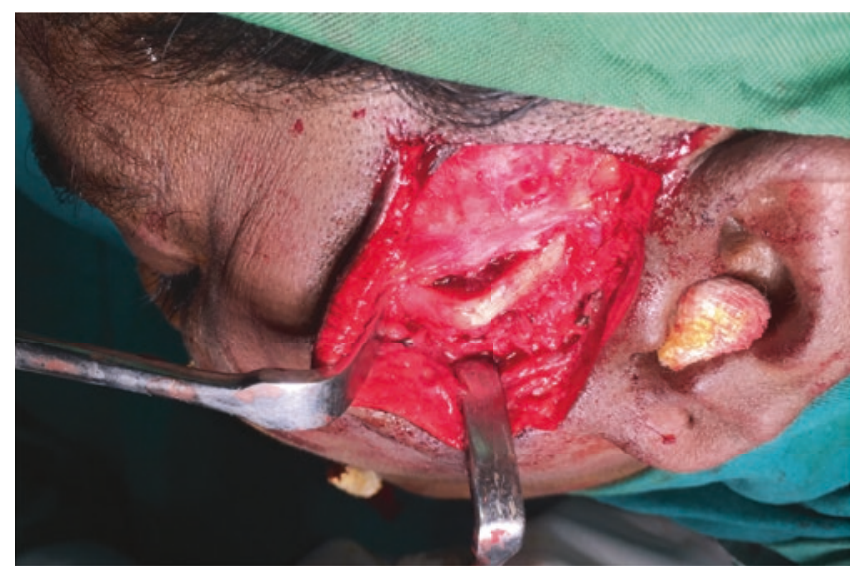

CAssociation of Oral and Maxillofacial Surgeons of India

Fig. 56.51 Preauricular approach demonstrating exposure of malunited zygomatic arch fracture

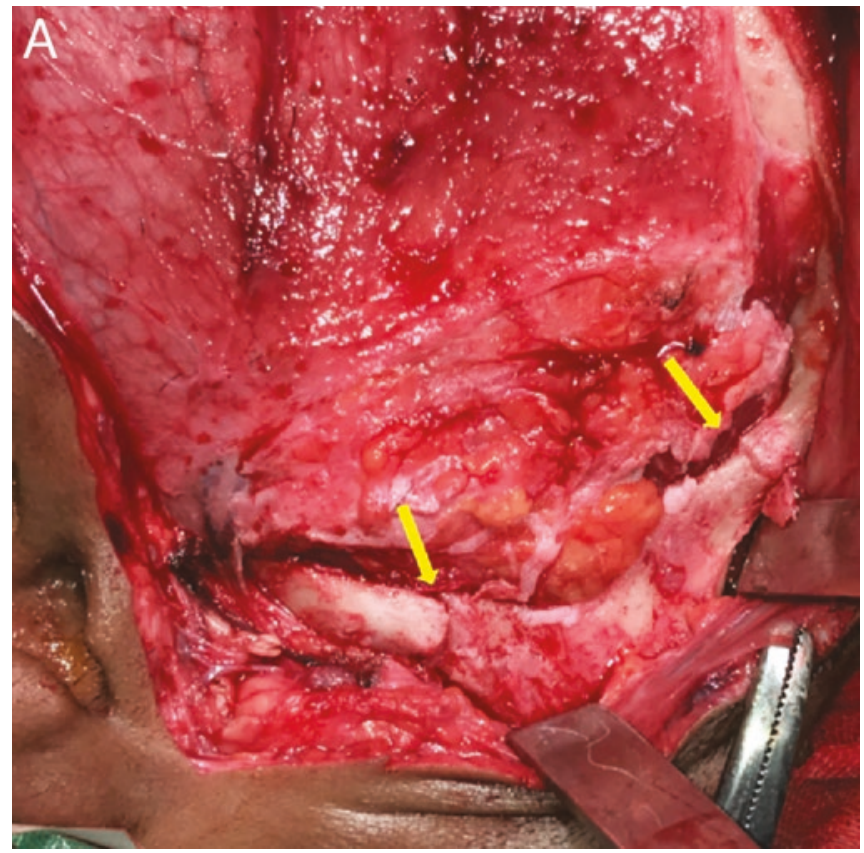

CAssociation of Oral and Maxillofacial Surgeons of India

\subsubsection{Coronal Incision [88] (Figs. 56.38,} $56.52 a, b$ and 85.1 )

Tessier introduced the use of coronal incision to access the superior and lateral orbits bilaterally along with naso-orbitoethmoid complex in congenital facial reconstruction. The approach can be extended with a preauricular incision to include the exposure of the zygomatic body and the arches bilaterally. This incision also facilitates the temporal approach to the SZ suture [82]. Disadvantages of the approach include the extensive length of incision, dissection, temporal hollowing, scar alopecia, risk of injury to the supraorbital nerve, and temporal branch of the facial nerve.

\subsubsection{Fixation Methods}

Fixation methods for ZMC fractures have evolved through the ages.

Three basic fixation methods are available for ZMC fractures [1] (Table 56.1):
1. Temporary support
2. Indirect fixation and
3. Direct fixation

The trend has gradually shifted from nonrigid fixation methods such as trans-osseous wiring, external pin fixation, and $\mathrm{K}$ wires to functionally rigid fixation methods including

Fig. 56.52 Coronal approach, intra-operative. (a) Exposure of arch demonstrating fractured zygomatic arch and FZ region (yellow arrows). (b)

Arch after reduction and fixation at ZT and FZ region

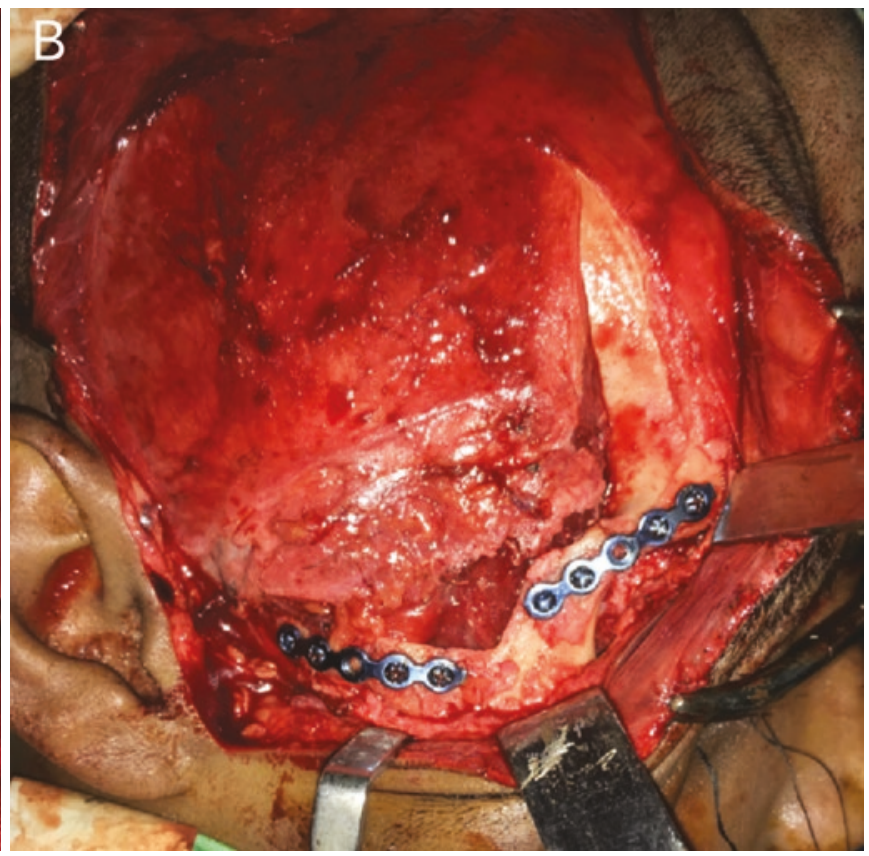


Table 56.1 Fixation methods for ZMC fractures

\begin{tabular}{|c|c|c|c|}
\hline & $\begin{array}{l}\text { Temporary } \\
\text { support }\end{array}$ & Indirect fixation & Direct fixation \\
\hline $\begin{array}{l}\text { Access to } \\
\text { fracture }\end{array}$ & $\begin{array}{l}\text { Fracture is not } \\
\text { visualized }\end{array}$ & $\begin{array}{l}\text { Fracture is not } \\
\text { visualized }\end{array}$ & $\begin{array}{l}\text { Fracture is } \\
\text { visualized by } \\
\text { surgical exposure }\end{array}$ \\
\hline $\begin{array}{l}\text { Fixation } \\
\text { technique }\end{array}$ & $\begin{array}{l}\text { Provide } \\
\text { support to } \\
\text { reduced } \\
\text { fragments }\end{array}$ & $\begin{array}{l}\text { Indirectly fixed } \\
\text { using anchorage } \\
\text { from a distant site }\end{array}$ & Directly fixed \\
\hline Modalities & $\begin{array}{l}\text { - Antral pack } \\
\text { - Antral } \\
\text { balloon } \\
\text { - Silicone } \\
\text { wedge } \\
\text { - Percutaneous } \\
\text { wire with } \\
\text { splint (arch) }\end{array}$ & $\begin{array}{l}\text { - Trans-osseous } \\
\text { pins (K wire, } \\
\text { Steinmann pins) } \\
\text { - External } \\
\text { fixatorsCranio- } \\
\text { zygomaticFronto- } \\
\text { zygomatic }\end{array}$ & $\begin{array}{l}\text { - Trans-osseous } \\
\text { wiring } \\
\text { - Miniplates and } \\
\text { screws } \\
\text { - Microcompressive } \\
\text { screws }\end{array}$ \\
\hline Advantages & $\begin{array}{l}\text { Less surgical } \\
\text { morbidity }\end{array}$ & $\begin{array}{l}\text { Less hardware } \\
\text { Less invasive }\end{array}$ & $\begin{array}{l}\text { - Functionally } \\
\text { stable/semi rigid/ } \\
\text { rigid (lag screw) } \\
\text { - Anatomic } \\
\text { reduction possible }\end{array}$ \\
\hline Limitations & $\begin{array}{l}\text { - Nonrigid } \\
\text { - Not precise } \\
\text { - Chances of } \\
\text { infection } \\
\text { - Poor patient } \\
\text { compliance }\end{array}$ & $\begin{array}{l}\text { - Poor patient } \\
\text { compliance } \\
\text { - Non-precise } \\
\text { - Chances of pin } \\
\text { track infection } \\
\text { - Requires second } \\
\text { intervention for } \\
\text { removal }\end{array}$ & $\begin{array}{l}\text { - Wiring is nonrigid } \\
\text { - Surgical } \\
\text { morbidity }\end{array}$ \\
\hline Indications & $\begin{array}{l}\text { When the } \\
\text { surgery must } \\
\text { be delayed } \\
\text { (eg. } \\
\text { compromised } \\
\text { systemic } \\
\text { status) }\end{array}$ & $\begin{array}{l}\text { - Comminuted } \\
\text { fractures } \\
\text { - Inability to } \\
\text { visualise fracture } \\
\text { site (Please add } \\
\text { bullets for both } \\
\text { these points) }\end{array}$ & $\begin{array}{l}\text { For most fractures, } \\
\text { unless } \\
\text { contraindicated }\end{array}$ \\
\hline
\end{tabular}

miniplates and compressive screws. However, some of the nonrigid fixation modalities are still applicable in certain clinical situations. A brief description of all fixation methods is provided below along with their indications and limitations.

- Trans-osseous wiring using stainless steel wires is rarely used in current practice due to its nonrigid mode of fixation that compromises post-reduction stability. However, it still remains a useful technique for fracture reduction by traction, especially at the FZ and IOR. The advantages include minimal periosteal stripping and lesser hardware as compared to use of miniplates and screws.

- Antral packing [89] with gauze or balloon/Foley's catheter is used in special scenarios where the ZMC is com- minuted. But it is an inaccurate technique with high relapse potential and increased possibility of infection.

Antral packing may be done either with a roller gauze pack or balloon. The technique followed for both is similar. The anterolateral wall of the maxilla is exposed by a Caldwell-Luc incision in the vestibule through which the fracture is inspected and manipulated to achieve reduction of the fragments. A trans-nasal antrostomy port is created in the inferior meatus. (refer Sect. 24.10, Fig. 24.24)

- The medicated ribbon gauze pack is introduced into the antrum through trans-nasal antrostomy, and one end of the gauze is packed tight in the antrum under direct visualization through the vestibular incision. The oral layer is closed, once the desired level of packing is achieved. The other end which is free is pulled out through the nostril and taped to the cheek. This is later used to retrieve the pack once the healing phase is complete.

- The inflatable balloon is positioned within the sinus cavity in a similar manner and verified through the vestibular approach. The balloon is then inflated with about 20cc of saline till adequate support is obtained for the reduced fragments. The vestibular approach is then closed meticulously without damaging the balloon. The balloon is left in situ for the fracture to heal. Removal is accomplished by deflating the balloon and pulling it out through the antrostomy port.

- Kirchner or $\mathbf{K}$ wires and Steinmann pins [1, 90] (Fig. 56.53a-c) are still popular in some units as they serve as tools of reduction as well as fixation. But these techniques are associated with cutaneous scars and poor patience compliance due to the transcutaneous presence of pins. The noteworthy advantages of external pin fixation are the reduced cost and the possibility of adjusting the fixation in the immediate postoperative period.

- $\mathrm{K}$ wires and Steinmann pins constitute an indirect method of fixation whereby the fractured zygomatic bone is fixed in a secure fashion to another stable point in the craniofacial skeleton. Such indirect anchorage may be obtained by using pins (1) to secure the fractured fragment to other stable bones or (2) to provide anchorage for connectors of an external fixator. The different techniques of indirect fixation that have been advocated for management of ZMC fractures include (Fig. 56.54):

(A) Trans-zygomatic - by this technique, the zygoma is first reduced through an intraoral approach to 
Fig. 56.53 Armamentarium for indirect fixation. (a) $\mathrm{K}$ wire. (b) Steinmann pin. (c) Manual K-wire driver
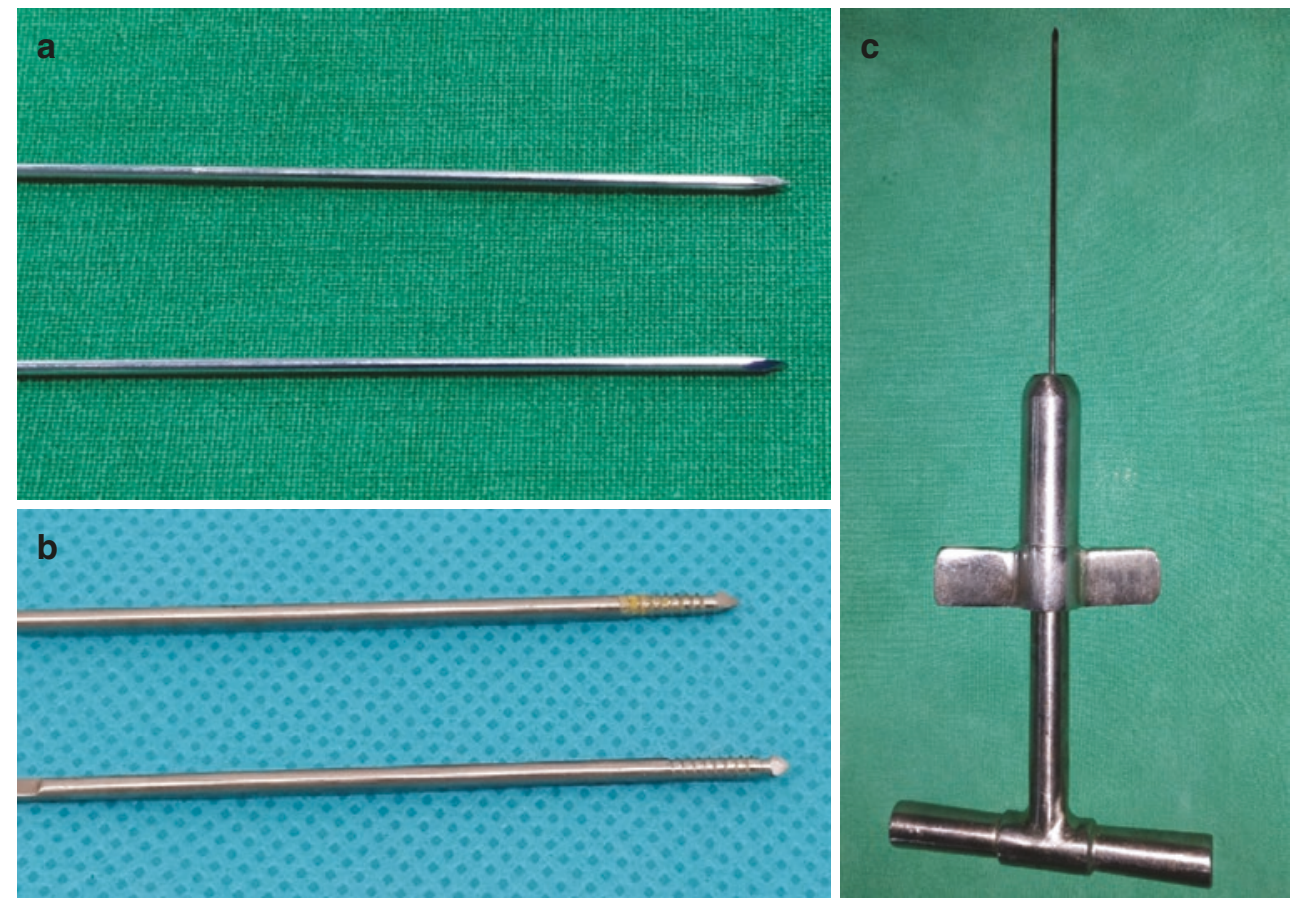

(C)Association of Oral and Maxillofacial Surgeons of India

enable adequate visualization of the entry of $\mathrm{K}$ wire/pin thorough the vestibular incision. The reduced $\mathrm{ZMC}$ is then stabilized by transfixing it to the contralateral zygoma using a $\mathrm{K}$ wire. The $\mathrm{K}$ wire is passed from the body of the reduced zygoma in a trans-facial fashion to engage the stable cortex of the contralateral zygoma by the use of a K-wire driver.

(B) Naso-zygomatic - this method involves the use of a $\mathrm{K}$ wire to stabilize the reduced $\mathrm{ZMC}$ to the frontal process of the maxilla on the contralateral side. The wire is driven from the frontal process of the maxilla in a forward and downward direction to engage the antral surface of the zygomatic body. This must be done with care to prevent any inadvertent damage to the nasolacrimal duct which lies adjacent to the path of pin.

(C) Zygomatico-palatal - this procedure involves fixation of the reduced $\mathrm{ZMC}$ to the palatal surface of the contralateral maxilla, by passing a $\mathrm{K}$ wire through the reduced $\mathrm{ZMC}$ in a downward and oblique direction.

Indirect fixation may also be performed by the use of external fixators or a halo frame that can be attached to pins for anchorage. This may include the techniques described below.

(D) Fronto-zygomatic fixation: This technique involves the use of a Steinmann pin for anchorage onto the reduced $\mathrm{ZMC}$ fragment. The pin is then anchored to another pin which is fixed on the stable orbital process of the frontal bone by the use of an external fixator device.

(E) Cranio-zygomatic fixation: This method is performed in the same fashion as the fronto-zygomatic method, except that the stable component for anchorage is from a halo frame that is cranially anchored, rather than a single pin on the frontal bone.

- Lag screws [91] have been found to be an effective alternative at the FZ region because of the additional stability offered by interfragmentary compression. But this technique requires adequate bone stock for fixation.

- Micro screws [92]: Micro screws are $2 \mathrm{~mm}$ screws which are used to fix sagittal zygomatic fractures by using the lag screw technique. These screws also reduce hardware (Fig. 56.55a-c).

- Miniplates [3, 4]: The principal method of fixation is miniplate osteosynthesis. Miniplates are chosen based on 

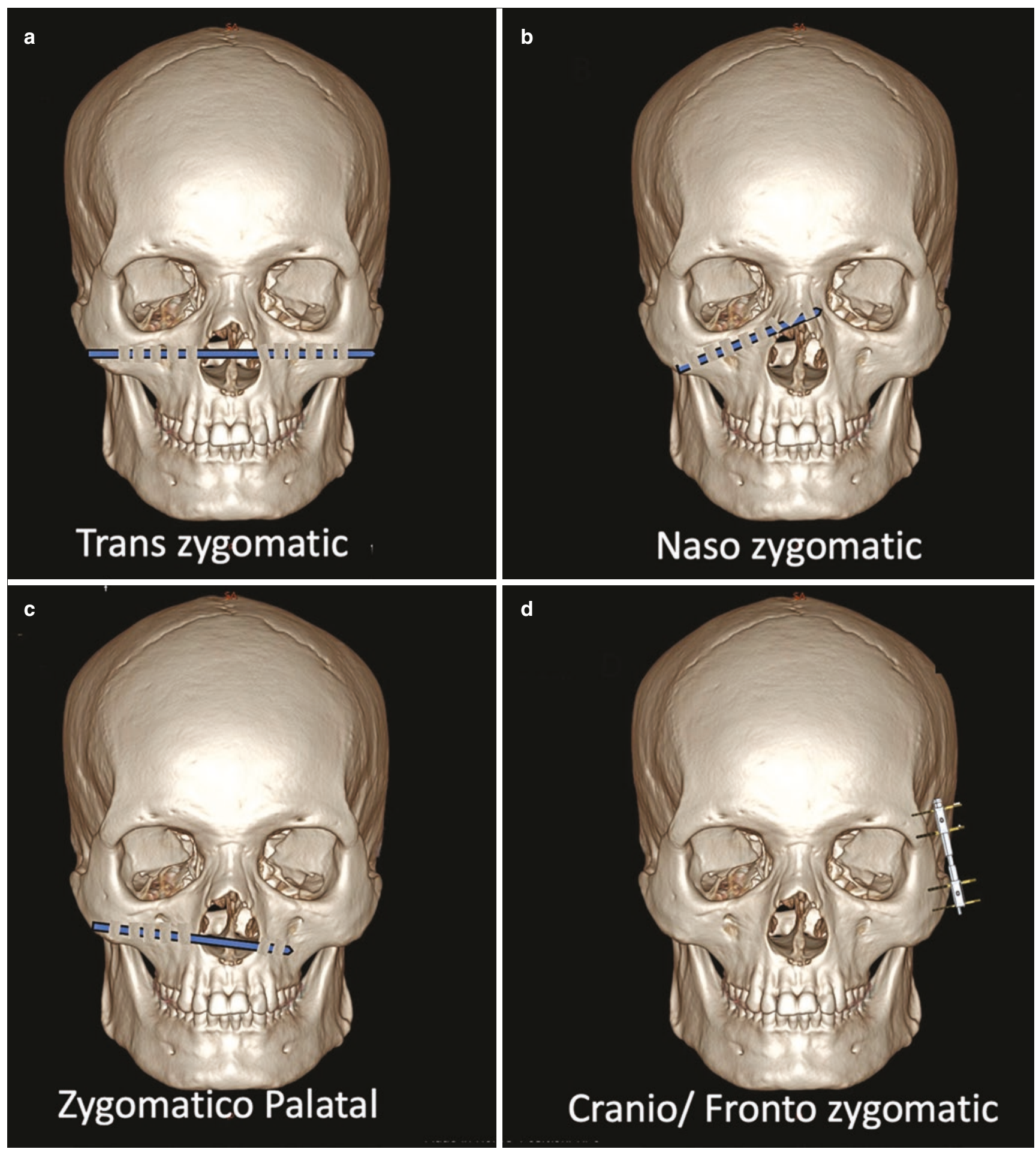

CAssociation of Oral and Maxillofacial Surgeons of India

Fig. 56.54 Techniques for indirect fixation 
rigidity requirements, anatomical site involved, presence of bone deficits, and biological considerations pertaining to protection of adjacent vital structures.

Shape of plates: The plates are chosen according to the contour of the bone that needs to be fixed; L plate for the ZM suture and a curved plate for the IOR.

Presence of bone loss: Comminuted fractures or bone loss may result in sagging of overlying soft tissues, especially in the ZM buttress region. This may be negated by using a broad mesh that bridges defects.

Biological considerations: Care must be taken to protect the roots, infra-orbital nerve and eye during fixation. In regions where the skin is thin, low-profile plates are preferred, $2 \mathrm{~mm}$ system for the ZM buttresses and $1.5 \mathrm{~mm}$ at the FZ, IOR, arch, and SZ suture [72].

Stability requirements: For ideal stability, screws of $6 \mathrm{~mm}$ length with a minimum of two screws on either side of fracture are essential. The only exception being the SZ suture where one screw on either side of the fracture line is adequate.

- Fixation points: The number of fixation points is directly proportional to the requirements of stability. Five different possibilities exist (Fig. 56.56a-f):

- One-point fixation [92] refers to fixation at either the FZ or ZM suture. This has been found to be adequate in resisting post-reduction in-stability in simple tripod fractures while reducing hardware and surgical exposure.
Comparative studies have shown that one-point fixation at the $\mathrm{ZM}$ buttress has been found to more advantageous due to many reasons: (1) absence of external scarring; (2) ease of surgical access; (3) unlike the FZ region, adequate soft tissue cover is present; and there are no issues of plate palpability; (4) easier to remove the plate, when needed; and most importantly (5) ZM buttress is a better indicator of zygoma alignment than the FZ region due to the wider area of articulation. However, FZ may be used in fractures with comminuted ZM buttress.

- Two-point fixation indicates fixation at ZM and FZ/ IOR $[93,94]$.

- Three-point fixation/tripoding includes fixation at the FZ, IOR, and the ZM. A recent meta-analysis indicates that three-point fixation is the most effective in ensuring absolute clinical stability against displacing forces after reduction [94].

- Four-point fixation/tetrapoding [95] involves fixation at the FZ, IOR, arch, and the ZM. This may be indicated in panfacial fractures requiring fixation of the arch to restore the anteroposterior projection of the face (case scenarios 1 and 2).

- Five-point fixation/pentapoding [4] is used to manage severely comminuted or dislocated ZMC fractures wherein the SZ suture is also fixed, in addition to the other four sites of fixation. The SZ fixation may be performed either through a temporal or an intra-orbital approach
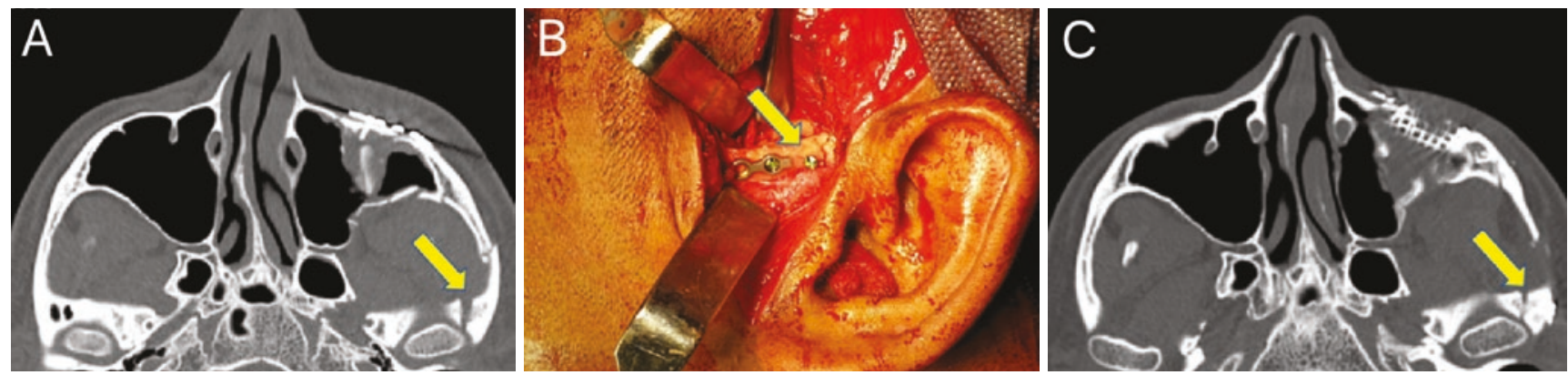

CAssociation of Oral and Maxillofacial Surgeons of India

Fig. 56.55 Fixation of zygomatic arch fracture with microcompressive screws a, b, and c. (a) Preoperative CT showing diastasis at the zygomatic root. (b) Intra-operative picture showing arch fixation with screw. (c) Postoperative CT showing adequate fracture reduction and screw fixation 

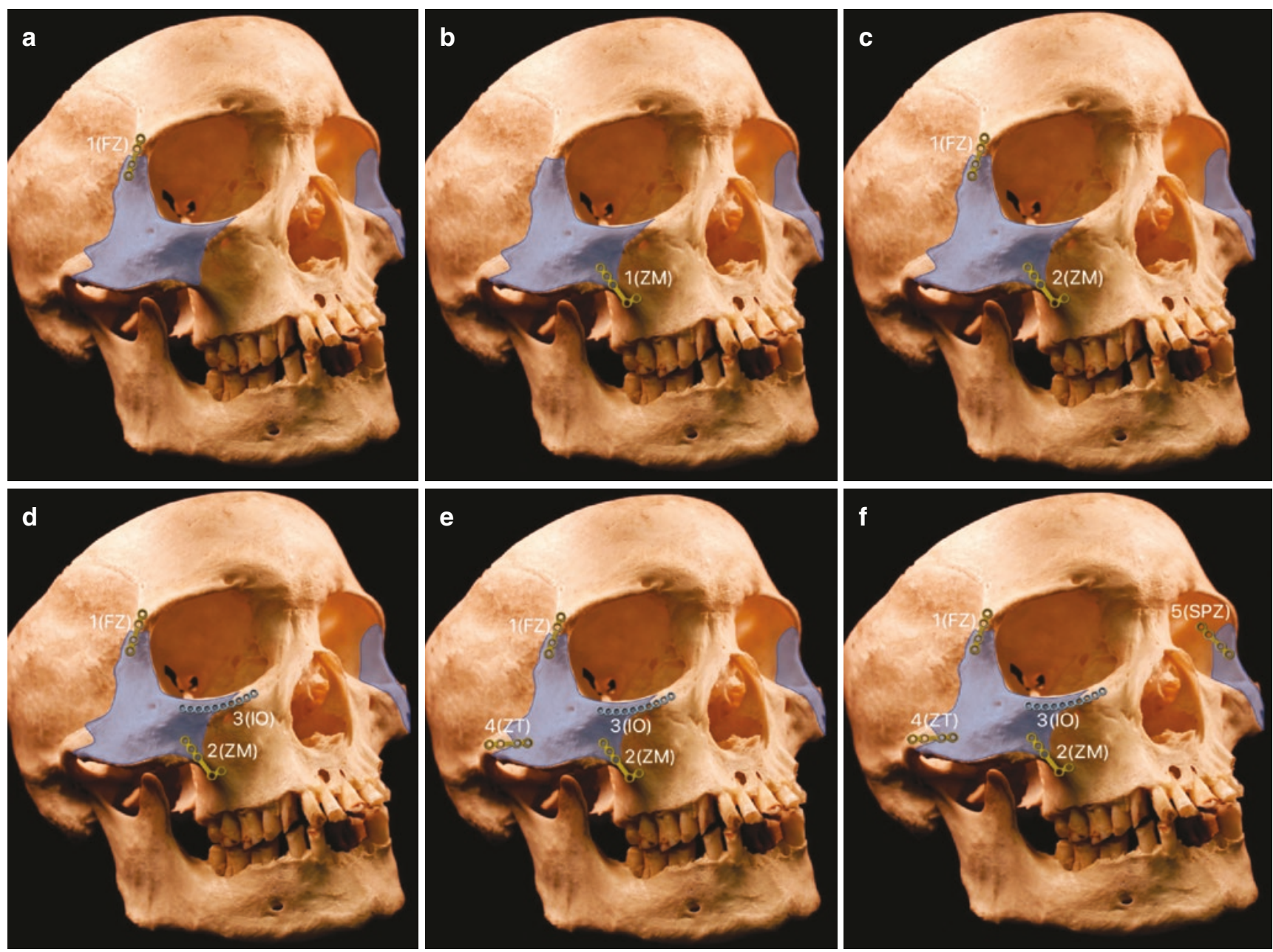

(C)Association of Oral and Maxillofacial Surgeons of India

Fig. 56.56 Types of fixation using miniplates. (a) One-point fixation at FZ suture; (b) one-point fixation at ZM buttress; (c) two-point fixation; (d) three-point fixation; (e) four-point fixation; and (f) five-point fixation (the 5th articulation (SPZ) of the right is unseen and hence is depicted on the contralateral side for better understanding)

- ZMC fractures requiring orbital reconstruction [59]: irrespective of the type of fixation, when ZMC fracture is associated with orbit, the orbital rims are fixed first. This is important because it is safer and easier to gauge the depth of orbital dissection from the restored infraorbital rim and also to facilitate floor reconstruction [66] (case scenario 2). Also, the size of the orbital defect is better assessed when the rims are aligned.

- Bio-resorbable plates [96, 97]

Though titanium miniplates are more commonly used to fix ZMC fractures, substantial clinical success has been obtained with use of bio-resorbable plates. They offer comparable post-reduction stability along with the added advantages of preventing thermal sensitivity and avoiding the need for second surgery to remove plates. Limitations associated with bio-resorbable plates are its technique sensitivity and increased operating time.

\subsubsection{Fixation of Zygomatic Arch}

The ORIF of arch fracture is indicated when the fragments are unstable after closed reduction and in cases where reestablishment of sagittal projection of face is needed. Fixation may be performed by one of the three methods, based on the fracture pattern (Fig. 56.57a, b, c): (1) a miniplate for an arch demonstrating a single fracture line (Fig. 56.52b), (2) a spanning adaptation plate (Fig. 56.62b) 
when the arch is multi-fragmented [98], and (3) a micro screw for an outfractured root or sagittal fracture of the arch [99] (Fig. 56.55). Kim et al. proposed plating on the superior surface of the upper border as an alternate line of arch fixation which negated the drawbacks associated with the conventional fixation [100] (Fig. 56.57).

\subsection{Soft Tissue Resuspension [101, 102]}

Accurate reduction and fixation of ZMC fractures frequently necessitates the use of multiple incisions on the midface which deglove the entire periosteum-muscle-fat complex of the midface and zygoma. Failure to re-approximate the dissected tissues may lead to undesirable changes in the soft tissue projection and form.
The various changes that may be a sequel to wide subperiosteal dissection of the midface include (1) cheek ptosis, (2) descent of the lower eyelid skin and infraorbital hollowness, (3) loss of malar prominence due to inferior displacement of the malar fat pad, and (4) exaggeration of the nasolabial fold [101].

Over the years many authors have documented these undesirable changes and proposed soft tissue resuspension methods to minimize them. This can be achieved by various methods (Fig. 56.58a): (1) re-approximating the incised periosteum using absorbable sutures, (2) by suspending the periosteum using heavy absorbable or nonabsorbable sutures to a drill hole placed in a superiorly positioned bony landmark
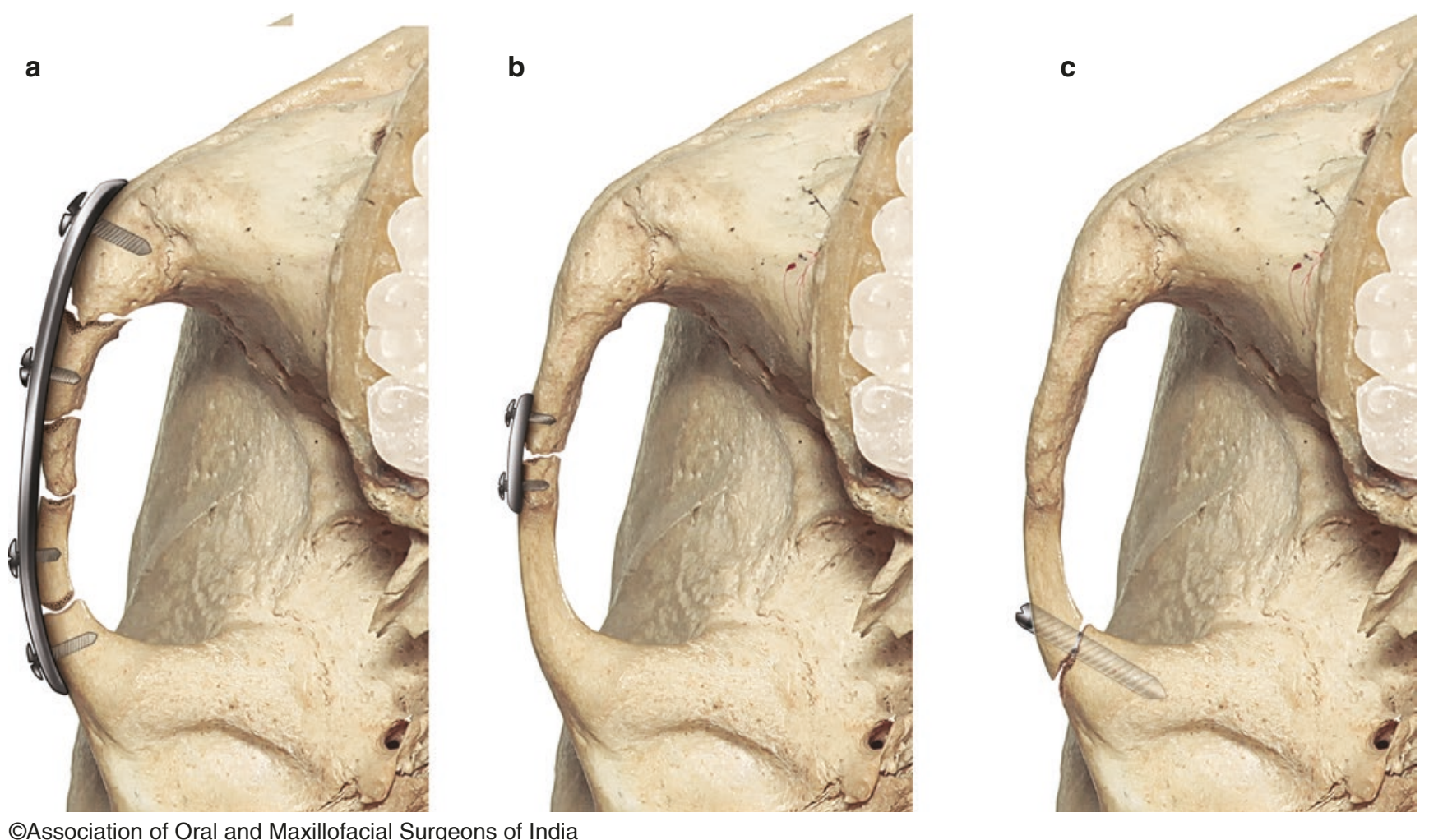

Fig. 56.57 Different fixation options for zygomatic arch fractures. (a) Adaptation plate. (b) Miniplate. (c) Compressive screw 
a

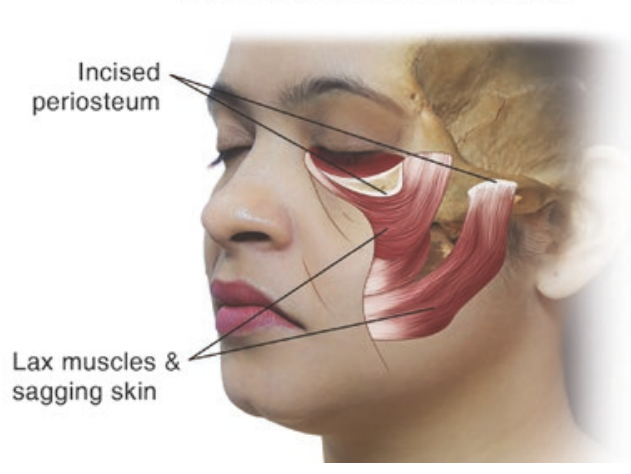

With soft tissue resuspension

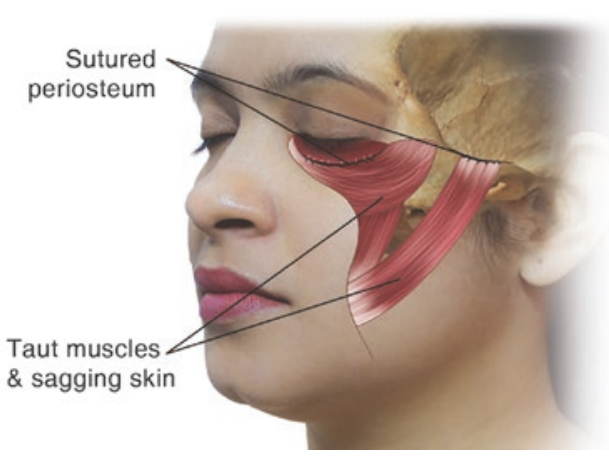

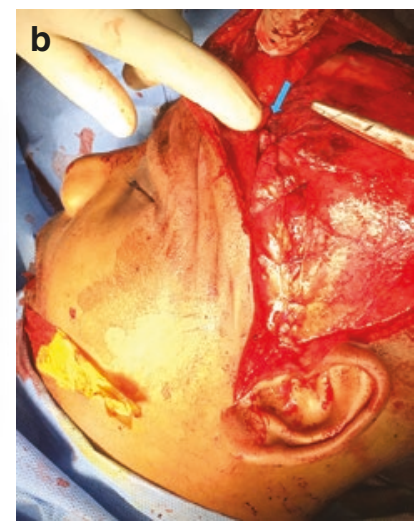

CAssociation of Oral and Maxillofacial Surgeons of India

Fig. 56.58 Soft tissue resuspension. (a) Graphical representation. (b) Resuspension of temporal soft tissues to deep temporal fascia (blue arrow)

such as the orbital rim [103], (3) resuspension of lateral facial and temporal soft tissues to the deep temporal fascia in the temporal region [104] (Fig. 56.58b), and (4) prophylactic endoscopic midface lift [101].

\subsection{Postoperative Care}

Following reduction of ZMC fractures, with or without fixation, the following measures are taken to maintain postsurgical stability and prevent soft tissue complications (Box 56.12):

\section{Box 56.12: Postsurgical Care}

- Soft diet

- Protection of surgical site and eye

- Frost suture

- Post-op sinus regimen

- Periodic assessment of vision

- Anti-edema measures

- Anti-emphysema measures

- Physiotherapy (eye and mouth opening)

- Soft diet: Patients managed with conservative methods are advised soft diet for a period of 2 weeks.

- Protection of surgical site: The reduced zygoma or the arch must be protected with a tape labelled "do not touch" to provide cognitive input to the patient and people around.

- Frost suture: This temporary suspension suture is maintained for 3-5 days in any patient undergoing an inferior eyelid approach for the prevention of ectropion.
- Post-op sinus regimen [105]: A sinus regimen including prophylactic antibiotics for sinus coverage and decongestants is advocated by some authors.

- Periodic assessment of vision [66]: Periodic ophthalmic examination for the first 2 postoperative weeks is mandatory, in an awake patient. In an unconscious patient, it is achieved by swinging flashlight test or VEP (visual evoked potential).

- Anti-edema measures: Head end elevation must be maintained to prevent facial edema.

- Anti-emphysema measures, such as avoiding nose blowing [106].

- Protection of eye with ophthalmic ointments.

- Physiotherapy to prevent postoperative trismus: Postoperative trismus is a common phenomenon following ORIF of ZMC fractures due to hematoma, reflex muscle spasms, and fibrosis. Measures such as physiotherapy, forced mouth opening using gag [107], and kinesiologic tapes [108] may be used to improve mouth opening.

- Eye movement exercises are encouraged to facilitate resolution of edema and expedite restitution of movements [66].

\subsection{Pediatric Considerations}

\subsubsection{Nonsurgical vs. Surgical Intervention [109]}

The incidence of ZMC fractures is high in pediatric population due to its prominence [109]. In children, most authors favor a "nonsurgical" management or "reduction without fixation" of ZMC fractures due to concerns regarding "surgery/implant-induced" growth disturbances of 
facial skeleton and injury to teeth. However, literature supports ORIF of zygoma fractures which are grossly displaced or unstable after reduction. This is very important in pediatric population to (1) correct the facial asymmetry which may cause psychological impact, (2) restitute normal mouth opening to permit mastication, and (3) restitute globe position and function to enable normal vision and prevent development of phthisical eye or hypoplasia of zygoma, in the future.

\subsubsection{Approaches and Fixation Principles}

The preferred approaches include vestibular and lateral brow with minimal soft tissue dissection. Literature suggests onepoint fixation at $\mathrm{FZ}$ region as adequate for pediatric $\mathrm{ZMC}$ fractures because of the short lever arm forces between the FZ and IOR [110]. But current studies have demonstrated that two-point fixations provide adequate stability and are associated with the least complication rates when compared with one and three-point fixations. Similarly, fixation at the zygomaticomaxillary buttress had the least complications when compared against the fronto-zygomatic and infraorbital fixations [111]. In contrast, Defazio et al. proposed that plating at the FZ and IOR may be done conveniently in children below 6 years without any risk of damage to tooth buds [112].
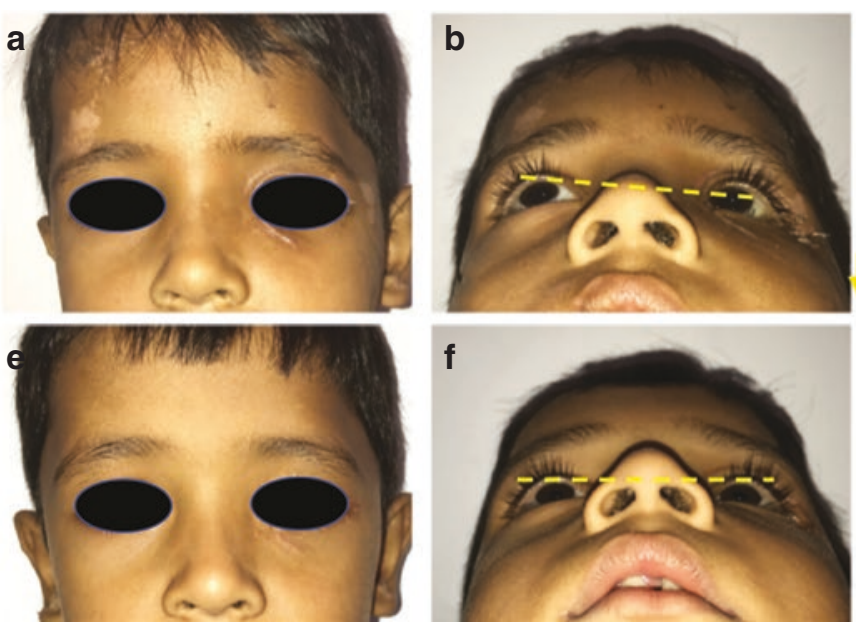

(c)Association of Oral and Maxillofacial Surgeons of India

Fig. 56.59 ZMC fracture management in a pediatric patient. (a) Frontal view of patient with left-sided ZMC fracture. (b) Basal view demonstrating loss of facial projection and enophthalmos of left side. (c) Preoperative 3D CT image demonstrating en bloc displacement of ZMC. (d) Preoperative coronal section demonstrating separation at FZ
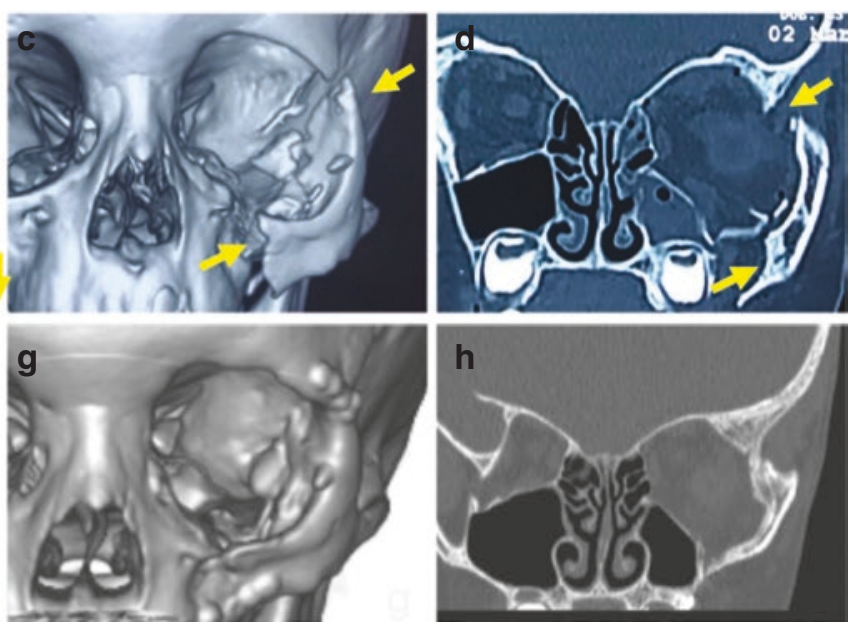

\subsubsection{Osteosynthesis Methods}

Fixation techniques prior to year 2000 advocated titanium miniplates for pediatric midface. However they must be removed after 2 months to prevent any growth disturbances, plate migration, or burying of plate due to bone apposition. Microplates and self-drilling screws are also reported to give adequate stability and fixation in this age group without compromising vital structures [110]. Alternatively, bioresorbable plates may be used which became popular after year 2004 to negate the need for re-surgery for plate removal [113]. Figure 56.59a-f shows a case of displaced zygoma fracture in a 5-year-old boy managed by ORIF. The plates were removed after 2 months.

\subsection{Malunited ZMC Fractures [114]}

Malunion of the zygoma may be a sequel to two clinical scenarios, (1) a neglected ZMC fracture which was never treated and (2) an improperly treated fracture. The protocol for the management of the malunited zygoma is based on the type of deformity which may be either cosmetic or functional. The protocol followed by the author is demonstrated in Fig. 56.60.

Deformities producing aesthetic concerns may again be subdivided into those demonstrating facial asymmetry or those showing altered globe positions.

suture and lateral displacement of the body of zygoma. (e) Postoperative frontal view. (f) Postoperative basal view demonstrating restoration of facial projection and enophthalmos correction. (g) Postoperative 3D CT. (h) Post-operative coronal section 


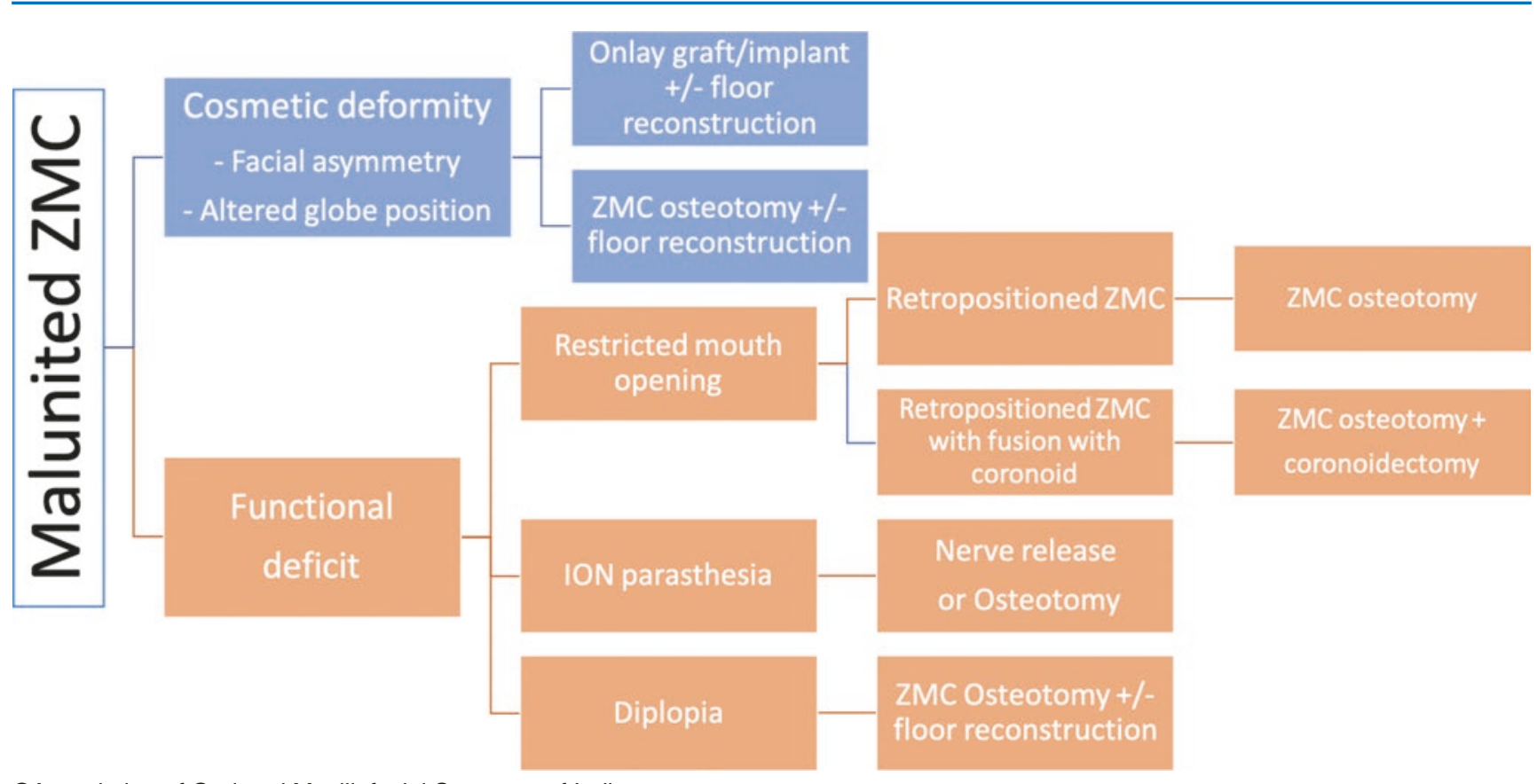

CAssociation of Oral and Maxillofacial Surgeons of India

Fig. 56.60 Management of malunited ZMC fracture-algorithm

- The patients with asymmetries involving only the malar or infra-orbital regions with no functional deficits can be treated with onlay grafts which may either be autogenous in nature (rib, iliac crest, calvarium) or alloplastic (Medpore, PEEK (polyether ether ketone), etc.) (Fig. 56.61).

- Patients demonstrating gross facial asymmetry along with orbital dystopia and/or anti-mongoloid slant of the palpebral fissure may not be amenable to treatment with onlay augmentations. In such cases, a conventional osteotomy (re-fracture) and repositioning of the zygomatic complex is advocated (case scenario 2).

- When either of the deformities are associated with large floor defects, they require concomitant orbital floor reconstructions.

Functional deficits secondary to malunited ZMC fractures essentially fall into three categories; Restricted mouth opening, parasthesia and diplopia.

- Restricted mouth opening due to retropositioned zygoma/ arch which either (1) forms a mechanical obstacle to mandibular translation or (2) fuses to the coronoid process of the mandible (extra-articular ankylosis) (Fig. 56.62a, b). The choice of treatment in these patients is dictated by the presence or absence of fusion (bony/fibrous); ZMC osteotomy, and repositioning alone are indicated in the absence of fusion, while presence of fusion mandates additional coronoidectomy [8, 115].

- Paresthesia over the infra-orbital nerve (ION) distribution: The entrapment of the ION or constriction of the infra-orbital foramen is not an uncommon finding. The first line of management in these patients is to perform a nerve release by an ostectomy around the infra-orbital foramen or by repositioning of the ZMC when it is compressing the nerve.

- Diplopia: The major cause for diplopia in ZMC fractures may either be gross displacement of the ZMC or mechanical restriction due to entrapment of orbital soft tissues (muscle, orbital septum, or fat) with resultant fibrosis or adhesions. Correction in these instances is achieved only by an osteotomy along with release of the entrapped tissues. These patients may also require orbital floor reconstructions if they present with floor defects that are large (>2 $\mathrm{cm}^{2}$ in area). Non-resolving diplopia may be subjected to management with prism glasses and/or strabismus surgery.

\subsection{Bilateral ZMC Fractures}

Bilateral fractures of the $\mathrm{ZMC}$ are a rare occurrence and present more difficulty in achieving adequate reduction. In contrast to unilateral fractures where the normal side is used as a guide to achieve symmetry on the fractured side, bilateral ZMC fractures are complex in management. Two options exist: (1) reducing the less displaced or comminuted side first and using it as a reference for the more displaced side [116]. This may however result in compromised results, if three- or four-point fixation is not achieved, and (2) meticulous preoperative planning [43] by virtual surgical procedure 
to achieve the ideal facial width and projection. This involves a sequence of segmenting and virtually repositioning the fracture fragments to the "best possible fit" position. Once this is completed, the stents for intra-operative guidance can be generated.

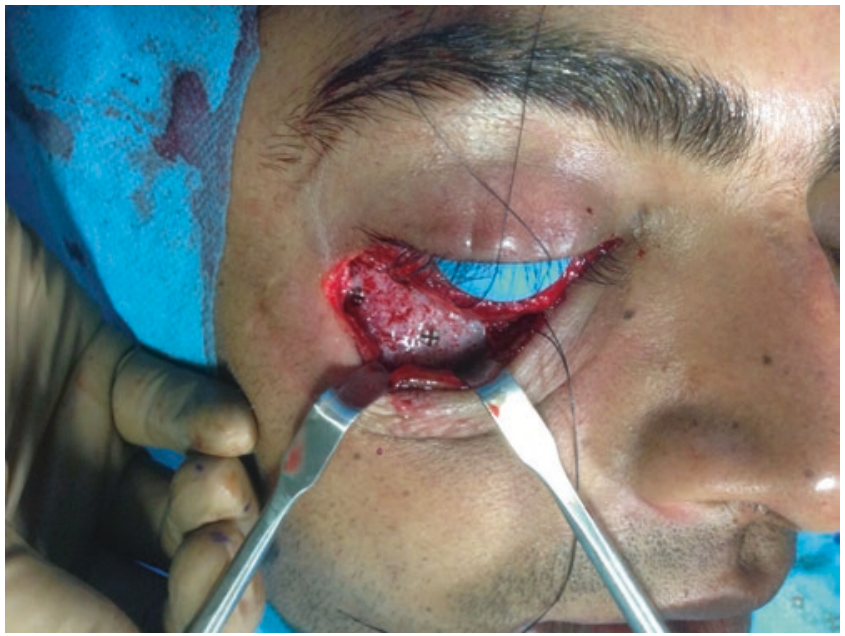

CAssociation of Oral and Maxillofacial Surgeons of India

Fig. 56.61 Use of Medpore onlay for malunited fracture
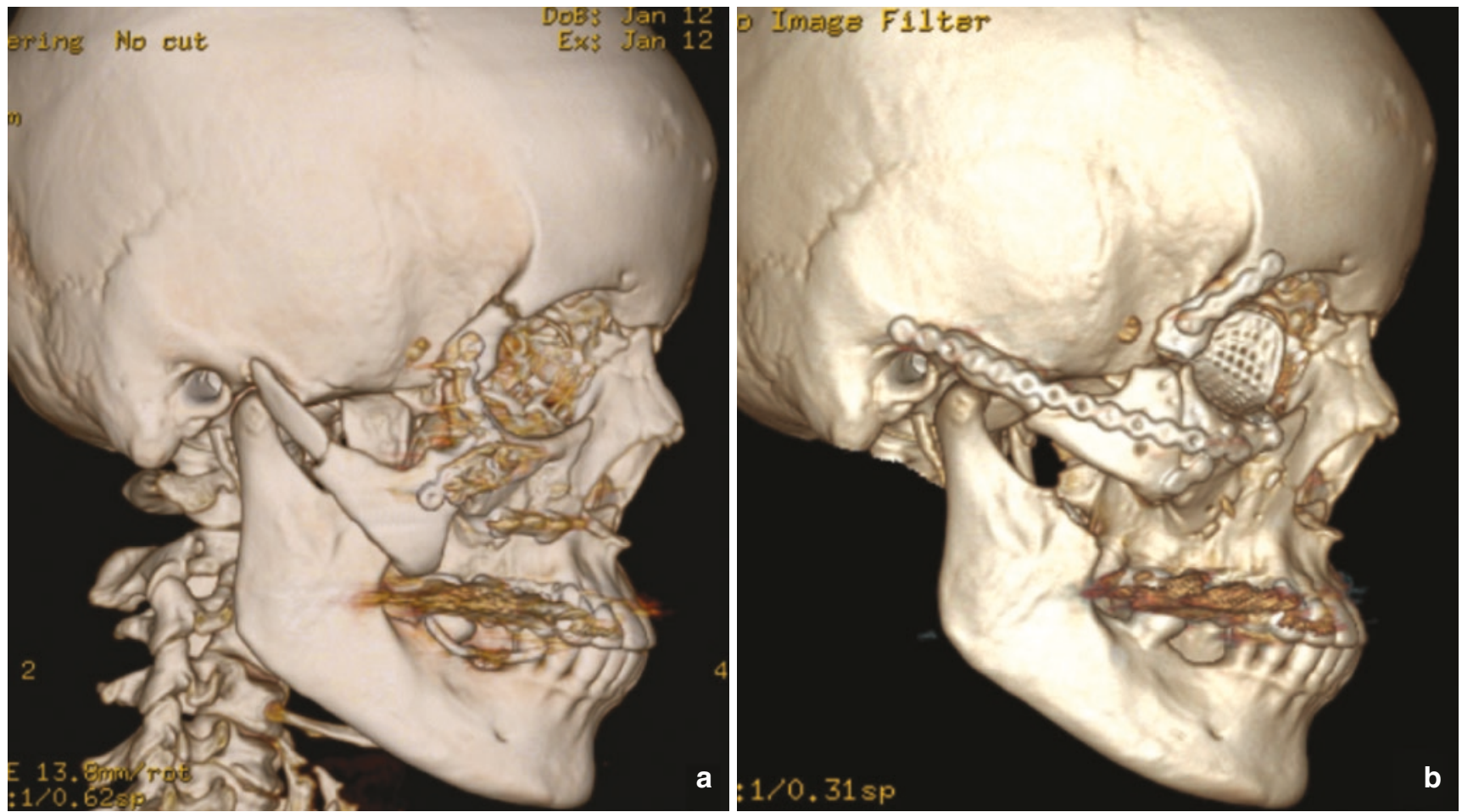

The incidence of postoperative complications increases with certain risk factors such as severe displacement, presence of sinus infection, and compound/comminuted ZMC fractures [37].

The various complications specific to surgeries of the ZMC may be categorized as intra-operative, immediate postoperative, and delayed postoperative complications.

- Intra-operative complications: Commonly encountered intra-operative complications are bradycardia and bleeding. Bradycardia due to oculocardiac/trigemino-cardiac reflex occurs typically during elevation of the ZMC [117]. Manipulation of zygoma stimulates the trigeminal nerve which subsequently stimulates the vagus nerve, due to the neuronal interconnections between them. Vagal stimulation is cardioinhibitory and hence results in bradycardia of varying degrees. This complication can be prevented by identifying risk factors and administering prophylactic vagolytic agents or minimizing nerve stimulation by administering regional blocks. However, management of bradycardia after its onset involves temporary cessation of manipulation and or medical management with atropine or epinephrine [64].

\subsection{Complications of ZMC Fractures [3-5]}

CAssociation of Oral and Maxillofacial Surgeons of India

Fig. 56.62 Coronoidectomy for malunited ZMC fracture. (a) Pre-operative scan showing malunion of the right ZMC with fusion of the body of zygoma and coronoid process, and (b) post-operative scan demonstrating reduction and fixation of the right zmc with ipsilateral coronoidectomy. 
Brisk intra-op bleeding can occur due to the sudden rupture of vessels (mainly infra-orbital artery) during reduction.

- Immediate postoperative complications: In the immediate postoperative phase, the adverse effects range from maxillary sinusitis, meteorosensitivity [3] (discomfort arising due to change in weather conditions) to infraorbital nerve paresthesia, diplopia, blindness, and SOF syndrome. The incidence of postoperative infra-orbital nerve paresthesia is higher with ZMC fractures which demonstrate more rotation, displacement, and comminution [118]. Interestingly, recovery from post-trauma ION paresthesia shows better prognosis with reduction and fixation due to de-compression on the nerve. Blindness following surgery may arise either due to direct injury to optic nerve by impingement of fracture fragments or hemorrhage into the optic sheath/retro-bulbar hemorrhage (Refer Fig. 56.16) producing nerve compression [119].

- Delayed post-op complications commonly witnessed include enophthalmos and hypophthalmos due to inadequate reduction or inadequate fixation. Oroantral fistula [120], TMJ dysfunction [121], and ankylosis of zygoma to coronoid process, referred to as Jacob's disease [1, 122], are also recorded in literature.

\subsection{Recent Trends}

Fractures of the ZMC are notorious for their sub-optimal outcomes due to over or under reductions. This may be attributed to difficulty in simultaneous visualization of its multiple articulations without increasing surgical morbidity due to additional exposures.

Technological advancements in the recent years have added ease as well as predictability to the reduction and fixation of these fractures while minimizing surgical morbidity. The most popular methods in contemporary surgical management are discussed below.

\section{Intra-operative reduction and fixation templates [123]}

This has been discussed earlier under the section for preoperative planning.

2. Computer-assisted patient-specific implants (PSI) [42]: Another method for improving intra-operative accuracy is the use of virtual surgery to plan for reduction of the fracture and design patient-specific implants (PSI). These PSI designs are then printed using a 3D printer which can double up as intra-operative reduction guides also. Refer to section 57.13.2 in Chap. 57 for additional information

3. Intra-operative navigation [124]: Intra-operative navigation is an excellent method for obtaining intra-operative guidance for precise reduction. Refer to Chap. 41. "Computer-assisted navigation surgery in oral and maxil- lofacial surgery" for additional information. The margin of error with use of intra-operative navigation is less than $1.2 \mathrm{~mm}$ with accurate restoration of facial symmetry. A case of deformity secondary to ZMC fracture treated using intra-operative navigation is illustrated in Fig. 56.63.

4. Intra-operative imaging: Intra-operative imaging greatly improves the accuracy of intra-operative fracture reduction. The various imaging modalities that are available include ultrasound, conventional C-arm (videofluoroscopy), and intra-operative CT. The quality of imaging with videofluoroscopy is not accurate in reflecting the complex anatomy of the cranio-facial skeleton. This makes intra-operative CT a more accurate and reliable tool. However, the associated radiation doses may be a concern. This has been surmounted with the advent of the intra-operative CBCT devices [125]. This device has the significant advantages of portability, ease of use, increased accuracy, and reduced radiation exposure.

5. Transbuccal Arch Fixation: A technique involving intra oral reduction of zygomatic arch and its fixation by transbuccal instrumentation has been described by Panneerselvam et al for fractures of the zygomatic arch which are displaced at the zygomatico temporal articulation. This technique minimises the potential morbidity associated with the coronal approach which is commonly used for ORIF of zygomatic arch [126].

\subsection{Conclusion}

The ZMC fracture is one of the most complex fractures to reduce and fix, because of its propensity to undergo displacements in all three planes of orientation, along its five articulations. Accurate reduction is challenging due to the difficulty in intra-operative assessment of reduction, inability to predict the rotation of the zygoma during reduction, and complexity involved in concomitant orbital fractures.

The surgical objectives must include (1) choice of incisions which provide maximal exposure with minimal morbidity, (2) increase in number of fixation points with increase in severity of fracture displacement, (3) achieving three-dimensional stability of ZMC complex and minimizing post-reduction complications, and (4) resuspension of overlying soft tissues to prevent sagging.

Preoperative planning and intra-operative imaging play a great role in improving accuracy of fracture reduction while minimizing surgical exposure and post-reduction complications. 


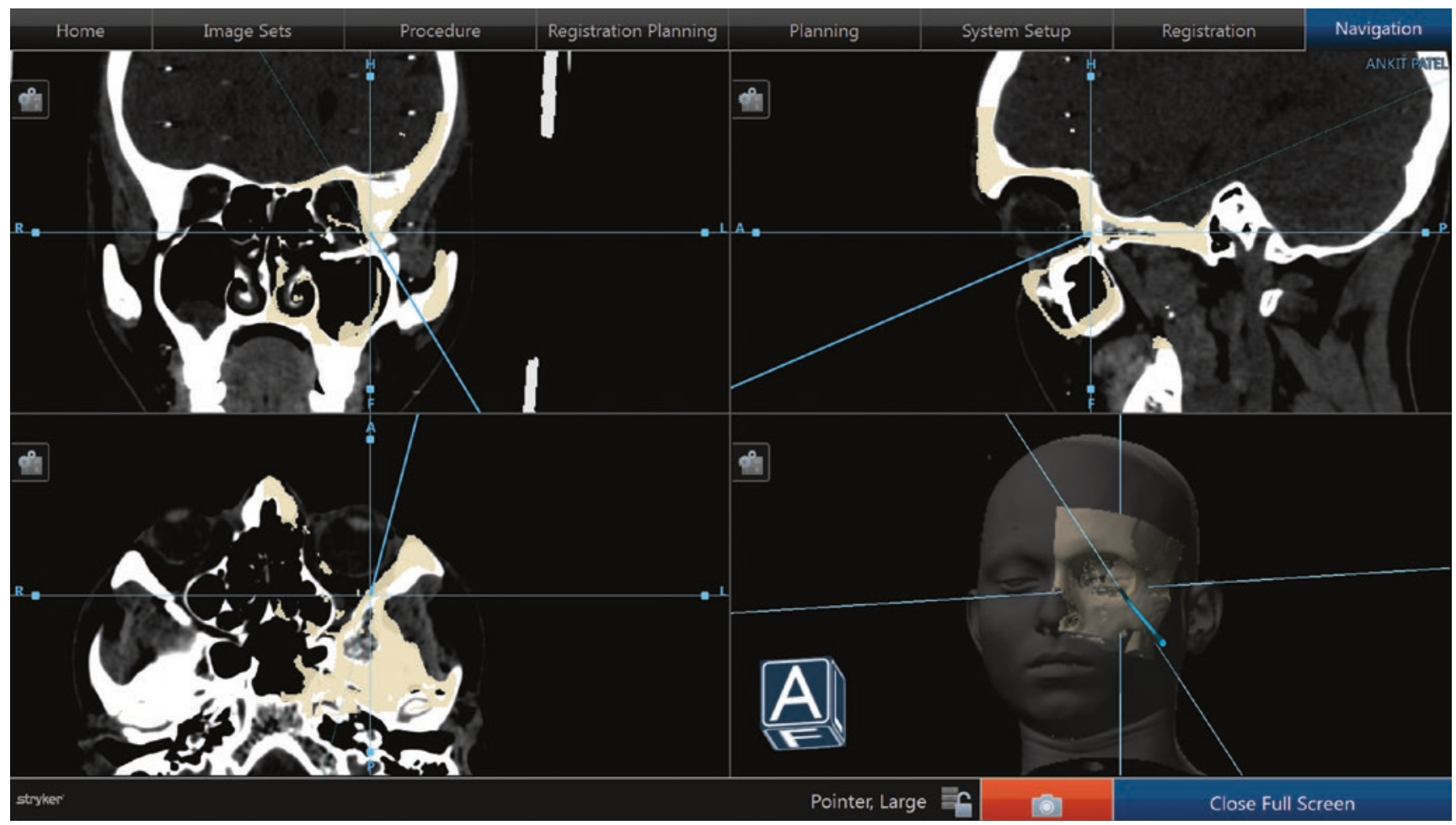

CAssociation of Oral and Maxillofacial Surgeons of India

Fig. 56.63 Intra-operative navigation for ZMC fracture. Multiplanar sections demonstrating superimposition of patient CT (white) and surgical. Plan (pink) with use of intra-operative navigation to verify position during surgery (blue pointer)

Acknowledgment The authors would like to acknowledge the efforts of the postgraduate trainees Dr. Vijitha and Dr. Logitha Sri towards the illustrations.

\subsection{Case Scenarios}

\section{Case Scenario 1: Fracture of right ZMC}

(Fig. 56.64)

\section{Patient: 21-Year-Old Male, with History of RTA}

Preoperative CT (Fig. 56.64a, c) showing right-sided fracture of the ZMC and arch with undisplaced frontal bone.

The sections demonstrate:

- Medial displacement with reduction of the transverse dimension of the face

- Diastasis at the FZ and ZM sutures

- Overriding of fragments at the IOR and SZ suture

- Medial displacement of the right zygomatic arch
Surgical plan: Reduction of ZMC fracture with fourpoint fixation

\section{Surgical procedure:}

- The exposure of fracture sites was done by:

1. Trans-conjunctival incision with extended lateral approach

2. Intraoral buccal sulcus approach

- Reduction of ZMC fracture and arch fracture by Balasubramaniam's approach

- Four-point fixation of fracture was performed at FZ, IOR, ZM, and SZ (Fig. 56.64f) regions with miniplates

Postoperative CT (Fig. 56.64b, d, e):

CT demonstrating optimal reduction of fractured ZMC and arch. The successful surgical outcome may be appreciated by the approximation and fixation at the SZ suture, which is the most reliable indicator of accurate ZMC reduction. 

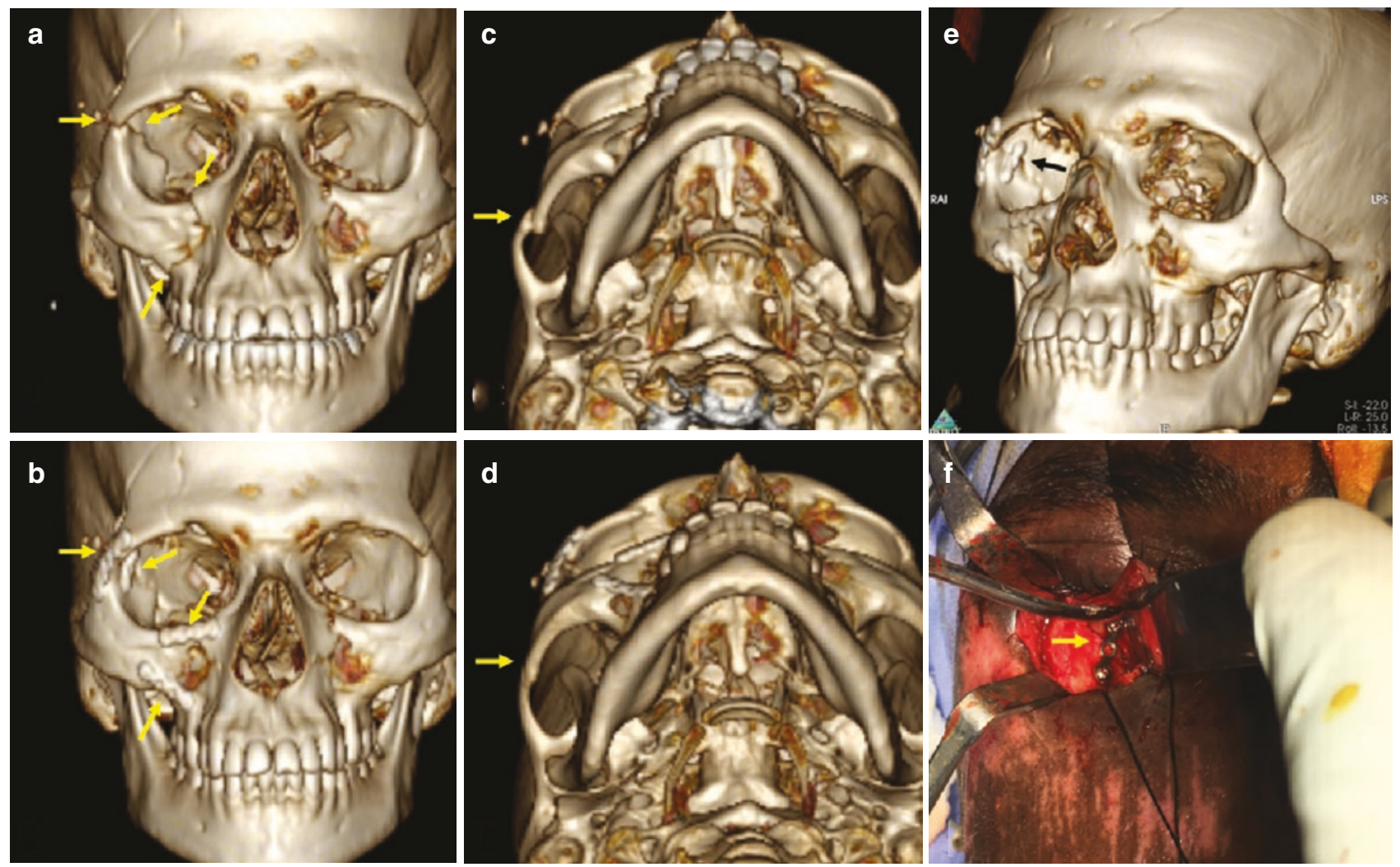

CAssociation of Oral and Maxillofacial Surgeons of India

Fig. 56.64 Case scenario 1. (a) Preoperative 3D CT-frontal view demonstrating fractures. (b) Postoperative 3D CT-frontal view demonstrating fixation. (c) Preoperative 3D CT-basal view demonstrating arch fracture. (d) Postoperative 3D CT-basal view demonstrating arch reduction. (e) Postoperative 3D CT demonstrating fixation at SZ suture. (f) Intra-operative fixation at $\mathrm{SZ}$ suture

\section{Case Scenario 2: Fracture of left ZMC and orbital floor (Fig. $56.65 \mathrm{a}-\mathrm{h}$ )}

\section{Patient: 27-Year-Old Male with History of RTA and delayed presentation after 2 months Preoperative CT findings (Fig. 56.65a, b):}

- En bloc fracture of the left ZMC with diastasis at the left infra-orbital rim, zygomatic arch, and FZ and SZ sutures.

- The fracture shows posterior, inferior, and lateral displacement and comminution at the infra-orbital rim, zygomaticomaxillary buttress, and the arch.

- The CT also demonstrates a concomitant left orbital floor fracture with resultant enophthalmos and hypo-ophthalmos (Fig. 56.65g).

Surgical plan: ZMC osteotomy, repositioning, and internal fixation

\section{Surgical procedure:}

- Virtual surgical planning to generate a mirrored STL model for pre-contouring of implants (Fig. 56.65c, d)

- Surgical exposure of the fracture through a transconjunctival (infra-orbital rim and floor), upper lid blepharoplasty (FZ and SZ sutures), vestibular for the ZM buttress, and preauricular approaches for the zygomatic arch.

- Mobilization of the malunited ZMC after osteotomy and ORIF with pre-contoured implants

- Fixation of the fracture performed at the FZ, infra-orbital rim, and the zygomatic arch regions

- Orbital exploration and reconstruction with pre-contoured left-sided anatomical titanium orbital implant

Postoperative features (Fig. 56.65e, $\mathrm{f}$ and $\mathrm{h}$ ):

The postoperative CT demonstrates optimal reduction and fixation of the left ZMC with reconstruction of the left orbital floor defect with titanium implant. 

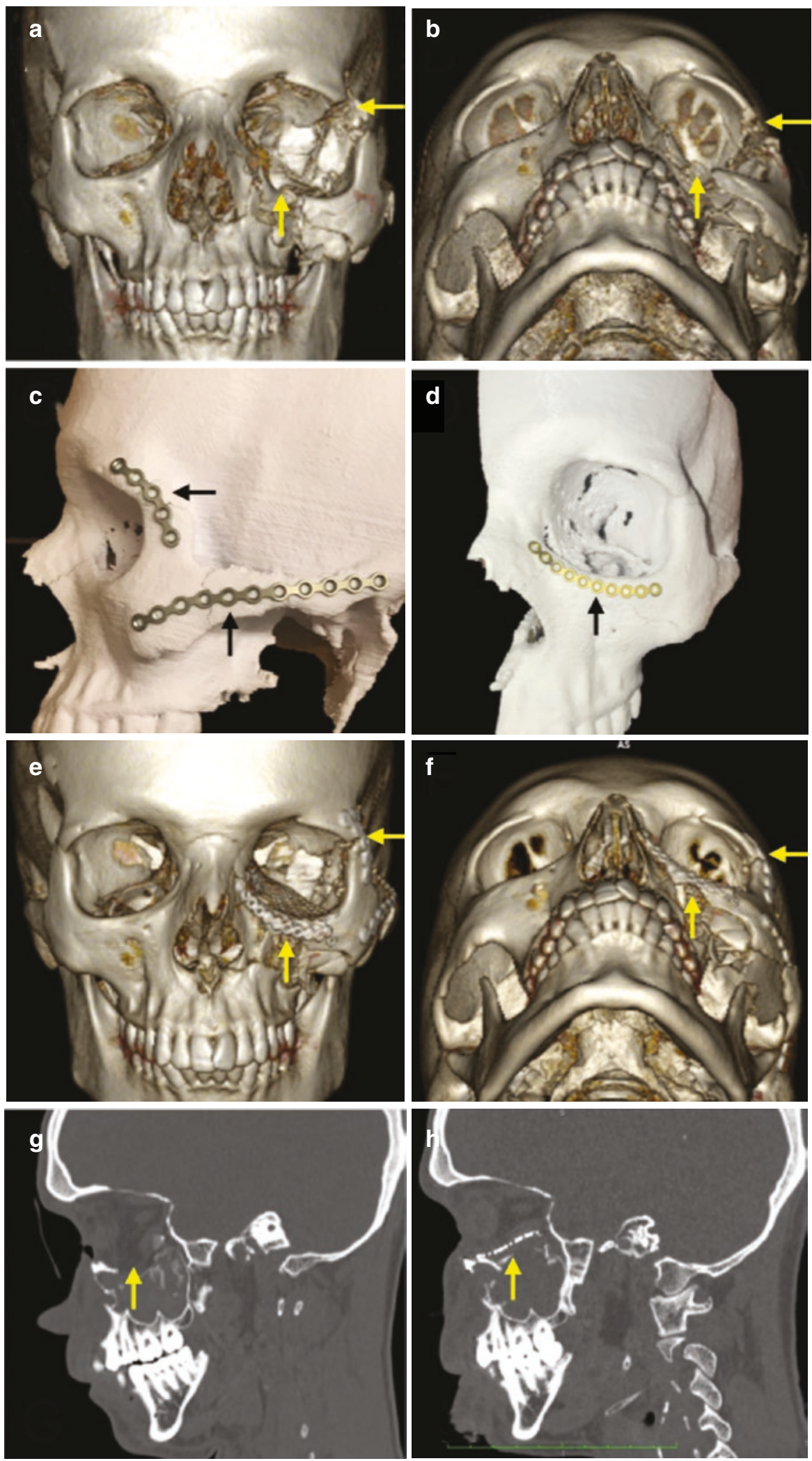

CAssociation of Oral and Maxillofacial Surgeons of India

Fig. 56.65 Case scenario 2. (a) Preoperative 3D CT-frontal view demonstrating fractures. (b) Preoperative 3D CT-basal view. (c) STL model surgery with pre-contoured plate. (d) STL model demonstrating mirroring of normal side and plate adaptation. (e) Postoperative 3D CT-frontal view demonstrating fixation. (f) Postoperative 3D CT-basal view demonstrating fixation. (g) Preoperative CT-sagittal view demonstrating floor fracture. (h) Postoperative CT-sagittal view demonstrating reconstruction of floor with orbital mesh 


\section{References}

1. Rowe NL, Williams JL. Maxillofacial injuries, Vol 1. Edinburgh: Churchill Livingstone; 1985. p. 435-537.

2. Maturo S, Lopez MA. Zygomatico-orbito-maxillary complex fractures. Oper Tech Otolaryngol. 2008;19:86-9.

3. Marinho RO, Freire-Maia B. Management of fractures of the zygomaticomaxillary complex. Oral Maxillofac Surg Clin North Am. 2013;25:617-36.

4. Ehrenfeld M, Manson PN, Prein J. Principles of internal fixation of the craniomaxillofacial skeleton trauma and orthognathic surgery. AO Foundation. p. 205-22.

5. Fonseca RJ, Walker RV. Oral and maxillofacial trauma, vol. 1. Philadelphia: Saunders; 1991.

6. Lockwood CB. The anatomy of the muscles, ligaments, and fasciae of the orbit, including an account of the capsule of Tenon, the check ligaments of the recti, and the suspensory ligaments of the eye. J Anat Physiol. 1885;20:i2-i25.

7. Brusati R. Mouth opening limitations due to coronoid-zygomaticmalar interference. Minerva Stomatol. 1975;24(4):177-98.

8. Lee SM, Baek JA, Kim Y. Ankylosis of the coronoid process to the zygomatic bone: a case report and review of the literature. J Oral Maxillofac Surg. 2019;77:1230.e1-11.

9. Cohen AJ, Narayanan D. Zygomatic complex facial fractures. 2017 (Cited September 17, 2018) Available from https://emedicine.medscape.com/article/1284142-overview.

10. Karlan MS, Cassisi NJ. Fractures of the zygoma. A geometric, biomechanical, and surgical analysis. Arch Otolaryngol. 1979;105:320-7.

11. Louis M, Agrawal N, Kaufman M, Truong TA. Midface fractures I. Semin Plast Surg. 2017; 31(2): 85-93.

12. Buehler JA, Tannyhill RJ 3rd. Complications in the treatment of midfacial fractures. Oral Maxillofac Surg Clin North Am. 2003;15:195-212.

13. Zachariades N, Papavassiliou D, Papademetriou I. The alterations in sensitivity of the infraorbital nerve following fractures of the zygomaticomaxillary complex. J Craniomaxillofac Surg. 1990; $18: 315-8$

14. Jamal BT, Pfahler SM, Lane KA, Bilyk JR, Pribitkin EA, Diecidue RJ, Taub DI. Ophthalmic injuries in patients with zygomaticomaxillary complex fractures requiring surgical repair. J Oral Maxillofac Surg. 2009;67:986-9.

15. Cavalcante JR, Junior JR, Peixoto TS, de Albuquerque TT, Cavalcanti AL. Reduction and fixation of unstable fractures of the zygomatic arch: report of a series of cases. J Surg Tech Case Rep. 2015;7:29-31.

16. Susarla SM, Bojovic B. Acute intraorbital hemorrhage following reduction of a displaced orbitozygomaticomaxillary complex fracture. Craniomaxillofac Trauma Reconstr. 2015;8:221-7.

17. Zingg M, Laedrach $\mathrm{K}$, Chen J, et al. Classification and treatment of zygomatic fractures: a review of 1,025 cases. J Oral Maxillofac Surg. 1992;50:778-90.

18. Colin-Durand J, Czerwinski M, Parker WL, Crepeau RJ. Repair of an avulsed zygoma: defining optimal management. J Oral Maxillofac Surg. 2008;66:2615-6.

19. Ozyazgan I, Günay GK, Eskitaş̧̧ioglu T, Ozköse M, Coruh A. A new proposal of classification of zygomatic arch fractures. J Oral Maxillofac Surg. 2007;65:462-9.

20. Yamamoto K, Murakami K, Sugiura T, Fujimoto M, Inoue M, Kawakami M, Ohgi K, Kirita T. Clinical analysis of isolated zygomatic arch fractures. J Oral Maxillofac Surg. 2007;65:457-61.

21. Hönig JF, Merten HA. Classification system and treatment of zygomatic arch fractures in the clinical setting. J Craniofac Surg. 2004;15(6):986-9.
22. Ellis E, El-Attar A, Moos KF. An analysis of 2,067 cases of zygomatico-orbital fracture. J Oral Maxillofac Surg. $1985 ; 43: 417-28$.

23. Rupp J. The 8-Point Eye Exam [Internet]. American Academy of Ophthalmology. 2019 [cited 21 May 2019].

24. Qayyum Z, Khan A, Khitab U. Characteristics and etiology of zygomatic complex fractures. Pak Oral Dent J. 2007;27(1):93-6.

25. King AB, Walsh FB. Trauma to the head with particular reference to the ocular signs: Part I. Injuries involving the cranial nerves. Am J Ophthalmol. 1949; 32(2):191-206.

26. Jeon HB, Kang DH, Oh SA, Gu JH. Comparative study of Naugle and Hertel exophthalmometry in orbitozygomatic fracture. J Craniofac Surg. 2016;27(1):142-4.

27. Nkenke E, Benz M, Maier T, Wiltfang J, Holbach LM, Kramer M, Häusler G, Neukam FW. Relative en-and exophthalmometry in zygomatic fractures comparing optical non-contact, non-ionizing $3 \mathrm{D}$ imaging to the Hertel instrument and computed tomography. J Cranio Maxillofac Surg. 2003; 31(6):362-8.

28. Smith SN, Nortjé CJ. Surgical emphysema following an undisplaced fractured zygoma: an unusual radiographic appearance. $\mathrm{Br}$ J Oral Surg. 1980;18(3):202-4.

29. Brasileiro BF, Cortez AL, Asprino L, Passeri LA, de Moraes M, Mazzonetto R, Moreira RW. Traumatic subcutaneous emphysema of the face associated with paranasal sinus fractures: a prospective study. J Oral Maxillofac Surg. 2005;63(8):1080-7.

30. Markiewicz MR, Gelesko S, Bell RB. Zygoma reconstruction. Oral Maxillofac Surg Clin North Am. 2013;25(2):167-201.

31. Perry M, Holmes S. Atlas of operative maxillofacial trauma surgery-primary repair of facial injuries. London: Springer; 2014.

32. Roth FS, Koshy JC, Goldberg JS, Soparkar CN. Pearls of orbital trauma management. Semin Plast Surg. 2010;24(4):398-410.

33. Bossert RP, Girotto JA. Blindness following facial fracture: treatment modalities and outcomes. Craniomaxillofac Trauma Reconstr. 2009;2:117-24.

34. McGrigor B, Campbell W. The radiology of war injuries. IV. Wounds of the face and jaw. Br J Radiol. 1950;23(276):685-96.

35. Dolan KD, Jacoby CG. Facial fractures. Semin Roentgenol. 1978;13(1):37-51.

36. Ogunmuyiwa SA, Fatusi OA, Ugboko VI, Ayoola OO, Maaji SM. The validity of ultrasonography in the diagnosis of zygomaticomaxillary complex fractures. Int J Oral Maxillofac Surg. 2012;41(4):500-5.

37. Ochs M, Chung W, Powers D. Trauma surgery. J Oral Maxillofac Surg. 2017;75(8):e151-94.

38. Ellstrom CL, Evans GR. Evidence-based medicine: zygoma fractures. Plast Reconstr Surg. 2013;132(6):1649-57.

39. Hurrell M, David M, Batstone M. A multi-outcome analysis of the effects of treatment timing in the management of zygomatic fractures. Int J Oral Maxillofac Surg. 2015;44:e83.

40. Knepil GJ, Loukota RA. Outcomes of prophylactic antibiotics following surgery for zygomatic bone fractures. J Craniomaxillofac Surg. 2010;38(2):131-3.

41. Soong PL, Schaller B, Zix J, Iizuka T, Mottini M, Lieger O. The role of postoperative prophylactic antibiotics in the treatment of facial fractures: a randomised, double-blind, placebo-controlled pilot clinical study. Part 3: Le Fort and zygomatic fractures in 94 patients. Br J Oral Maxillofac Surg. 2014; 52(4):329-33.

42. Zhang X, Han CY, Dai MJ, Chen JL, Zheng XH, Long J, Tang W, Tian WD, Liu L. Application of computer-assisted surgery techniques in the management of zygomatic complex fractures. Chin J Traumatol. 2018;21(5):281-6.

43. Xia JJ, Gateno J, Teichgraeber JF. A new paradigm for complex midface reconstruction: a reversed approach. J Oral Maxillofac Surg. 2009;67(3):693-703. 
44. Li P, Zhou ZW, Ren JY, Zhang Y, Tian WD, Tang W. Accuracy of three-dimensional facial soft tissue simulation in posttraumatic zygoma reconstruction. Int J Oral Maxillofac Surg. 2016;45(12):1665-70.

45. Krimmel M, Cornelius CP, Reinert S. Endoscopically assisted zygomatic fracture reduction and osteosynthesis revisited. Int $\mathbf{J}$ Oral Maxillofac Surg. 2002;31(5):485-8.

46. Gillies HD, Kilner TP, Stone D. Fractures of the Malar-zygomatic compound: With a description of a new X-ray position. Br J Surg. 1927;14(56):651-6.

47. Poswillo D. Reduction of the fractured malar by a traction hook. Br J Oral Surg. 1976;14(1):76-9.

48. Lee EI, Mohan K, Koshy JC, Hollier LH. Optimizing the surgical management of zygomaticomaxillary complex fractures. Semin Plast Surg. 2010;24(4):389-97.

49. Dingman RO, Natvig P. Surgery of facial fractures. Philadelphia: WB Saunders; 1964. p. 212-3.

50. Balasubramaniam $\mathrm{S}$. Intra-oral approach for reduction of malar fractures. Br J Oral Surg. 1966;4:189-91.

51. Quinn JH. Lateral coronoid approach for intraoral reduction of fractures of the zygomatic arch. J Oral Surg. 1977;35(4):321-2.

52. Pilanci O, Basaran K, Datli A, Kuvat SV. "Roller coaster maneuver via lateral orbital approach" for reduction of isolated zygomatic arch fractures. J Craniofac Surg. 2013;24(6):2082-4.

53. Carter TG, Bagheri S, Dierks EJ. Towel clip reduction of the depressed zygomatic arch fracture. J Oral Maxillofac Surg. 2005;63(8):1244-6.

54. Ahn HC, Youn DH, Choi MSS, Chang JW, Lee JH. Wire or hook traction for reducing zygomatic fracture. Arch Craniofac Surg. 2015;16(3):131-5.

55. Bazani PL, Bonardi JP, Magro-Filho O. The use of foley catheter for treatment of unstable fracture zygomatic arch. J Craniofac Surg. 2016;27(4):1012.

56. Camilleri AC, Gilhooly M, Cooke ME. Stabilisation of the unstable fractured zygomatic arch with a Kirschner wire. Br J Oral Maxillofac Surg. 2005;43(2):183-4. PubMed PMID: 15749224

57. Yoon H, Kim J, Chung S, Chung YK. Effectiveness of dualmaneuver using $\mathrm{K}$-wire and dingman elevator for the reduction of unstable zygomatic arch fracture. Arch Craniofac Surg. 2014;15(2):59-62.

58. van Hout WM, van Cann EM, Muradin MS, Frank MH, Koole R. Intraoperative imaging for the repair of zygomaticomaxillary complex fractures: a comprehensive review of the literature. J Craniomaxillofac Surg. 2014;42(8):1918-23.

59. Ellis E 3rd, Perez D. An algorithm for the treatment of isolated zygomatico-orbital fractures. J Oral Maxillofac Surg. 2014;72(10):1975-83.

60. Menon A, Karikal A, Shetty V. Does C-arm guidance improve reduction of zygomatic arch fractures? A randomized controlled trial. J Oral Maxillofac Surg. 2018;76(11):2376-86.

61. Cannizzaro D, Revay M, Mancarella C, Colletti G, Costa F, Cardia A, Fornari M. Intraoperative imaging O-Arm ${ }^{\mathrm{TM}}$ in secondary surgical correction of post-traumatic orbital fractures. Oral Maxillofac Surg Cases. 2017;3(3):56-60.

62. Bujtar P, Steele P, Holland I, Halsned M. Buttress guide: direct positioning splint to align a complex fracture of the zygoma. Br J Oral Maxillofac Surg. 2017;55(1):97-9.

63. Lubbers HT, Zweifel D, Gratz KW, Kruse A. Classification of potential risk factors for trigeminocardiac reflex in craniomaxillofacial surgery. J Oral Maxillofac Surg. 2010;68:1317-21.

64. Shearer ES, Wenstone R. Bradycardia during elevation of zygomatic fractures. A variation of the oculocardiac reflex. Anaesthesia. 1987;42:1207-8.

65. Padaki P, Graham R, Markose G. Modified Zimmer finger splint revisited. Br J Oral Maxillofac Surg. 2017;55(10):e141.
66. Cornelius C, Gellrich N, Hillerup S, Kusumoto K, Schubert W. Midface - indication - zygoma, zygomatic complex fractureAO Surgery Reference [Internet]. www2.aofoundation.org. 2019 [cited 18 June 2019]. Available from:. https://www2.aofoundation.org/wps/portal/surgery?bone $=\mathrm{CMF} \&$ segment $=$ Midface $\&$ cla ssification $=92-Z y g o m a, \% 20 Z$ ygomatic $\% 20$ complex $\% 20$ fracture \&showPage $=$ indication

67. Gruss JS, Van LW, Phillips JH, Antonyshyn O. The importance of the zygomatic arch in complex midfacial fracture repair and correction of posttraumatic orbitozygomatic deformities. Plast Reconstr Surg. 1990;85(6):878-90.

68. Humphrey CD, Kriet JD. Surgical approaches to the orbit. Oper Tech Otolaryngol Head Neck Surg. 2008;19(2):132-9.

69. Farber SJ, Nguyen DC, Skolnick GB, Woo AS, Patel KB. Current management of zygomaticomaxillary complex fractures: A multidisciplinary survey and literature review. Craniomaxillofac Trauma Reconstr. 2016;9(04):313-22.

70. Ellis E, Zide MF, editors. Surgical approaches to the facial skeleton. Lippincott Williams \& Wilkins; 2006.

71. Al-Moraissi EA, Thaller SR, Ellis E. Subciliary vs. transconjunctival approach for the management of orbital floor and periorbital fractures: A systematic review and meta-analysis. J Cranio Maxillofac Surg. 2017;45(10):1647-54.

72. Cornelius C, Gellrich N, Hillerup S, Kusumoto K, Schubert W. Midface - indication - zygoma, zygomatic complex fracture-AO Surgery Reference [Internet]. www2.aofoundation. org. 2019 [cited 18 June 2019]. Available from:. https://www2. aofoundation.org/wps/portal/surgery?contentUrl=/srg/92/04Approaches/A30_2-lower-eyelid-transcutan.jsp. Accessed 12 June 2019.

73. Wilson S, Ellis E. Surgical approaches to the infraorbital rim and orbital floor: the case for the subtarsal approach. J Oral Maxillofac Surg. 2006;64(1):104-7.

74. Connolly KL, Albertini JG, Miller CJ, Ozog DM. The suspension (Frost) suture: experience and applications. Dermatol Surg. 2015;41(3):406-10.

75. Al-Moraissi EA, Elsharkawy AT, Al-Tairi NH, Farhan AH, Abotaleb BM, Al-Sharaee YA, Olufunmilayo OF, Alzubaidi A. What surgical approach has the lowest risk of the lower lid complications in the treatment of orbital floor and periorbital fractures? A frequentist network meta-analysis. J Craniomaxillofac Surg. 2018;46:2164-75.

76. Sebastiani AM, Trento GS, Antonini F, Kluppel LE, Scariot R, Costa DJ, Rebellato NL. Cicatricial ectropion correction in the inferior eyelid with cartilaginous tissue graft: Case report. Int J Med Surg Sci. 2014;1(3):217-2.

77. Pascali M, Avantaggiato A, Brinci L, Cervelli V, Carinci F. Tarsal sling: an essential stitch to prevent scleral show in lower blepharoplasty. Aesthet Surg J. 2015;35(1):11-9.

78. Kushner GM. Surgical approaches to the infraorbital rim and orbital floor: the case for the transconjunctival approach. J Oral Maxillofac Surg. 2006;64(1):108-10.

79. Elsheikh E, Hussein AM, Tantawy AA, Abdelbaki YM. Transconjunctival versus subciliary approach to the infraorbital margin for open reduction of zygomaticomaxillary complex fractures: a randomized feasibility study. Oral Maxillofac Surg. 2017;21(2):187-92.

80. Ishida K. Evolution of the surgical approach to the orbitozygomatic fracture: From a subciliary to a transconjunctival and to a novel extended transconjunctival approach without skin incisions. J Plast Reconstr Aesthet Surg. 2016;69(4):497-505.

81. Martinez AY, Bradrick JP. Y modification of the transconjunctival approach for management of zygomaticomaxillary complex fractures: a technical note. J Oral Maxillofac Surg. 2012;70(1):97-101. 
82. Sharma R, Singh S, Patrikar S. Retroseptal transconjunctival approach for fractures of the zygomaticomaxillary complex: a retrospective study. Br J Oral Maxillofac Surg. 2018;56(1):29-33.

83. Yoon SH, Lee JH. The reliability of the transconjunctival approach for orbital exposure: measurement of positional changes in the lower eyelid. Arch Craniofac Surg. 2017;18(4):249.

84. Salhi S, Cordoba C. Distichiasis following transconjunctival approach to the inferior orbital rim and orbital floor. JPRAS Open. 2015;5:29-33.

85. Courtney DJ. Upper buccal sulcus approach to management of fractures of the zygomatic complex: a retrospective study of 50 cases. Br J Oral Maxillofac Surg. 1999;37(6):464-6.

86. Choi KY, Ryu DW, Yang JD, Chung HY, Cho BC. Feasibility of 4-point fixation using the preauricular approach in a zygomaticomaxillary complex fracture. J Craniofac Surg. 2013;24(2):557-62.

87. Massimo P, Corrado T, Roberto C, Fabia C, Massimo R. The deep subfascial approach to the temporomandibular joint. J Oral Maxillofac Surg. 2004;62:1097-102.

88. Zhang QB, Dong YJ, Li ZB, Zhao JH. Coronal incision for treating zygomatic complex fractures. J Craniomaxillofac Surg. 2006;34(3):182-5. Epub 2006 Mar 14.

89. Erich JB. Treatment of fractures of the zygoma and floor of the orbit. Am J Surg. 1966;112(3):432-5.

90. Park BY, Song SY, Yun IS, Lee DW, Rah DK, Lee WJ. First percutaneous reduction and next external suspension with Steinmann pin and Kirschner wire of isolated zygomatic fractures. J Craniofac Surg. 2010;21(4):1060-5.

91. Chotkowski G, Eggleston TI, Buchbinder D. Lag screw fixation of a nonstable zygomatic complex fracture: case report. J Oral Maxillofac Surg. 1997;55(2):183-5.

92. Stevens MR, Menis MA. Microscrew fixation of zygomatic arch fractures. J Oral Maxillofac Surg. 1993;51(10):1158-9.

93. Kim ST, Go DH, Jung JH, Cha HE, Woo JH, Kang IG. Comparison of 1-point fixation with 2-point fixation in treating tripod fractures of the zygoma. J Oral Maxillofac Surg. 2011;69(11):2848-52.

94. Jazayeri HE, Khavanin N, Jason WY, Lopez J, Shamliyan T, Peacock ZS, Dorafshar AH. Fixation points in the treatment of traumatic zygomaticomaxillary complex fractures: a systematic review and meta-analysis. J Oral Maxillofac Surg. 2019.

95. Sharma R, Muralidharan CG, Roy ID, Jain NK, Patrikar S. Radiological evaluation of sphenozygomatic suture fixation for restoration of orbital volume: a retrospective study. J Craniomaxillofac Surg. 2016;44(12):1903-8.

96. Wu CM, Chen YA, Liao HT, Chen CH, Pan CH, Chen CT. Surgical treatment of isolated zygomatic fracture: outcome comparison between titanium plate and bioabsorbable plate. Asian J Surg. 2018;41(4):370-6.

97. Chu SG, Lee JS, Lee JW, Yang JD, Chung HY, Cho BC, Choi KY. Comparisons among four types of absorbable plates used for internal fixation of zygomaticomaxillary complex fractures. J Craniomaxillofac Surg. 2019;47(3):383-8.

98. Xie L, Shao Y, Hu Y, Li H, Gao L, Hu H. Modification of surgical technique in isolated zygomatic arch fracture repair: seven case studies. Int J Oral Maxillofac Surg. 2009;38(10):1096-100.

99. Ribeiro AL, de Souza Rodrigues TM, de Melo A-JS, Pinheiro JD. Interfragmentary screw fixation of the zygomatic arch in complex midface and zygomaticomaxillary fractures. J Oral Maxillofac Surg. 2015;73(3):494-8.

100. Kim H, Yoon J, Lee BI. Radiological morphometric analysis of the zygomatic arch: Application of osteosynthesis on the upper arch border for rigid fixation. J Plast Reconstr Aesthet Surg. 2019;72(5):831-41.

101. Brown R, Lozada K, Kadakia S, Gordin E, Ducic Y. Prophylactic midface lift in midfacial trauma. Facial Plast Surg. 2017;33:347-51.
102. Gruss JS, Whelan MF, Rand RP, Ellenbogen RG. Lessons learnt from the management of 1500 complex facial fractures. Ann Acad Med Singapore. 1999;28:677-86.

103. Phillips JH, Gruss JS, Wells MD, Chollet A. Periosteal suspension of the lower eyelid and cheek following subciliary exposure of facial fractures. Plast Reconstr Surg. 1991;88:145-8.

104. Frodel JL Jr, Rudderman R. Facial soft tissue resuspension following upper facial skeletal reconstruction. J Craniomaxillofac Trauma. 1996;2:24-30.

105. Susarla SM, Peacock ZS. Zygomaticomaxillary complex fracture. Eplasty. 2014;14.

106. Mahmood S, Keith DJ, Lello GE. When can patients blow their nose and fly after treatment for fractures of zygomatic complex: the need for a consensus. Injury. 2003;34(12):908-11.

107. Chang CM, Ko EC, Kao CC, Chang PY, Chen MY. Incidence and clinical significance of zygomaticomaxillary complex fracture involving the temporomandibular joint with emphasis on trismus. Kaohsiung J Med Sci. 2012;28(6):336-40.

108. Ristow O, Pautke C, Kehl V, Koerdt S, Schwärzler K, Hahnefeld L, Hohlweg-Majert B. Influence of kinesiologic tape on postoperative swelling, pain and trismus after zygomatico-orbital fractures. J Craniomaxillofac Surg. 2014;42(5):469-76.

109. Ferreira P, Marques M, Pinho C, Rodrigues J, Reis J, Amarante J. Midfacial fractures in children and adolescents: a review of 492 cases. Br J Oral Maxillofac Surg. 2004;42:501-5.

110. Zimmermann CE, Troulis MJ, Kaban LB. Pediatric facial fractures: recent advances in prevention, diagnosis and management. Int J Oral Maxillofac Surg. 2006;35:2-13.

111. Luck JD, Lopez J, Faateh M, Macmillan A, Yang R, Davidson EH, Nam AJ, Grant MP, Tufaro AP, Redett RJ, Manson PN, Dorafshar AH. Pediatric zygomaticomaxillary complex fracture repair: location and number of fixation sites in growing children. Plast Reconstr Surg. 2018;142:51e-60e.

112. DeFazio MV, Fan KL, Avashia YJ, Danton GH, Thaller SR. Fractures of the pediatric zygoma: a review of the clinical trends, management strategies, and outcomes associated with zygomatic fractures in children. J Craniofac Surg. 2013;24:1891-7.

113. Iatrou I, Theologie-Lygidakis N, Tzerbos F. Surgical protocols and outcome for the treatment of maxillofacial fractures in children: 9 years' experience. J Craniomaxillofac Surg. 2010;38:511-6.

114. Perino KE, Zide MF, Kinnebrew MC. Late treatment of malunited malar fractures. J Oral Maxillofac Surg. 1984;42(1):20-34.

115. Rikalainen R, Lamberg MA, Tasanen A. Extra-articular fibrous ankylosis of the mandible after zygomatic fracture. J Maxillofac Surg. 1981;9:132-6.

116. Ramanathan M, Cherian MP. Isolated bilateral zygomatic complex and arch fracture: a rare case report. Craniomaxillofac Trauma Reconstr. 2010;3(04):185-8.

117. Loewinger J, Cohen M, Levi E. Bradycardia during elevation of a zygomatic arch fracture. J Oral Maxillofac Surg. 1987;45:710-1.

118. Benoliel R, Birenboim R, Regev E, Eliav E. Neurosensory changes in the infraorbital nerve following zygomatic fractures. Oral Surg Oral Med Oral Pathol Oral Radiol Endod. 2005;99:657-65.

119. Buckley SB, McAnear JT, Dolwick MF, Aragon SB. Monocular blindness developing 7 days after repair of zygomaticomaxillary complex fracture: A clinical report. Oral Surg Oral Med Oral Pathol. 1985;60(1):25-8.

120. Dym H, Wolf JC. Oroantral communication. Oral Maxillofac Surg Clin North Am. 2012;24:239-47.

121. Rajantie H, Snäll J, Thorén H. Postoperative temporomandibular dysfunction in patients with fractures of the zygomatic complex: a prospective follow-up study. Br J Oral Maxillofac Surg. 2018;56(7):573-7. 
122. i de la Torre ÒE, Klok EV, i Roig AM, Mommaerts MY, i Ayats JP. Jacob's disease: report of two cases and review of the literature. J Craniomaxillofac Surg. 2001;29(6):372-6.

123. Liu XZ, Shu DL, Ran W, Guo B, Liao X. Digital surgical templates for managing high-energy zygomaticomaxillary complex injuries associated with orbital volume change: a quantitative assessment. J Oral Maxillofac Surg. 2013;71:1712-23.

124. Gong X, He Y, An J, Yang Y, Huang X, Liu M, Zhao Y, Zhang Y. Application of a computer-assisted navigation system (CANS) in the delayed treatment of zygomatic fractures: a randomized controlled trial. J Oral Maxillofac Surg. 2017;75:1450-63.
125. Pohlenz P, Blake F, Blessmann M, Smeets R, Habermann C, Begemann P, Schmelzle R, Heiland M. Intraoperative cone-beam computed tomography in oral and maxillofacial surgery using a $\mathrm{C}$-arm prototype: first clinical experiences after treatment of zygomaticomaxillary complex fractures. J Oral Maxillofac Surg. 2009;67:515-21.

126. Panneerselvam E, Balasubramanian S, Kempraj J, Babu VR, Raja VBKK. Management of Zygomatic Arch Fractures by Intraoral Open Reduction and Transbuccal Fixation: A Technical Note. Craniomaxillofacial Trauma \& Reconstruction. 2020 Jun;13(2):130-132. DOI: 10.1177/1943387520911866.

Open Access This chapter is licensed under the terms of the Creative Commons Attribution 4.0 International License (http://creativecommons. $\mathrm{org} /$ licenses/by/4.0/), which permits use, sharing, adaptation, distribution and reproduction in any medium or format, as long as you give appropriate credit to the original author(s) and the source, provide a link to the Creative Commons license and indicate if changes were made.

The images or other third party material in this chapter are included in the chapter's Creative Commons license, unless indicated otherwise in a credit line to the material. If material is not included in the chapter's Creative Commons license and your intended use is not permitted by statutory regulation or exceeds the permitted use, you will need to obtain permission directly from the copyright holder. 